\title{
Field Testing of Compartmentalization Methods for Multifamily Construction
}

K. Ueno and J.W. Lstiburek Building Science Corporation

March 2015 


\section{NOTICE}

This report was prepared as an account of work sponsored by an agency of the United States government. Neither the United States government nor any agency thereof, nor any of their employees, subcontractors, or affiliated partners makes any warranty, express or implied, or assumes any legal liability or responsibility for the accuracy, completeness, or usefulness of any information, apparatus, product, or process disclosed, or represents that its use would not infringe privately owned rights. Reference herein to any specific commercial product, process, or service by trade name, trademark, manufacturer, or otherwise does not necessarily constitute or imply its endorsement, recommendation, or favoring by the United States government or any agency thereof. The views and opinions of authors expressed herein do not necessarily state or reflect those of the United States government or any agency thereof.

Available electronically at www.osti.gov/bridge

Available for a processing fee to U.S. Department of Energy and its contractors, in paper, from:

U.S. Department of Energy

Office of Scientific and Technical Information

P.O. Box 62

Oak Ridge, TN 37831-0062

phone: 865.576.8401

fax: 865.576.5728

email: mailto:reports@adonis.osti.gov

Available for sale to the public, in paper, from:

U.S. Department of Commerce

National Technical Information Service

5285 Port Royal Road

Springfield, VA 22161

phone: 800.553 .6847

fax: 703.605.6900

email: orders@ntis.fedworld.gov

online ordering: www.ntis.gov/ordering.htm 


\title{
Field Testing of Compartmentalization Methods for Multifamily Construction
}

\author{
Prepared for: \\ The National Renewable Energy Laboratory \\ On behalf of the U.S. Department of Energy's Building America Program \\ Office of Energy Efficiency and Renewable Energy \\ 15013 Denver West Parkway \\ Golden, CO 80401 \\ NREL Contract No. DE-AC36-08GO28308 \\ Prepared by: \\ K. Ueno and J.W. Lstiburek \\ Building Science Corporation \\ 3 Lan Drive, Suite 102 \\ Westford, MA 01886 \\ NREL Technical Monitor: Stacey Rothgeb \\ Prepared under Subcontract No. KNDJ-0-40337-05
}

March 2015 
The work presented in this report does not represent performance of any product relative to regulated minimum efficiency requirements.

The laboratory and/or field sites used for this work are not certified rating test facilities. The conditions and methods under which products were characterized for this work differ from standard rating conditions, as described.

Because the methods and conditions differ, the reported results are not comparable to rated product performance and should only be used to estimate performance under the measured conditions. 


\section{Contents}

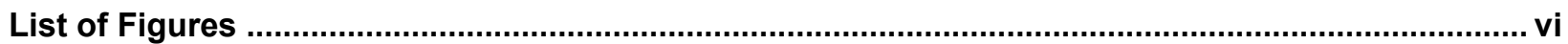

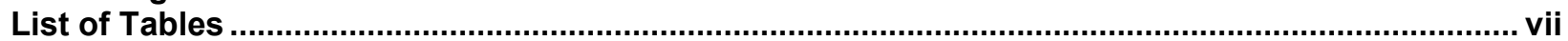

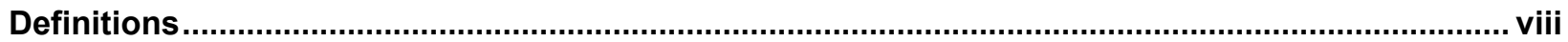

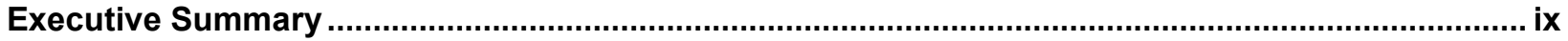

1 Introduction

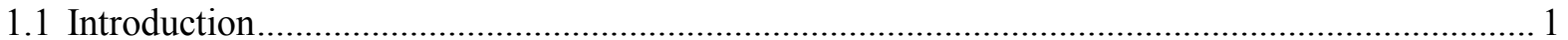

1.2 Relevance to Building America's Goals ................................................................................... 1

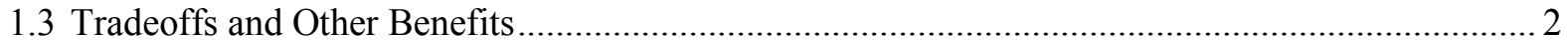

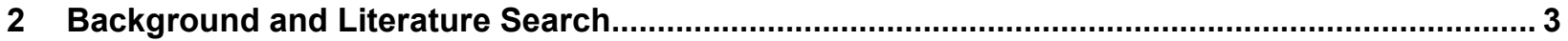

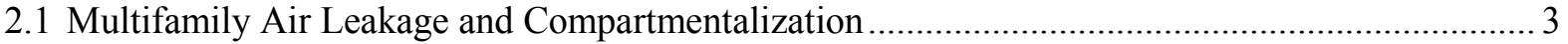

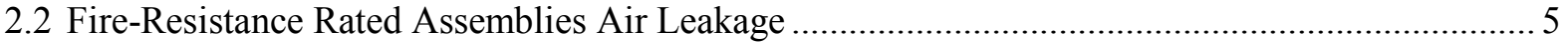

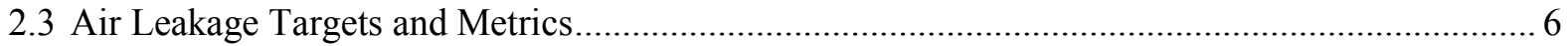

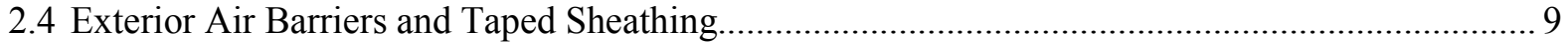

3 Multifamily Test Building and Construction Details …......................................................... 11

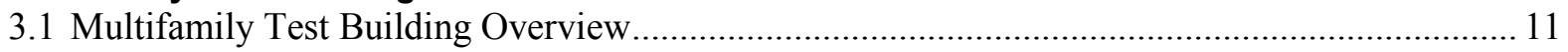

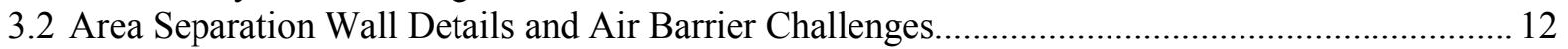

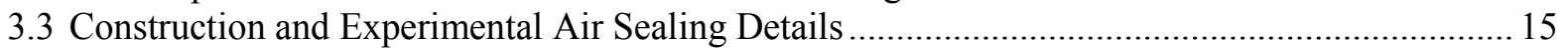

3.3.1 "Improved" Package of Air Sealing Details: Overview ................................................. 16

3.3.2 "Improved" Package of Air Sealing Details: Conventional Air Sealing Details .............. 16

3.3.3 "Improved" Package of Air Sealing Details: Area Separation Walls ............................... 17

3.3.4 "Improved" Package of Air Sealing Details: Adhered Tape Details ............................... 19

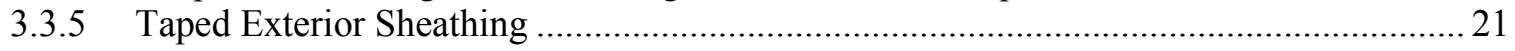

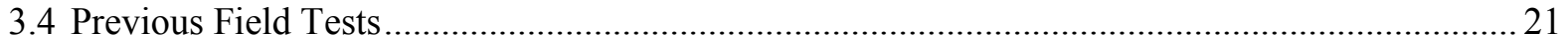

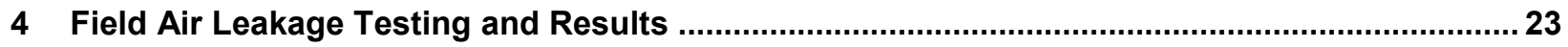

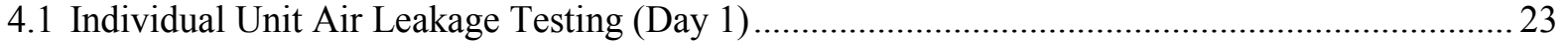

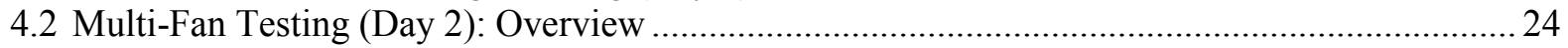

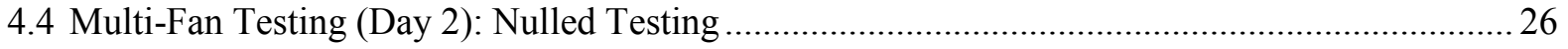

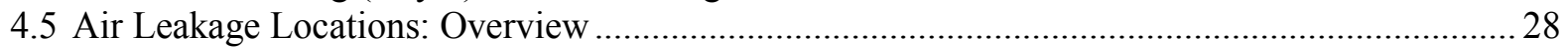

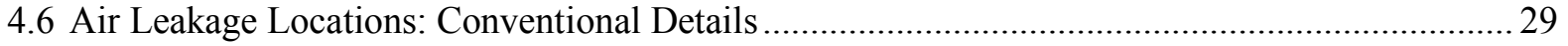

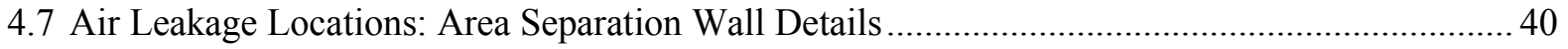

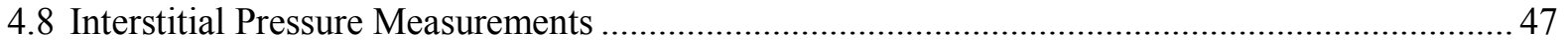

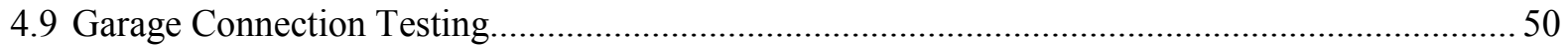

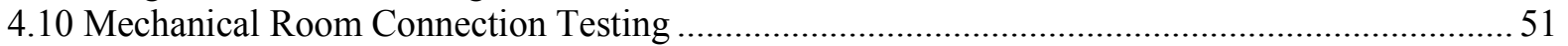

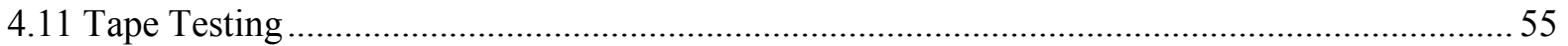

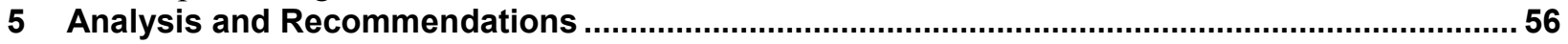

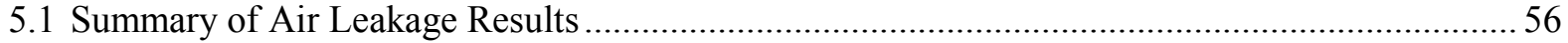

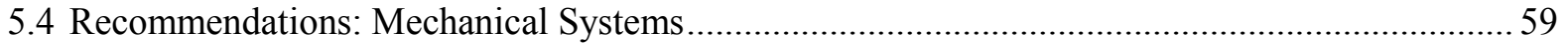

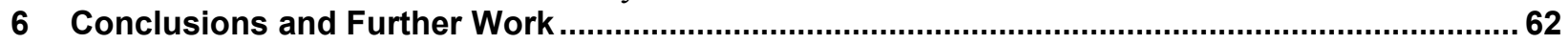

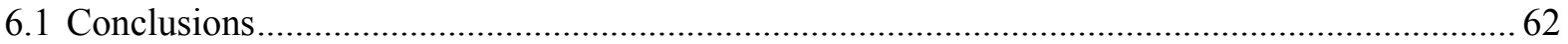

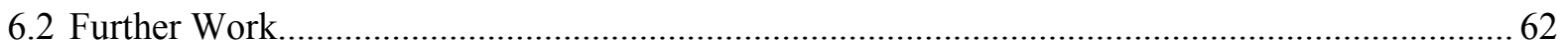

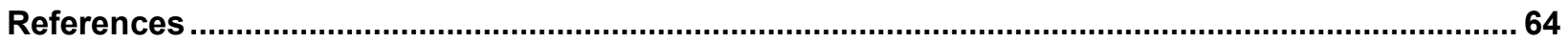

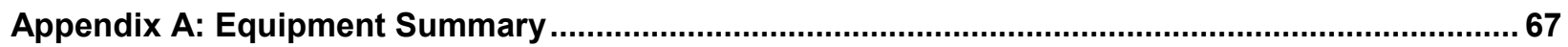

Appendix B: Air Leakage Test Results-Unguarded Tests Day 1.................................................... 68

Appendix C: Air Leakage Test Results-Unguarded and Guarded Tests Day 2 ................................ 70 


\section{List of Figures}

Figure 1. Villages at Pepper Mill Building 13 (5 units), front and rear elevations .......................... 11

Figure 2. Floor plans for typical middle unit ("Adams" plan, 34-ft $\times 20$-ft footprint) ........................ 12

Figure 3. Floor plans for typical end unit ("Jefferson" plan, 34-ft $\times 24$-in. footprint) ....................... 12

Figure 4. Area separation wall (fire-resistance rated wall assembly) typical section at foundation 13

Figure 5. Area separation wall (fire-resistance rated wall assembly) at floor framing ...................... 14

Figure 6. Area separation wall (fire-resistance rated wall assembly) detail at offset units .............. 15

Figure 7. Experimental air barrier listing, with unit numbers and taping locations.......................... 15

Figure 8. Connection from interior wall top plate to ceiling gypsum board ...................................... 16

Figure 9. Wall bottom plate air sealing details................................................................................. 17

Figure 10. Vertical section detail of fire separation/demising wall at penetration to vented attic ... 18

Figure 11. Wall top plate seal at fire separation/demising wall in attic ........................................... 18

Figure 12. Expanding foam at garage, top plate to area separation wall ....................................... 19

Figure 13. Sealant tape installed at area separation wall, sheathing-to-foundation connection ..... 19

Figure 14. Wood ledger condition at area separation wall .......................................................... 20

Figure 15. Sealant tape at area separation wall, sheathing-to-foundation connection ....................20

Figure 16. Tape air barrier connection at wall top plate, prior to installation of roof trusses .......... 21

Figure 17. Taped seams of exterior sheathing and gypsum fire separation wall ............................21

Figure 18. Individual unit air leakage testing, and multi point test results ..................................... 24

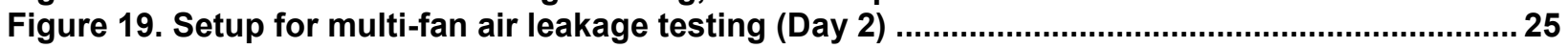

Figure 20. Multi-fan test setup, outside pressure tap in garage ..................................................25

Figure 21. Outside ventilation air intake; motorized damper at air handler ......................................26

Figure 22. TECLOG3 unit pressures for multipoint nulled test of five units ...................................27

Figure 23. Air leakage location infrared image key, middle unit...................................................29

Figure 24. Rear second-floor kitchen, Unit 6704 (middle) ................................................................ 30

Figure 25. Rear second-floor kitchen/dining area, Unit 6704 (middle) ............................................ 30

Figure 26. Overhang detail in framed building, showing gap in sheathing at inside corner ............ 31

Figure 27. Overhang detail at taped sheathing condition................................................................ 31

Figure 28. Rear overhang infrared image, units 6702 and 6704 (taped and conventional) ............... 32

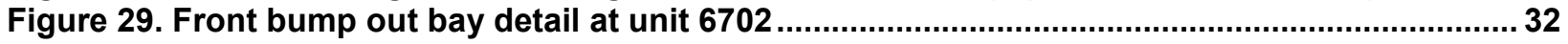

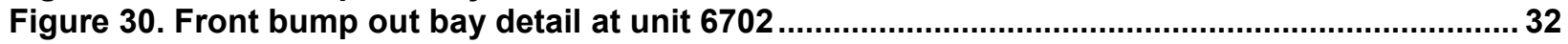

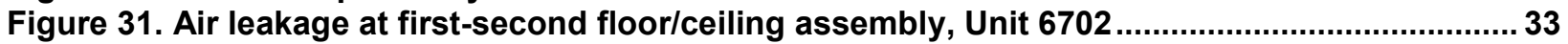

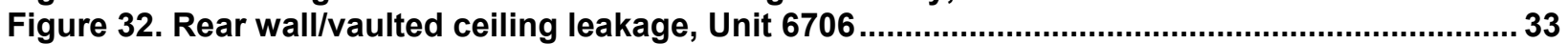

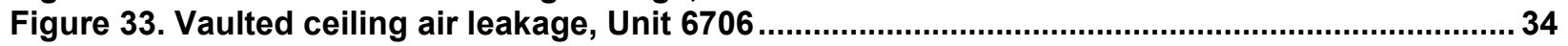

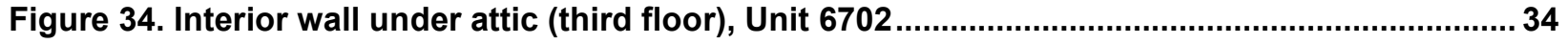

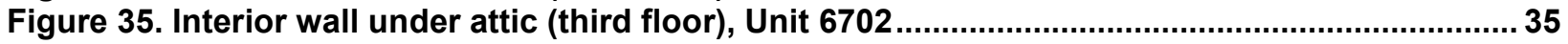

Figure 36. Return duct air leakage and attic kneewall leakage (Unit 6704) ....................................... 35

Figure 37. Attic knee wall condition and sheathing (Unit 6704) ......................................................... 36

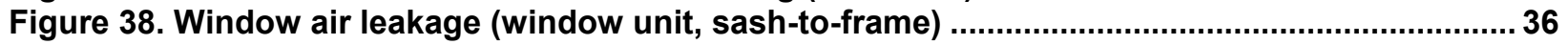

Figure 39. Sliding glass door air leakage at weep hole (door unit) ............................................... 37

Figure 40. Sliding glass door air leakage at weep hole (door unit) ................................................ 37

Figure 41. Window air leakage (window-to-wall connection at sill), Unit 6706................................. 37

Figure 42. Air leakage at door (door jamb gasket and frame-to-wall connection) ........................... 38

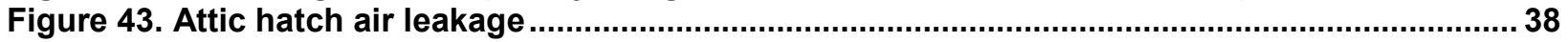

Figure 44. Exhaust fan air leakage (through unit and around unit) ............................................... 39

Figure 45. Microwave/range hood air leakage (through unit and around unit) .................................. 39

Figure 46. Bathroom recessed light air leakage (around unit/trim ring) ........................................... 40

Figure 47. Plan of two adjacent middle units (first floor), with key locations highlighted ................40

Figure 48. Air leakage at stair tread-to-riser joints, location (A) ................................................... 41

Figure 49. Measurement of pressure difference under stairs, location (A) ..................................... 41

Figure 50. Air leakage at stair landing (first-to-second floor) ...................................................... 42

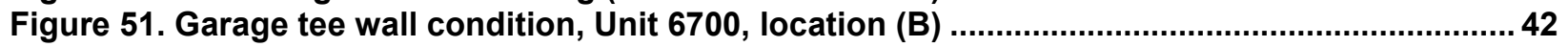

Figure 52. Garage tee wall conditions, showing ladder blocking ....................................................... 43

Figure 53. Area separation wall "jog" at exterior, location (C) .................................................... 43 
Figure 54. Second floor living room leakage pattern over garage, Unit 6706, location (D) ............. 44 Figure 55. Missing gypsum fireblocking at garage ceiling rim joist area .........................................4 44

Figure 56. Leakage at vaulted ceiling connection to separation wall, Unit 6706 ............................ 45

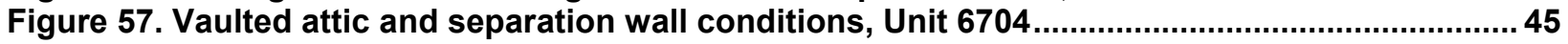

Figure 58. Exterior infrared of three middle unit attic demising walls ..............................................46

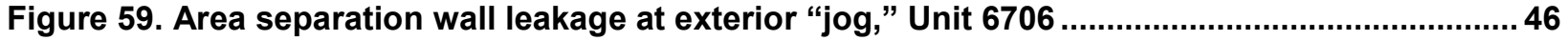

Figure 60. Separation wall "jog" at second and third floors, frame building .................................. 47

Figure 61. Air leakage at light mounted on area separation wall.................................................47

Figure 62. Pressure difference measurements at electrical box penetrations .................................. 48

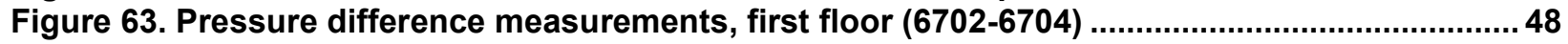

Figure 64. Pressure difference measurements, second floor $(6702-6704)$....................................... 49

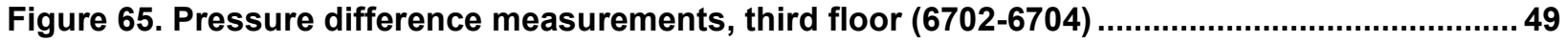

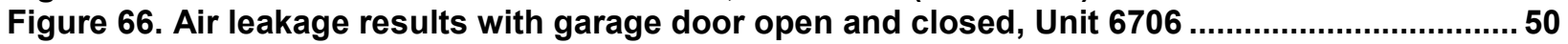

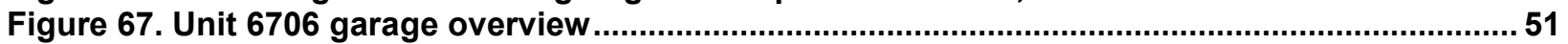

Figure 68. Mechanical room located in rear garage (Unit 6706)................................................ 52

Figure 69. Nulled and non-nulled testing of the garage mechanical room TECLOG3 output ..........52

Figure 70. Garage mechanical room nulled and non-nulled tests, Unit 6706................................. 53

Figure 71. Furnace and water heater at mechanical room (Unit 6700); supply register....................5 54

Figure 72. Ceiling and wall penetrations at mechanical room (Unit 6702)........................................54

Figure 73. Ceiling penetrations at mechanical room (Unit 6702) ..................................................... 54

Figure 74. Test application of two types of adhesive sheathing tape ................................................55

Figure 75. Test application of two types of adhesive sheathing tape .......................................... 55

Figure 76. Garage tee wall intersection, current (L) and proposed air sealing details (R)................58

Figure 77. Stairwell on exterior wall ............................................................................................59

Figure 78. MSHP 3:1 outdoor unit (L) and indoor ceiling recessed air handler (R) .......................60

Figure 79. Conceptual example of multi-head MSHP layout in three-story unit ...............................60

Figure 80. Detailed test results for Unit 6700 (end, improved and taped)........................................68

Figure 81. Detailed test results for Unit 6702 (middle, improved and taped) ...................................68

Figure 82. Detailed test results for Unit 6704 (middle, conventional construction) ..........................69

Figure 83. Detailed test results for Unit 6706 (middle, improved, no sheathing tape) .....................69

Figure 84. Detailed test results for Unit 6708 (end, improved, no sheathing tape).........................69

Figure 85. Detailed test results for Unit 6700 (end, improved and taped)....................................... 70

Figure 86. Detailed test results for Unit 6702 (middle, improved and taped) .................................. 70

Figure 87. Detailed test results for Unit 6704 (middle, conventional construction) .......................... 71

Figure 88. Detailed test results for Unit 6706 (middle, improved, no sheathing tape) ..................... 71

Figure 89. Detailed test results for Unit 6708 (end, improved, no sheathing tape)......................... 71

\section{List of Tables}

Table 1. Summary of Airtightness Targets and Standards...............................................................

Table 2. Summary of Previous Air Leakage Testing at Villages at Pepper Mill.................................. 22

Table 3. Air Leakage Testing Results From Individual Unit Testing (Day 1) .................................... 23

Table 4. Air Leakage Testing Results From Individual Unit Testing (Day 2), With $\Delta$ From Day 1 Tests

Table 5. Air Leakage Testing Results From Nulled Testing, With $\Delta$ From Individual Tests ............ 27

Table 6. Results of Mechanical Room Air Leakage Connection Testing .........................................53

Table 7. Unguarded and Guarded Air Leakage Test Results, With ACH50....................................56

Table 8. Unguarded and Guarded Air Leakage Test Results, With CFM50/ft ${ }^{2}$ Enclosure .................56

Table 9. Unguarded and Guarded Air Leakage Test Results, With $\Delta$ CFM50 ...................................57

Table 10. Mini-Split System Rough Equipment Costs (30,000 Btu/h Heat Pump)............................. 61

Table 11. Conventional Split System Rough Equipment Costs (30,000 Btu/h Air Conditioner and

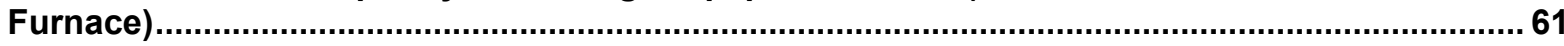

Table 12. Equipment Summary, With Range and Accuracy …..................................................6 67

Unless otherwise noted, all figures and tables were created by Building Science Corporation. 


\section{Definitions}

ACH50 Air changes per hour at 50 Pascal test pressure

ASHRAE American Society of Heating, Refrigerating and Air-Conditioning Engineers, Inc.

ASTM American Society for Testing and Materials

BSC Building Science Corporation

CFM Cubic feet per minute

CFM50 Cubic feet per minute at 50 Pascal test pressure

DOE U.S. Department of Energy

EPA U.S. Environmental Protection Agency

EqLA Equivalent Leakage Area

HVAC Heating, ventilation, and air conditioning

ICC International Code Council

IECC International Energy Conservation Code

IRC International Residential Code for One- and Two-Family Dwellings

LEED Leadership in Energy \& Environmental Design

MSHP Mini-split heat pump

NRCERT New River Center for Energy Research and Training

NREL National Renewable Energy Laboratory

OSB Oriented Strand Board

TEC The Energy Conservatory

UL Underwriters Laboratories

USGBC U.S. Green Building Council 


\section{Executive Summary}

The 2012 International Energy Conservation Code (IECC) has an airtightness requirement of 3 air changes per hour at 50 Pascals test pressure (3 ACH50) for single-family and multifamily construction (in climate zones 3-8). The Leadership in Energy \& Environmental Design certification program and ASHRAE Standard 189 have comparable compartmentalization requirements. ASHRAE Standard 62.2 will soon be responsible for all multifamily ventilation requirements (low rise and high rise); it has an exceptionally stringent compartmentalization requirement. These code and program requirements are driving the need for easier and more effective methods of compartmentalization in multifamily buildings.

Fire-resistance rated wall assemblies (or area separation walls) have been identified as the major source of difficulty in air sealing/compartmentalization, particularly in townhouse construction. The current research examined the taping of exterior sheathing details to improve air sealing results in townhouse and multifamily construction, when coupled with a better understanding of air leakage pathways.

The background literature was examined on several topics, including multifamily air leakage and compartmentalization, air leakage of fire-resistance rated wall assemblies, the current applicable air leakage targets and metrics, and exterior air barriers and taped sheathing.

A building comprising five vertical townhome units was built in the Washington, D.C., area; the townhomes were three-story slab-on-grade units (1700-2000 $\left.\mathrm{ft}^{2}\right)$ with a rear-facing "tuck under" garage. The three-story townhome design results in $3 \mathrm{ACH} 50$ being equivalent to a stringent surface-area based target (0.16-0.17 CFM50/ $\mathrm{ft}^{2}$ building enclosure).

The party walls between units were area separation walls, with a 2-hour fire resistance rating (Underwriters Laboratories U347 assembly; equivalent to U373 and U336). This assembly has a 1 -in. vertical air cavity on each side of a 2 -in. vertical gypsum panel in the middle of the assembly, resulting in an airflow network that is connected over multiple floors (despite nominal draft stopping), and has potential connections to exterior conditions.

The test townhomes were built with several experimental airtightness details, including taping of exterior sheathing as an air barrier closure detail (in particular, at area separation walls). Various measures were applied to the units for this experiment, including a "control" conventional construction unit and some units with "improved" detailing (without taped sheathing).

Airtightness testing included "unguarded" testing, or total leakage of each unit (to exterior and to adjacent units), and "guarded" testing (or pressure neutralization), which nominally measured leakage to the exterior only (adjacent units run at equal test pressure to null out interunit air leakage). Guarded testing was accomplished by installing fans in all five units and running them in parallel. During testing, air leakage was localized with observations, differential pressure diagnostics, and infrared thermography. The test building had units ready for sale, so no intrusive disassembly could be done to determine the source of air leakage. However, a similar building at the same community was still in frame; it was examined to correlate leakage issues with construction details. 
In both the unguarded and guarded (pressure neutralized) testing, no units met the 3 ACH50 target of the 2012 IECC. For reference, typical results for this builder were 4.8 ACH50 at this development, and 3.2 ACH50 at a development that had used a spray latex sealant (both unguarded tests). However, these units either achieved or were close to the normalized $0.30 \mathrm{CFM} 50 / \mathrm{ft}^{2}$ enclosure standard used by some programs.

Middle units had worse air leakage than end units; guarded testing showed greater reductions for middle units than end units, which is consistent with one versus two area separation walls. But the fact that the units do not meet the requirements in the nulled test indicates that the issues may not be confined to area separation wall problems.

The guarded or nulled test results should be interpreted with caution: interstitial pressure measurements showed that the area separation wall cavity was well connected to the exterior or other units in some cases. As a result, the leakage between units was not completely eliminated in these guarded tests. These inadvertent connections occurred at details such as garage ceilings, wall jogs, and attics. Substantial air leakage issues were found at the garage (50\% interior/ $50 \%$ exterior) and mechanical room.

The results show no improvement associated with taping of the exterior sheathing; in fact, some cases are slightly worse. No noticeable change was seen in the "improved" units compared to the conventional control. Unfortunately, the experiment was hampered by other variables, such as unplanned additional air sealing in some units and missing or incompletely executed air barrier details in other units. Testing identified several air leaks not specific to multifamily construction; variation in this leakage made it difficult to consistently differentiate experimental options.

The literature indicates that taped sheathing is useful for achieving very stringent airtightness targets (e.g., 1 ACH50 and lower). However, if there are more substantial air leaks - as was the case here- the difference will likely be difficult to discern.

As demonstrated by the inability to reach airtightness targets, further work needs to be conducted on developing airtightness details for area separation walls (or similar demising or party walls). These details would ideally be executed more consistently than current detailing, and be more readily inspectable. They should also integrate with the current construction practices and sequencing. Clear guidance to code officials on accepted air sealing materials in area separation walls would simplify the practice of providing airtightness at these troublesome details.

Although these units failed to meet $3 \mathrm{ACH} 50$, all were close to meeting the standard of $0.30 \mathrm{CFM} 50 / \mathrm{ft}^{2}$ enclosure. Area-based metrics address the penalty seen here for smaller units, and have been espoused by Building Science Corporation, ASHRAE, Passive House Institute US, Steven Winter Associates, and others. Maxwell (2014) suggested that $0.30 \mathrm{CFM} 50 / \mathrm{ft}^{2}$ enclosure may be a useful target for multifamily construction, and Brennan (2014) has stated that ASHRAE 62.2 is shifting to this standard as well. Overall, much of the industry appears to be converging toward this airtightness target. Of course, if and when the relevant standards change, the direction of research should be adapted accordingly. 


\section{Introduction}

\subsection{Introduction}

The 2012 International Energy Conservation Code (IECC) has an airtightness requirement of 3 air changes per hour at $50 \mathrm{~Pa}$ test pressure (3 ACH50) for single-family and multifamily construction (in climate zones 3-8). The Leadership in Energy \& Environmental Design (LEED ${ }^{\mathrm{TM}}$ ) certification program and ASHRAE Standard 189 have comparable compartmentalization requirements. ASHRAE Standard 62.2 will soon be responsible for all multifamily ventilation requirements (low rise and high rise); it has an exceptionally stringent compartmentalization requirement. These code and program requirements are driving the need for easier and more effective methods of compartmentalization.

Builders and practitioners have found that fire-resistance rated wall assemblies are a major source of difficulty in air sealing/compartmentalization, particularly in townhouse construction. This problem is exacerbated when garages are "tucked in" to the units and living space is located over the garages.

The current research examined the taping of exterior sheathing details to improve air sealing results in townhouse and multifamily construction, when coupled with a better understanding of air leakage pathways. Current approaches are cumbersome, expensive, time consuming, and ineffective; these details were proposed as a more effective and efficient method.

The effectiveness of these air sealing methods was tested with blower door testing, including "nulled" or "guarded" testing (adjacent units run at equal test pressure to null out inter-unit air leakage, or "pressure neutralization"). Pressure diagnostics were used to evaluate unit-to-unit connections and series leakage pathways (i.e., air leakage from exterior, into the fire-resistance rated wall assembly, and to the interior).

\subsection{Relevance to Building America's Goals}

The National Renewable Energy Laboratory (NREL) and the Standing Technical Committee on Enclosures presented top priorities for research in their document, "Building America Technical Innovations Leading to 50\% Savings - A Critical Path" (NREL 2013). The document stated that multifamily residential buildings comprise a significant segment of the residential building stock, and these buildings are on the critical path for achieving energy savings at scale.

Building America has goals of reducing home energy use by 30\%-50\% (compared to 2009 energy codes for new homes and pre-retrofit energy use for existing homes). Of course, air leakage is a significant contributor to heating and cooling energy use (particularly in cold and mixed climates). This measure will result in energy improvements proportional to the reduction in air leakage that production builders can cost-effectively achieve. Retrofit work has sometimes revealed catastrophic air leakage at fire-resistance rated wall assemblies. Addressing this leakage in a manner that satisfies local code officials (in terms of maintaining the fire performance of the rated assembly) can result in significant savings. 


\subsection{Tradeoffs and Other Benefits}

The primary benefit to improved airtightness is reduced heating and cooling energy use. Greatly reducing or eliminating uncontrolled air leakage also increases occupant comfort and reduces the risk of air leakage-based condensation failures of building enclosures. In mixed-humid and hothumid climates, these measures improve the ability of space conditioning systems to control interior humidity levels.

In multifamily construction, research has shown that good compartmentalization is vital for fire, smoke, odor, contaminant, and sound control. In multistory/high-rise construction, compartmentalization can ensure more reliable suite ventilation in buildings with common ventilation systems. These issues are summarized in the literature search presented by Finch et al. (2009), and are covered in work by Hill $(2005,2006)$. Environmental tobacco smoke is an airborne contaminant of particular concern; measurements of compartmentalization before and after retrofit airtightness measures were studied by the Center for Energy and Environment (CEE 2004). 


\section{Background and Literature Search}

This section is divided into several topics that are relevant to this research:

- Section 2.1 is a literature review on multifamily air leakage and compartmentalization.

- Section 2.2 discusses research on air leakage of fire-resistance rated assemblies.

- Section 2.3 summarizes the current applicable air leakage targets and metrics.

- Section 2.4 presents information about exterior air barriers and taped sheathing.

\subsection{Multifamily Air Leakage and Compartmentalization}

Compartmentalization, as a concept, dates back to the Empire State Building during the Great Depression. It was espoused as an approach to deal with durability, fire safety, comfort, and indoor air quality in high-rise and multifamily construction. However, the concept was not formally memorialized until Handegord (2001).

Lstiburek (2005b) proposed performance metrics based on Handegord that were adopted by ASHRAE Standard 189 (ASHRAE 2009). A comparable metric was adopted by both the 2012 IECC (ICC 2012a) and LEED Mid-Rise Multifamily (USGBC 2010a). A significantly tighter metric was adopted by ASHRAE Standard 62.2 in 2013 (ASHRAE 2013) that is proving to be very difficult to meet.

Work was done in Canada by Hill $(2005,2006)$ and overseen by Handegord for Canada Mortgage and Housing Corporation. Hill (2005) tested airtightness in eight suites in a new multiunit residential building; leakage rates were 1.2-3.2 ACH50 (2.2 ACH50 average, 0.75 ACH50 standard deviation). This included leakage from the exterior and to common spaces and adjacent units; the airflow from exterior and interior spaces appeared to be roughly comparable. These high-rise unit results are likely not directly comparable to low-risk, wood-frame townhome construction. The building ventilation system was designed with door undercuts at the hallway to provide make-up air for exhaust systems; flows were lower than specified; operating multiple unit exhaust fans resulted in significant depressurization $(-20$ to $-75 \mathrm{~Pa})$. This depressurization reduced the flow from some exhaust fans, as they were forced to "compete" for air.

Hill (2006) tested compartmentalization techniques in two suites in a high-rise multiunit residential building, using the airtight drywall approach at demising walls; the units were tested and compared to conventionally constructed units. The results were generally encouraging; the test units had lower normalized leakage relative to similar units. The test units achieved tightness levels of 1.8 and 2.2 ACH50; conventional units ranged from 1.3 to 4.6 ACH50. Leakage locations included plumbing, electrical, and mechanical penetrations, windows and window-towall joints, and interior wall sill plates.

Gadgil et al. (2006) compiled data (Residential Energy Consumption Survey and similar) on air leakage of apartment (multiunit residential) buildings, and "commercial" (nonresidential) buildings. They concluded that these buildings were roughly twice as leaky as single-family homes (as a surface area-normalized metric). They reiterated the fact that indoor-to-outdoor air leakage and unit-to-unit air leakage are interrelated: in poorly compartmentalized buildings, 
leakage from one suite can influence leakage in other units. They cite literature stating that commonly, $10 \%-40 \%$ of the air coming into apartments originates from other units, not from the exterior; some cases report that $100 \%$ air leakage is supplied from other units. They also warned that improving indoor-to-outdoor airtightness in apartment buildings without addressing unit-tounit airtightness might result in greater pollutant exposure to occupants.

Genge (2007) discussed measurement of air leakage in multiunit residential buildings, driven by LEED requirements in multifamily buildings. He noted the importance of leakage to the exterior and compartmentalization. He discussed equipment and procedures for executing multiunit residential building tests, including running multiple calibrated fans, at one per floor. By sequentially adding fans at a fixed test pressure, this method can measure leakage to the outside as well as leakage to adjacent interior spaces ("nulling" test).

Finch et al. (2009) measured air leakage in six suites in four multiunit residential buildings, with a focus on leakage rates through isolated wall and floor/ceiling assemblies, and providing baseline data. He performed nulling or "pressure neutralizing" tests, noting that they are costly and time intensive, and therefore not common. He had an extensive review of the North American and European literature, including studies on isolating air leakage of various enclosure components. The overall leakage measurements were over a wide range (2.6-14 ACH50, 4.3 standard deviation); more interestingly, there was substantial variation in terms of the air leakage location, between various suites. A range of 33\%-80\% of the leakage came from the exterior; common areas/hallways comprised $11 \%-52 \%$ of the total leakage. Wood-frame walls were found to have higher leakage than steel stud and gypsum board walls covered with self-adhered membrane. Low air leakage to the exterior was correlated with higher wintertime interior relative humidity, based on long-term monitoring.

Griffiths (2012) reported on a Building America Expert Meeting (March 2012) on air change rates and enclosure leakage in attached dwellings; representatives from Building America research teams, national laboratories, and testing and weatherization agencies gave presentations. Discussion points included testing methods for multifamily buildings, including whether (1) a standardized test method is needed; and (2) additional research is needed on the test methods. They also noted the expense, difficulty, and rarity of guarded testing, noting that a method to calculate leakage to the exterior would be useful for gauging energy benefits from improved air tightness. Materials presented by speakers included:

- Iain Walker of Lawrence Berkeley National Laboratory covered ASHRAE Standard 62.2's application to multifamily buildings, including the compartmentalization requirement added in Addendum $\mathrm{j}$. He noted that this level of airtightness will have effects on unit depressurization and combustion air.

- Srikanth Puttagunta of Steven Winter Associates, Inc. presented on guarded, unguarded, and zone pressure diagnostic testing of a new construction townhome project. There was some discussion on measurement anomalies that suggested fundamental problems with nulled testing; representatives from The Energy Conservatory (TEC) (testing equipment manufacturer) also contributed to the discussion, offering potential explanations. 
- Chase Counts of New River Center for Energy Research and Training (NRCERT) presented on developing a protocol for auditing low-rise multifamily complexes based on its experience with roughly 40 such tests. He covered methods and equipment, noting the extensive manpower and logistics requirements for large-scale testing.

- Michael Lubliner of Washington State University covered multiblower door testing of low rise multifamily buildings, including results from guarded and unguarded apartment leakage tests, from pre- and post-retrofit weatherization and installation of dense pack wall insulation.

Otis and Maxwell (2012) presented a Building America Measure Guideline on air sealing of attics in multifamily buildings. It included air sealing methods for a variety of conditions, from row houses with easy attic access, to older masonry townhomes with no access without removal of the ceiling finish. Details were provided addressing fire-rated wall assembles between units. It included case studies on retrofit air sealing of three types of multifamily buildings.

Klocke et al. (2014) discussed the challenges of achieving the 3 ACH50 requirement of the 2012 IECC in multifamily dwellings. In particular, they noted that in multifamily construction, air leakage originates both from outside and interior sources; the latter has less influence on energy performance because of a minimal temperature difference. Previous comparisons of guarded testing (running units at the same pressure to eliminate inter-unit leakage) and unguarded testing showed a $22 \%-27 \%$ reduction in air leakage. They presented results from roughly 600 high performance apartment air leakage tests (unguarded). Most (90\%) met the ENERGY STAR ${ }^{\circledR}$ multifamily requirement of $0.30 \mathrm{CFM} 50 / \mathrm{ft}^{2}$ enclosure; roughly half met a standard of $0.25 \mathrm{CFM} 50 / \mathrm{ft}^{2}$ enclosure; only $10 \%$ met the rough equivalent of 2012 IECC (3 ACH50).

Klocke et al. performed unguarded testing in three low-rise multifamily new construction projects in New York. They examined variables such as unit vertical (bottom/middle/top) and horizontal (end versus middle) locations. Typical unguarded air leakage values were in the 4-6 ACH50 range; one project had noticeably better leakage numbers due to the use of spray foam in demising walls. The best of the three projects had 50\% of units meeting 3 ACH50; other projects had $12 \%$ and $0 \%$ meeting the requirement. The team proposed a change to the building code, to switch from the 3 ACH50 target to a surface-area based target of 0.25 CFM50/ $\mathrm{ft}^{2}$ enclosure in low-rise multifamily buildings. They also proposed language for a sampling protocol in multifamily testing.

\subsection{Fire-Resistance Rated Assemblies Air Leakage}

Some practitioners have examined the issue of air leakage associated with fire-resistance rated assemblies or area separation walls in multifamily buildings. A typical assembly is the Underwriters Laboratories (UL) U347/U373/U336 2-hour rated assembly.

Holton and Prahl (2005) examined the issue of air leakage at these fire-resistance rated assemblies (area separation walls) in multifamily buildings (such as side-by-side townhomes). They noted that poor thermal performance (specifically, air leakage) has negative results for energy efficiency and comfort. One example was air leakage from the party wall into a vented (unconditioned) attic, resulting in heat loss and ice dam issues. Many party wall designs call out 
for an air space between the fiberglass batt stud bay insulation and the 1-in. gypsum shaft liner board core, resulting in an air leakage path that can be connected over multiple floors. The authors questioned whether this air gap is actually necessary for fire performance. Many fireresistance rated walls provide both interior-to-interior and interior-to-exterior separation (because planes shift between units): this condition increases the risk of air leakage.

Although the core of the wall (double-layer 1-in. gypsum shaft board, typical) is relatively monolithic, the wall assembly to either side of the core has many mechanical, electrical, and structural penetrations, which are thus in turn connected to the air space. Similarly, bathtubs and stairwells on common walls have high risks of air leakage. Assemblies need to be developed that improve airtightness and simultaneously address fire, acoustic, and moisture issues. At the same time, air sealing details must be durable and accommodate movement. The authors demonstrate a series of common problematic air leakage details at fire-resistance rated walls, with proposed solutions.

Prahl continued this work, proposing changes to the International Residential Code (IRC) and International Building Code to allow for limited quantities of sealants at these critical details (ICC 2013). However, the committee rejected this proposed change, which was the focus of continuing effort under the Building America program.

Rudd and Prahl (2014a) proposed a plan to engage with stakeholders on using air sealing materials in fire-resistance rated wall assemblies (area separation walls), including a collation of the relevant IRC, IECC, and ASTM materials. Among other sections, they cite the sections of the IRC (ICC 2012b) relevant to fireblocking of cavities ( $\$$ R302.11), which calls for cutting off "concealed draft openings" in wood-frame construction at ceiling/floor levels, horizontally every $10 \mathrm{ft}$ (maximum), at soffits/drop ceilings, and stairs, among others. These fireblocking requirements essentially correspond to the air sealing of cavities of fire-resistance rated wall assemblies. They note that the fireblocking materials described in $\S R 302.11$ should be acceptable in these assemblies.

Rudd and Prahl (2014b) conducted a Building America Focus Meeting on "Code Challenges with Multi-Family Area Separation Walls," with participation from stakeholders in the construction and product manufacturing industries. They proposed a modification of the typical U347/U373/U336 wall, with an additional layer of gypsum sheathing on the unit-to-unit side of the wood framing; this would isolate the stud bays and make air sealing similar to typical exterior wall construction. However, industry stakeholders pushed back, citing cost and constructability reasons, including sequencing and the difficulty of installing clips through this sheathing. Industry stakeholders also noted that the proposed air sealing materials within the wall should be irrelevant to the fire performance of the assembly, but that work with UL (a request for an engineering opinion and/or a full-scale burn test) might be needed to move forward.

\subsection{Air Leakage Targets and Metrics}

The airtightness targets discussed earlier are covered in more detail in this section and summarized in Table 1. 
The 2012 IECC (ICC 2012a) provides a residential airtightness requirement in Chapter 4: Residential Energy Efficiency. It is a whole-house (as opposed to compartmentalization) requirement that applies to single-family and multifamily units.

R402.4.1.2 Testing. The building or dwelling unit shall be tested and verified as having an air leakage rate of not exceeding 5 air changes per hour in Climate Zones 1 and 2, and 3 air changes per hour in Climate Zones 3 through 8. Testing shall be conducted with a blower door at a pressure of 0.2 inches $w . g$. (50 Pascals).

The LEED compartmentalization requirement (USGBC 2010a) can be divided into the prerequisite (requirement) and credit categories. The requirement is covered in $\S E Q 12$ : Compartmentalization of Units (in Mid-rise Buildings); it is stated as an area-based (as opposed to volume-based) calculation. The area used in the calculation includes all surfaces enclosing the apartment, including leakage to exterior and adjacent units/common spaces.

Prerequisites (Mandatory Measures)

12.1 Compartmentalization of Units: Demonstrate acceptable sealing of residential units by a blower door test. Follow the procedure described in the ENERGY STAR Testing and Verification Protocols for multifamily high-rise buildings, with an allowable maximum leakage of 0.30 cfm 50 per square foot of enclosure (i.e. all surfaces enclosing the apartment, including exterior and party walls, floors, ceiling).

Credits

12.2 Enhanced Compartmentalization of Units (1 Point): Significantly reduce smoke and other indoor air pollutant exposure and transfer (1 point). Meet the requirements of part (a) above and perform a blower door test to ensure that smoke transfer is minimized. Follow the procedure described in the ENERGY STAR Testing and Verification Protocols for multifamily high-rise buildings, with an allowable maximum leakage of $0.225 \mathrm{cfm} 50$ per square foot of enclosure (i.e. all surfaces enclosing the apartment, including exterior and party walls, floors, ceiling).

These targets were changed from the previous 2008 pilot version of the midrise multifamily program, which used 7 and $4 \mathrm{ACH} 50$ as the prerequisite and credit targets, respectively (USGBC 2010b):

The maximum unit leakage prerequisite was modified from 7.0 ACH50 to $0.30 \mathrm{cfm} 50$ per square foot of enclosure (i.e. all surfaces enclosing the apartment, including exterior and party walls, floors, ceiling). Credit is given for projects that achieve less than $0.225 \mathrm{cfm} 50$ per square foot of enclosure, rather than 4.0 ACH50 or $\leq 1.25 \mathrm{in}^{2}$ per $100 \mathrm{ft}^{2}$ of enclosure area. 
ASHRAE Standard 189-2009 (ASHRAE 2009) also specifies an airtightness target for the whole building (as opposed to compartmentalization), under "Normative Appendix B: Prescriptive Continuous Air Barrier." It is stated in terms of cubic feet per minute per square foot of enclosure at a $75 \mathrm{~Pa}$ test pressure $\left(\mathrm{CFM} 75 / \mathrm{ft}^{2}\right)$.

c. Building. Testing the completed building and demonstrating that the air leakage rate of the building envelope does not exceed $0.4 \mathrm{cfm} / \mathrm{ft}^{2}$ under a pressure differential of $0.3 \mathrm{in}$. water $\left(1.57 \mathrm{lb} / \mathrm{ft}^{2}\right)\left(2.0 \mathrm{~L} / \mathrm{s}^{\prime} \cdot \mathrm{m}^{2}\right.$ under a pressure differential of $75 \mathrm{~Pa}$ ) in accordance with ASTM E779 or an equivalent approved method.

ASHRAE Standard 62.2-2013 (ASHRAE 2013) has a requirement for compartmentalization in multifamily buildings, under $\S 8.4$ "Other Requirements." Although the current scope of this standard is "single-family houses and multi-family structures of three stories or fewer above grade," the committee proposed to apply it to all residential dwelling units (any unit with sleeping quarters, toilets and baths, and kitchens within) (ASHRAE 2014).

8.4.1 Transfer Air. Measures shall be taken to minimize air movement across envelope components separating dwelling units, including sealing penetrations in the common walls, ceilings, and floors of each unit and by sealing vertical chases adjacent to the units. All doors between dwelling units and common hallways shall be gasketed or made substantially airtight.

8.4.1.1 Compliance. One method of demonstrating compliance with Section 8.4.1 shall be to verify a leakage rate below a maximum of 0.2 cfm per ft ${ }^{2}(100 \mathrm{~L} / \mathrm{s} \mathrm{per}$ $100 \mathrm{~m}^{2}$ ) of the dwelling unit envelope area (i.e., the sum of the area of walls between dwelling units, exterior walls, ceiling, and floor) at a test pressure of 50 Pa by a blower door test conducted in accordance with either ANSI/ASTM-E779, Standard Test Method for Determining Air Leakage Rate By Fan Pressurization, 1 or ANSI/ASTM-E1827, Standard Test Methods for Determining Airtightness of Buildings Using an Orifice Blower Door. The test shall be conducted with the dwelling unit as if it were exposed to outdoor air on all sides, top, and bottom by opening doors and windows of adjacent dwelling units.

However, current discussions (Brennan 2014) indicate that the target is being loosened from $0.2 \mathrm{CFM} 50 / \mathrm{ft}^{2}$ to $0.3 \mathrm{CFM} 50 / \mathrm{ft}^{2}$.

The ENERGY STAR Multifamily High Rise program (EPA 2013) has a compartmentalization requirement of $0.3 \mathrm{CFM} 50 / \mathrm{ft}^{2}$, for both the Prescriptive Path (Version 1.0) and the Performance Path (Version 1).

Apartments shall be sealed to reduce air exchange between the apartment and outside as well as the apartment and other adjacent spaces. A maximum air leakage rate of 0.30 CFM50 per square feet of enclosure is allowed.

Finally, Lstiburek (2005b) discussed HVAC in multifamily buildings, which included a recommendation for a compartmentalization target as follows. 
To achieve compartmentalization unit airtightness should meet a minimum resistance or air permeance of $2 \mathrm{~L} /\left(\mathrm{s} \cdot \mathrm{m}^{2}\right)$ at $75 \mathrm{~Pa}\left(0.4 \mathrm{cfm} / \mathrm{ft}^{2}\right.$ at $0.30 \mathrm{in.}$ w.g.).

The previous targets and recommendations are summarized in Table 1 below.

Table 1. Summary of Airtightness Targets and Standards

\begin{tabular}{|c|c|c|c|}
\hline Standard & \multicolumn{2}{|c|}{ Target (CFM50/ft ${ }^{2}$ Enclosure) } & Notes \\
\hline 2012 IECC & $\begin{array}{c}0.16 \\
0.17\end{array}$ & (Whole house) & $\begin{array}{l}\text { Converted from } 3 \mathrm{ACH} 50 \text {, } \\
\text { for the tested townhomes }\end{array}$ \\
\hline $\begin{array}{l}\text { LEED Mid-Rise } \\
\text { (Prerequisite) }\end{array}$ & 0.30 & (Compartmentalization) & \\
\hline LEED Mid-Rise (Credit) & 0.225 & (Compartmentalization) & \\
\hline ASHRAE Standard 189 & 0.31 & (Whole building) & $\begin{array}{c}\text { Converted from } \\
0.4 \text { CFM } 75 / \mathrm{ft}^{2} \text { enclosure }\end{array}$ \\
\hline ASHRAE Standard 62.2 & $0.20^{b}$ & (Compartmentalization) & \\
\hline $\begin{array}{c}\text { ENERGY STAR } \\
\text { Multifamily Hi-Rise }\end{array}$ & 0.30 & (Compartmentalization) & \\
\hline $\begin{array}{l}\text { Lstiburek (2005b) } \\
\text { Recommendation }\end{array}$ & 0.31 & (Compartmentalization) & $\begin{array}{c}\text { Converted from } \\
0.4 \text { CFM } 75 / \mathrm{ft}^{2} \text { enclosure }\end{array}$ \\
\hline $\begin{array}{l}\text { Klocke et al. (2014) } \\
\text { Recommendation }\end{array}$ & $0.25^{\mathrm{c}}$ & (Compartmentalization) & $\begin{array}{c}\begin{array}{c}\text { For multifamily } \\
\text { construction }\end{array} \\
\end{array}$ \\
\hline
\end{tabular}

${ }^{\mathrm{a}}$ This conversion assumes all enclosure surface area, including adiabatic walls. IECC does not provide guidance on what surface area should be included.

${ }^{\mathrm{b}}$ Will be increased to $0.30 \mathrm{CFM} 50 / \mathrm{ft}^{2}$ enclosure in the near future (Brennan 2014).

${ }^{\mathrm{c}}$ The research team is now proposing a change to the New York State code requiring $0.30 \mathrm{CFM} 50 / \mathrm{ft}^{2}$ for multifamily compartmentalization (Maxwell 2014).

Conversions were required for direct comparison between these standards; they were all converted into CFM50/ $\mathrm{ft}^{2}$ of enclosure. The current ASHRAE Standard 62.2 requirements are clearly the tightest of the surface area-based standards.

However, when the 2012 IECC requirement is normalized over the surface area of the tested townhomes (all surface area included in this calculation, including adiabatic walls), it is even more stringent than the ASHRAE 62.2 standard. This is due to surface area effects on small (1700- to $2000-\mathrm{ft}^{2}$ ) townhome units, spread vertically over three floors (high surface area-tovolume ratio). In comparison, a compact (rectangular) 2000- $\mathrm{ft}^{2}$ house (two story with basement) would have a surface area target of $0.24 \mathrm{CFM} 50 / \mathrm{ft}^{2}$ at the 2012 IECC requirement of 3 ACH50. The 2012 IECC does not provide guidance about what surface areas to include in the calculation (only exterior surfaces, or exterior and adiabatic surfaces).

\subsection{Exterior Air Barriers and Taped Sheathing}

Lstiburek (2006) categorizes various air barrier strategies, which include interior-side options (e.g., gypsum board, polyethylene), framing cavity options (spray foams), and exterior-side options (e.g., house wraps, taped sheathings, self-adhered membranes). Lstiburek (2005a) also explains the advantages and disadvantages of an exterior strategy. Construction advantages include the ease of installation (and inspection) and the lack of detailing issues at partition walls, floors, and service penetrations. Performance advantages include control of wind-washing (of 
cavity insulation) from the exterior and control of exterior hot-humid air into insulated cavities in hot-humid climates. The primary disadvantage of the exterior strategy is its inability to control the entry of interior moisture-laden air into framing cavities in the winter, which is a risk factor in cold climates. This problem is often addressed by providing insulation outboard of the exterior air barrier, thus reducing condensation risks.

In terms of putting exterior air barriers into practice, Lstiburek (2013b) documented that exceptional airtightness can be achieved when using self-adhered membrane over exterior structural sheathing as the primary air barrier, which is becoming a more common practice in commercial construction when paired with exterior insulation.

Another exterior air barrier strategy is to tape the seams of a structural sheathing. A proprietary sheathing with an integrated water-resistive barrier surface (Huber Engineered Woods Zip System) is designed to be taped at the seams to create monolithic air and water control. It has resulted in substantial improvements in building airtightness, according to field anecdotes and the literature (Uhler 2011; Bailes 2013).

Rosenbaum (2010) also promoted the concept of exterior air barriers by taping a rigid structural sheathing, particularly in high performance housing (less than 1 ACH50). This and similar work was also covered by Holladay (2010). Similar to previous work, Rosenbaum pointed out that structural sheathing-based exterior air barriers have many advantages, including:

- Fewer intersections need to be sealed (e.g., tee wall intersections, floor framing).

- The air barrier has fewer penetrations (i.e., mechanical services such as wiring and plumbing), and the location of the penetrations is clearer.

- It can better accommodate design complexity.

- It has high durability because it uses oriented strand board (OSB) or plywood as the air barrier.

- The air barrier is visible and verifiable, and testable earlier in the construction process.

One further issue with taping structural sheathing is adhesion between the tape and the sheathing. Holladay (2013a) performed bench top testing of tapes used for air sealing. He tested 11 tapes (in the categories of rubberized asphalt, butyl, and acrylic) on a variety of substrates (including rigid foam insulation, plywood and OSB, house wrap, and polyethylene). He found that OSB was generally the most difficult substrate for adhesion; some of the more expensive European tapes adhered to this substrate without primer, but most tapes had poor performance. Priming the OSB surface improved adhesion somewhat. Holladay (2013b) revisited the tape test rig after 10 months of exposure; he noted that the bond of many tapes had grown more tenacious over time, and identified two tapes that had good performance on OSB.

Of course, proper field application of these tapes is critical for long-term performance. Lstiburek (2013a) discusses the fact that tapes will not adhere to muddy, dirty, cold, wet, and frozen surfaces. Application technique (pressing in place with a roller) and termination at the top edge (for tapes vulnerable to low-angle shear) are also critical. 


\section{Multifamily Test Building and Construction Details}

\subsection{Multifamily Test Building Overview}

The field testing was conducted at K. Hovnanian Homes' Villages at Pepper Mill development in Capitol Heights, Maryland, roughly 10 miles east of Washington, D.C. A new building comprising five vertical townhome units (Figure 1) incorporated the experimental air sealing measures (see Section 3.3).

These townhomes are three-story slab-on-grade units (1700-2000 $\left.\mathrm{ft}^{2}\right)$. Each has a ground floor comprising a rear-facing "tuck under" garage, a front conditioned entry stairwell/ground-floor room, and a conditioned mechanical room opening to the garage (Figure 2 and Figure 3 ). The three-story compact floor plan explains the unfavorable surface area-to-volume issues discussed previously (see Table 1).

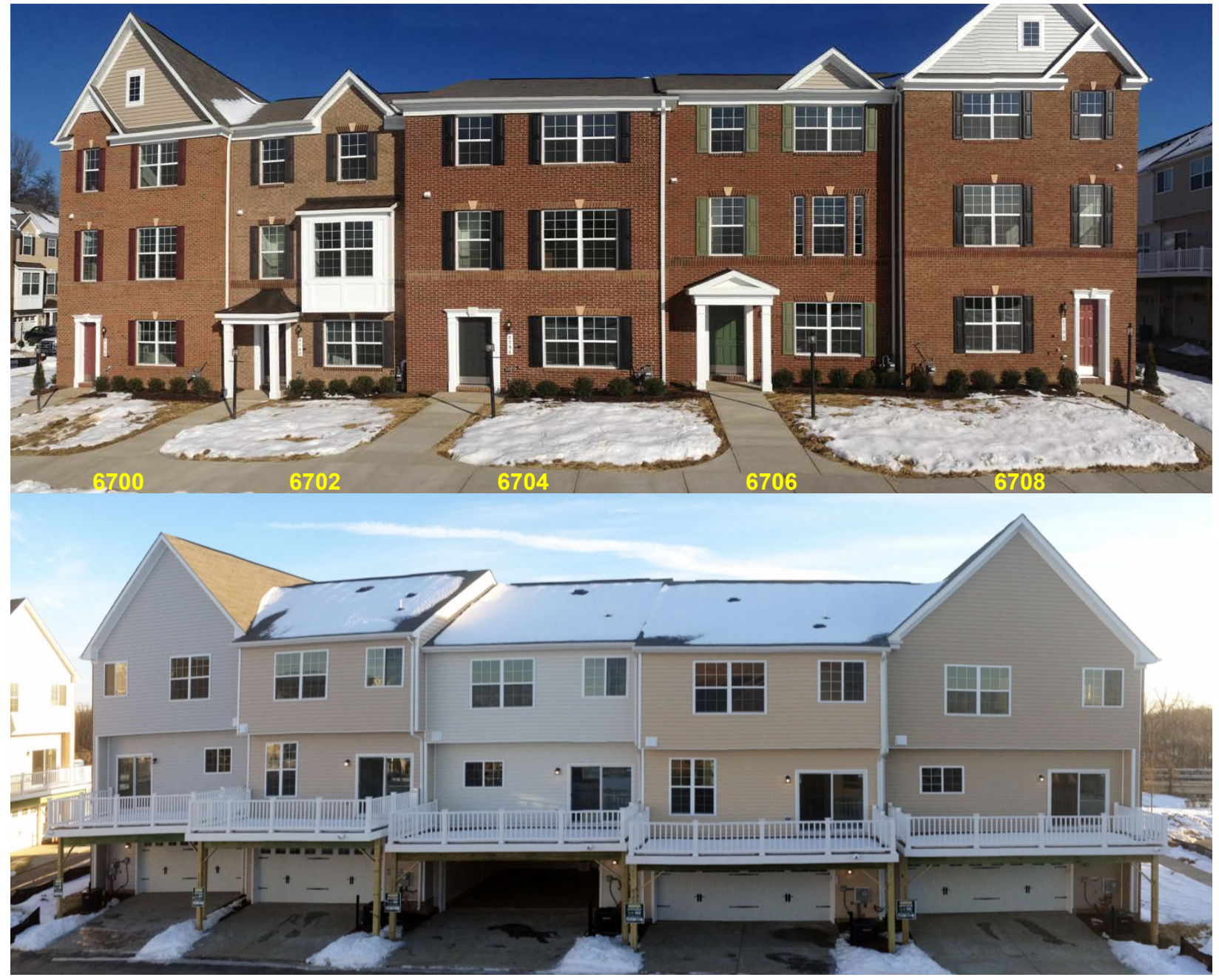

Figure 1. Villages at Pepper Mill Building 13 (5 units), front and rear elevations 

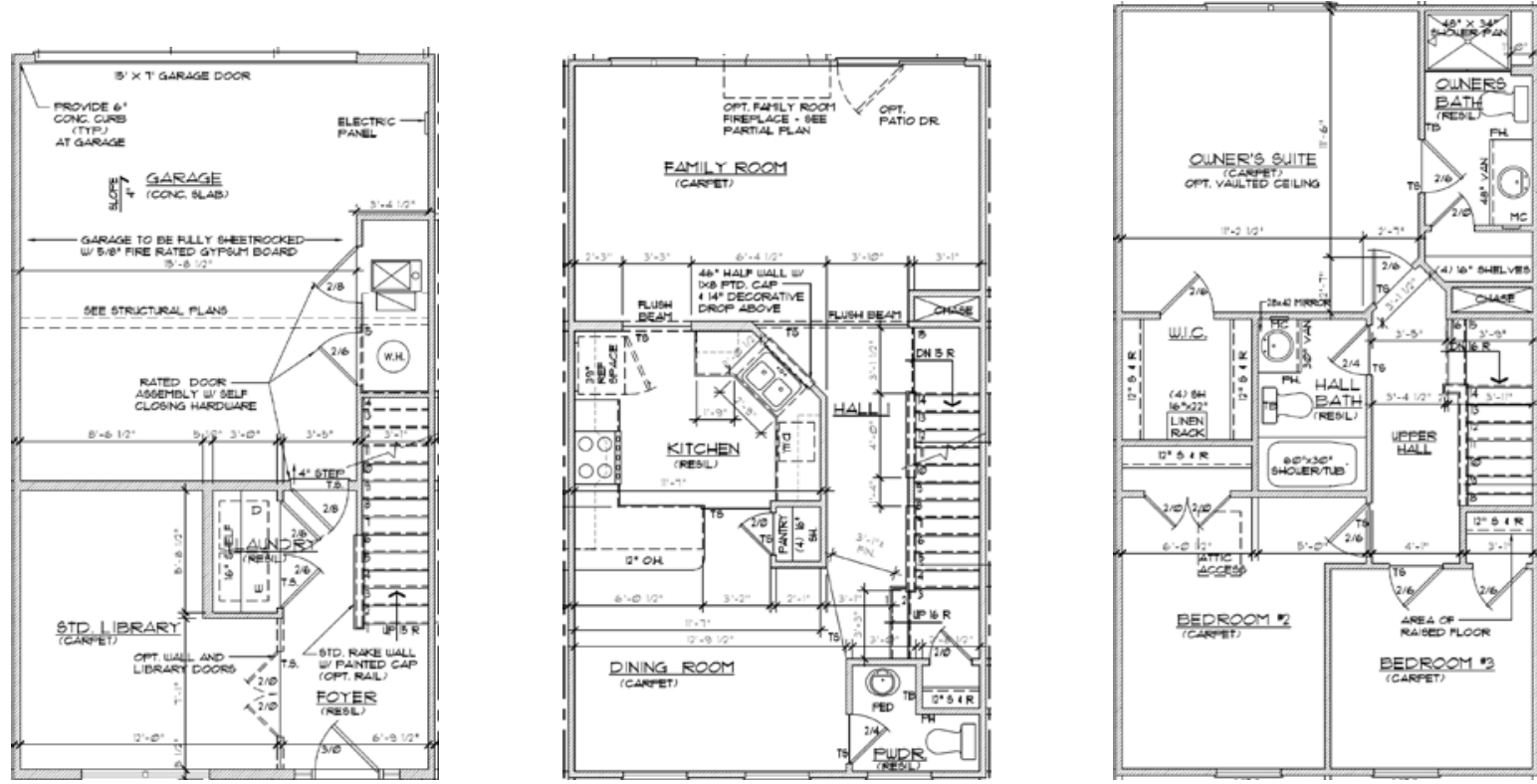

Figure 2. Floor plans for typical middle unit (“Adams” plan, 34-ft $\times 20-\mathrm{ft}$ footprint)
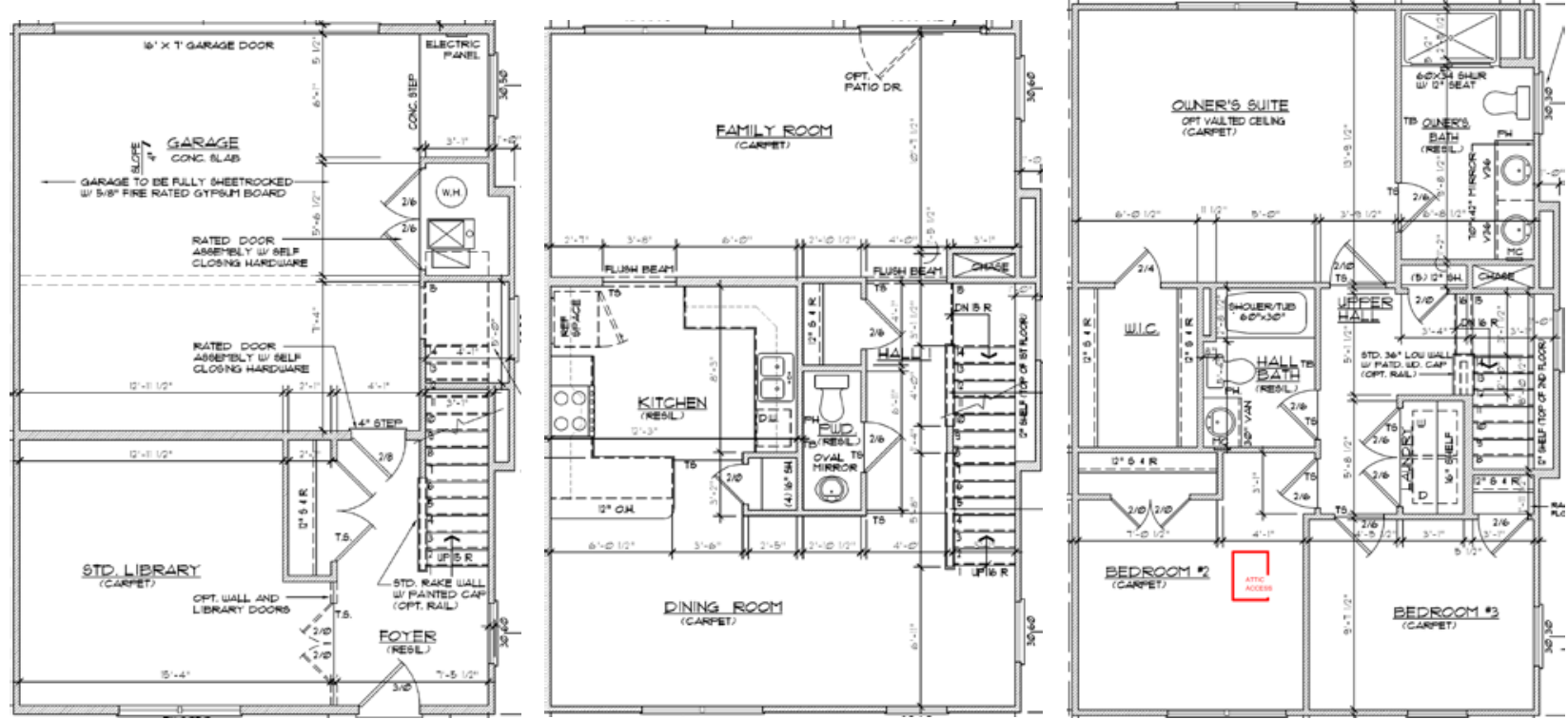

Figure 3. Floor plans for typical end unit (“Jefferson” plan, 34-ft $\times 24-\mathrm{ft}$ footprint)

\subsection{Area Separation Wall Details and Air Barrier Challenges}

The common or party walls between units are fire-resistance rated walls (UL U347 assembly; equivalent to U373 and U336), with a 2-hour fire resistance rating, as shown in Figure 4. Figure 4 through Figure 6 are based on the builder's plans, which are based on the manufacturer's assembly details. This wall is constructed with a nominal 1-in. air gap (minimum $3 / 4$ in.) between the $2 \times 4$ walls and the double 1-in. gypsum panels; the wall is designed to "break away" (via aluminum clips that will melt/fail) during a structure fire, leaving the adjacent townhomes intact. 
However, the air space results in an airflow network (via the 1-in. gap between the $2 \times 4$ wall and the gypsum panels) that can be connected over multiple floors, and has potential connections to exterior conditions (exterior walls and attic floor).

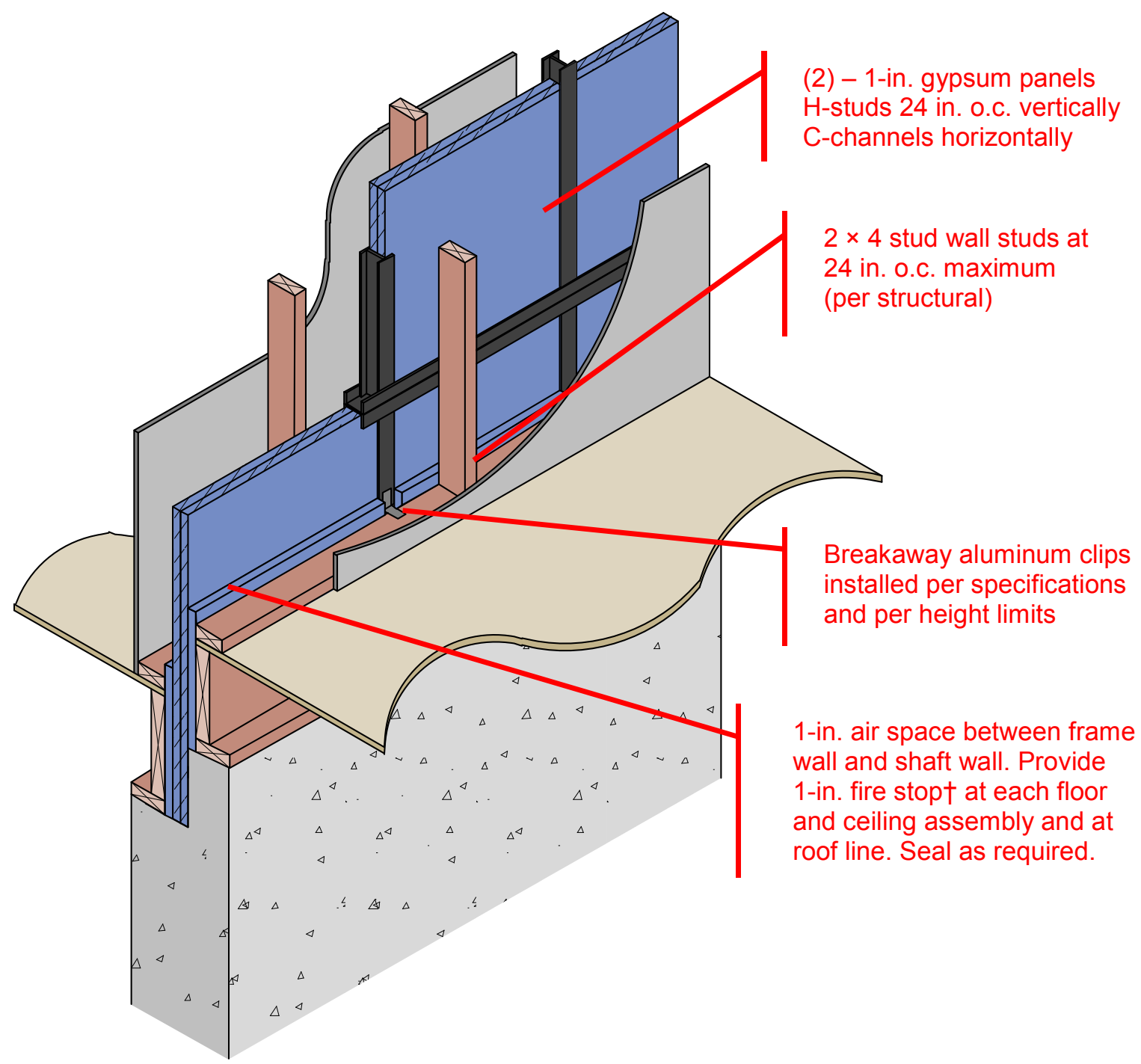

Figure 4. Area separation wall (fire-resistance rated wall assembly) typical section at foundation

The air gap is nominally compartmentalized by 1-in. thick gypsum "fire stop" in the cavity at floor levels (Figure 4 and Figure 5), exterior walls (Figure 6), and the attic floor. This "fire stop" is highlighted ( $\dagger$ ) in Figure 4 and Figure 5: it is called out in the manufacturer's illustrations, but is not part of the U347 assembly. This "fire stop" callout overlaps in concept with the fireblocking requirements of the IRC ( $§$ R302.11). The "fire stop" air seal is reliant on a tight fit in the opening, which may or may not occur, given framing construction tolerances. Also, interunit leakage may occur at the H-stud and C-channel joints of the double 1-in. gypsum board wall.

Manufacturers' details of the rated assemblies provide only nominal guidance on how air sealing would be executed, per the quote below (emphasis added by Building Science Corporation 
[BSC]). The lack of correct air sealing at this detail is one of the fundamental sources of the air leakage issues seen at these assemblies.
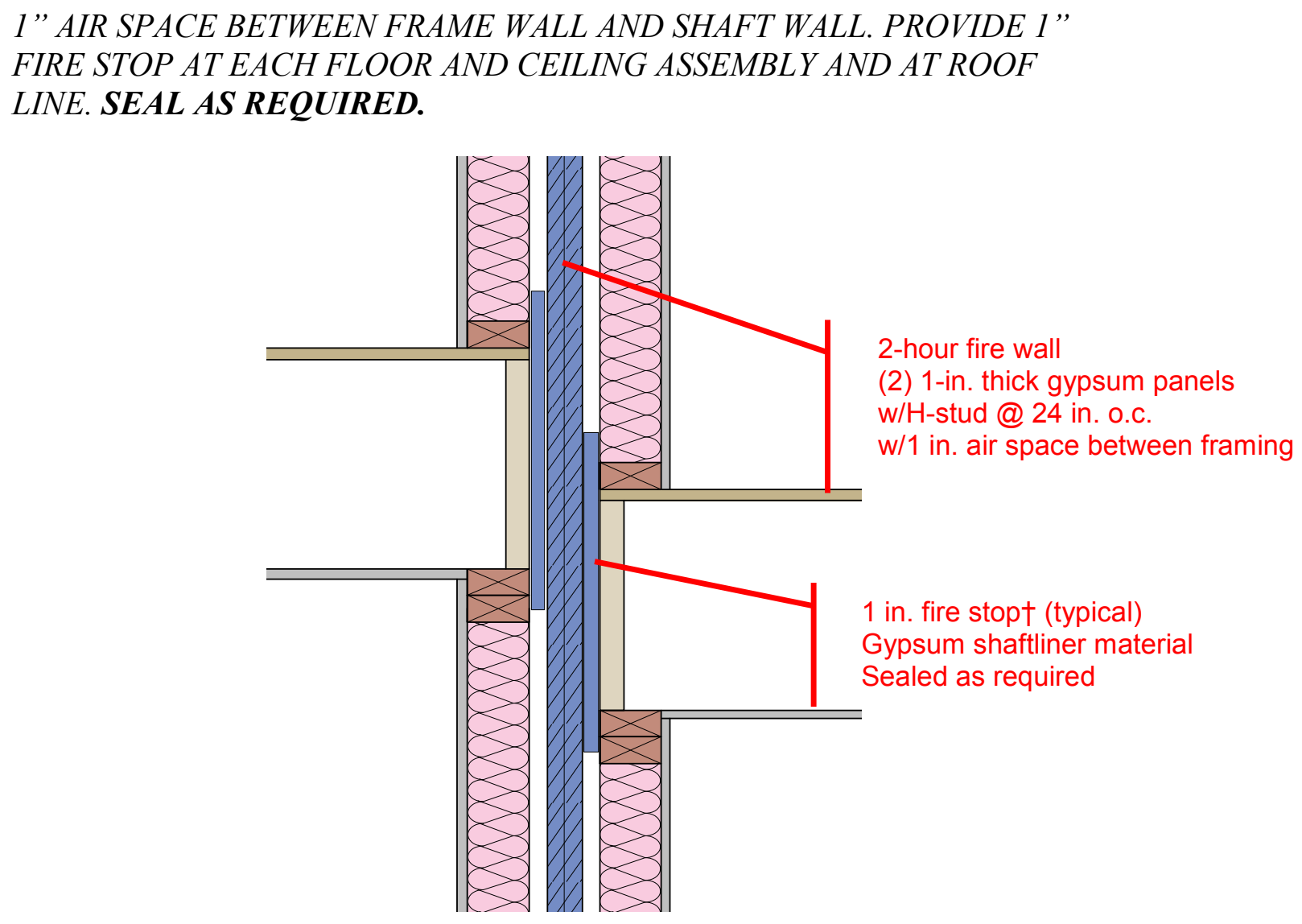

Figure 5. Area separation wall (fire-resistance rated wall assembly) at floor framing

Another problem geometry is shown in Figure 6: the fire separation wall penetrates to the exterior (because of a wall offset), leaving the edges of multiple layers exposed to the exterior. 


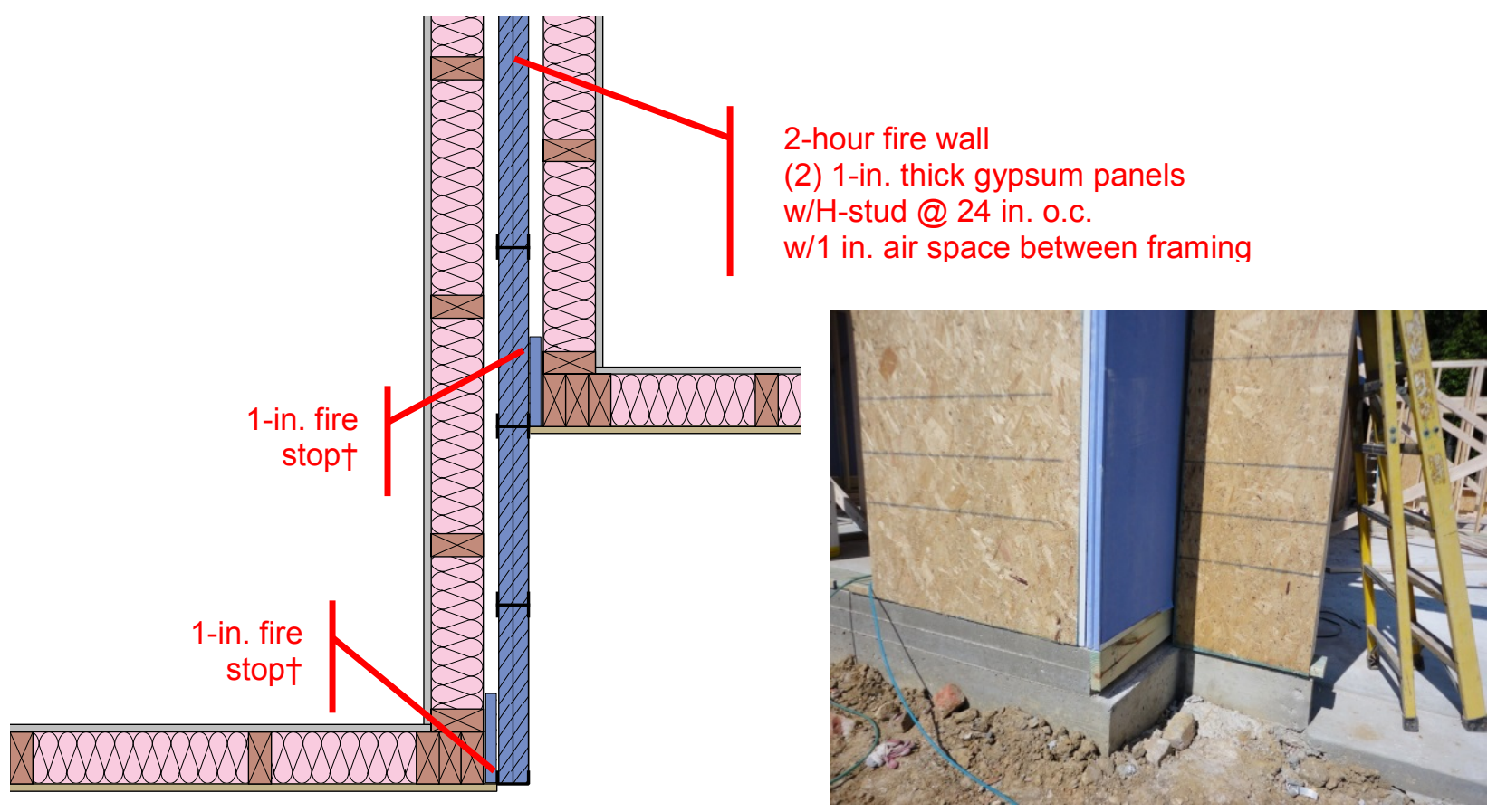

Figure 6. Area separation wall (fire-resistance rated wall assembly) detail at offset units

\subsection{Construction and Experimental Air Sealing Details}

Several experimental air barrier details were added to various units in the test building (listed in Figure 7 and covered in more detail below). The middle unit (6704) was planned as a control, with air sealing per current practice. However, the site supervisor changed the experiment by adding further ceiling/attic air sealing at unit 6704 only. All four remaining units had an "improved" package of air sealing details. Two units (6700 and 6702) also added the taping of the exterior sheathing; the conceptual taped locations are shown by blue highlighted lines.

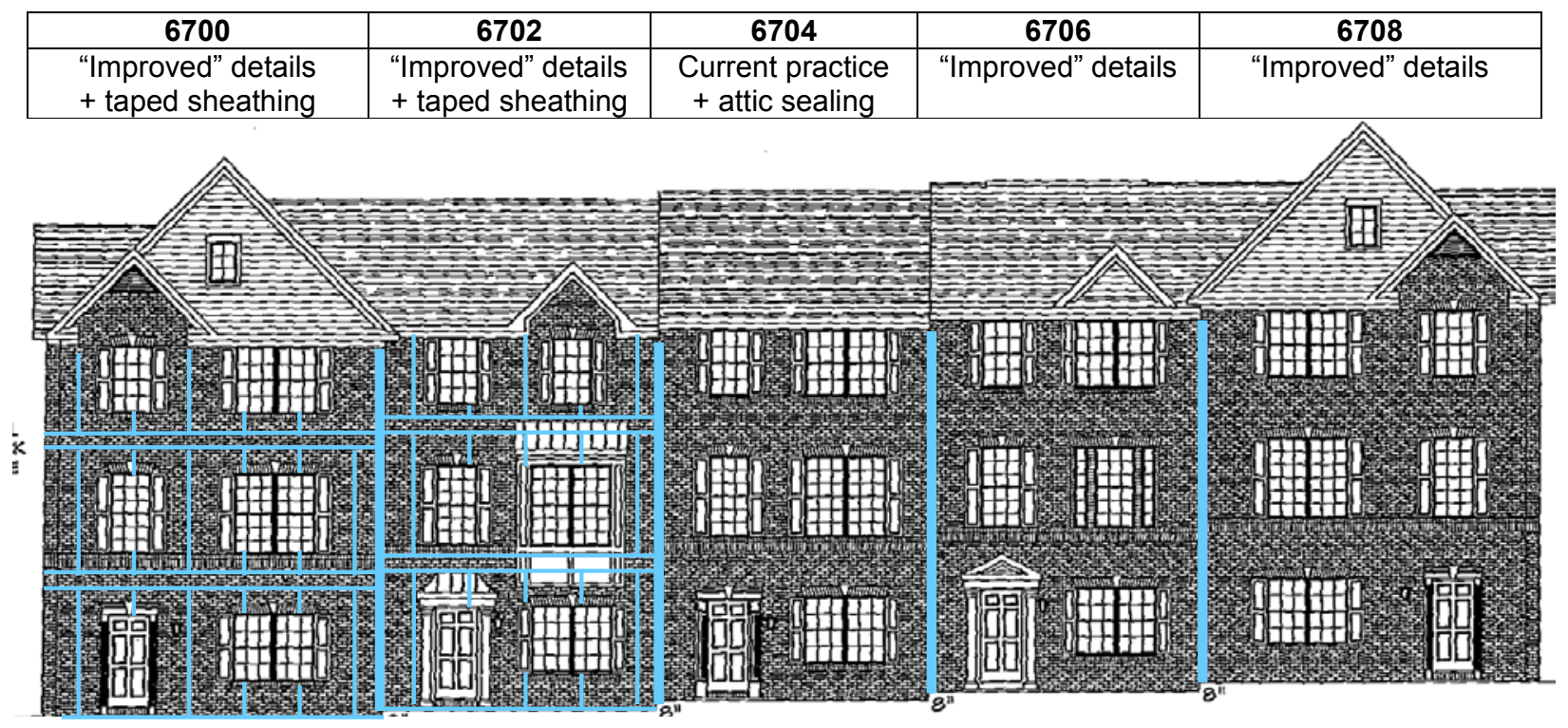

Figure 7. Experimental air barrier listing, with unit numbers and taping locations 


\subsection{1 "Improved" Package of Air Sealing Details: Overview}

The "improved" package included eight air sealing details; they are divided into three groupings and discussed further in Sections 3.3.2 through 3.3.4.

- Conventional air sealing details

- Sealing of interior top plates below attics to ceiling gypsum board

○ Bottom plate air sealing detail with acrylic caulk or latex-based spray sealant

- Area separation wall details

- Sealing at area separation wall penetration into attic with expanding foam

- Seal top plate of garage area to area separation wall with expanding foam

- Adhered tape details (details overlap with area separation wall details)

- Butyl tape seal from bottom of exterior sheathing to slab foundation

○ Butyl tape seal over end or "cap" of exposed area separation wall (per Figure 6)

○ Butyl tape seal over wood ledger/blocking at foundation

○ Butyl tape seal from top of exterior sheathing to top plate.

\subsection{2 "Improved" Package of Air Sealing Details: Conventional Air Sealing Details}

Some details in the "improved" package are basic best practice for using the interior gypsum board as the air barrier. At the wall top plates connected to the attic, the gypsum board is sealed to the top plates with caulk per Figure 8 .
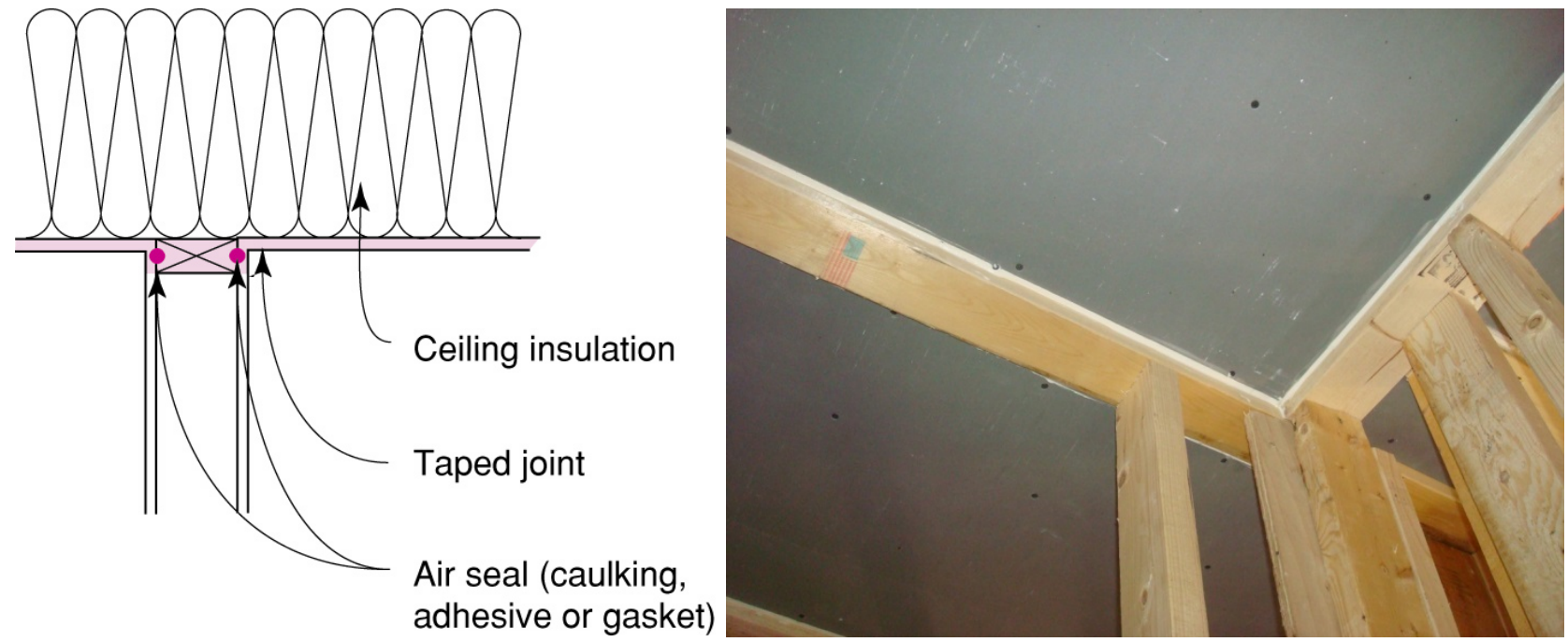

Figure 8. Connection from interior wall top plate to ceiling gypsum board

(Lstiburek 2006) 
The wall bottom plate at the exterior wall was air sealed with acrylic caulk, per Figure 9.

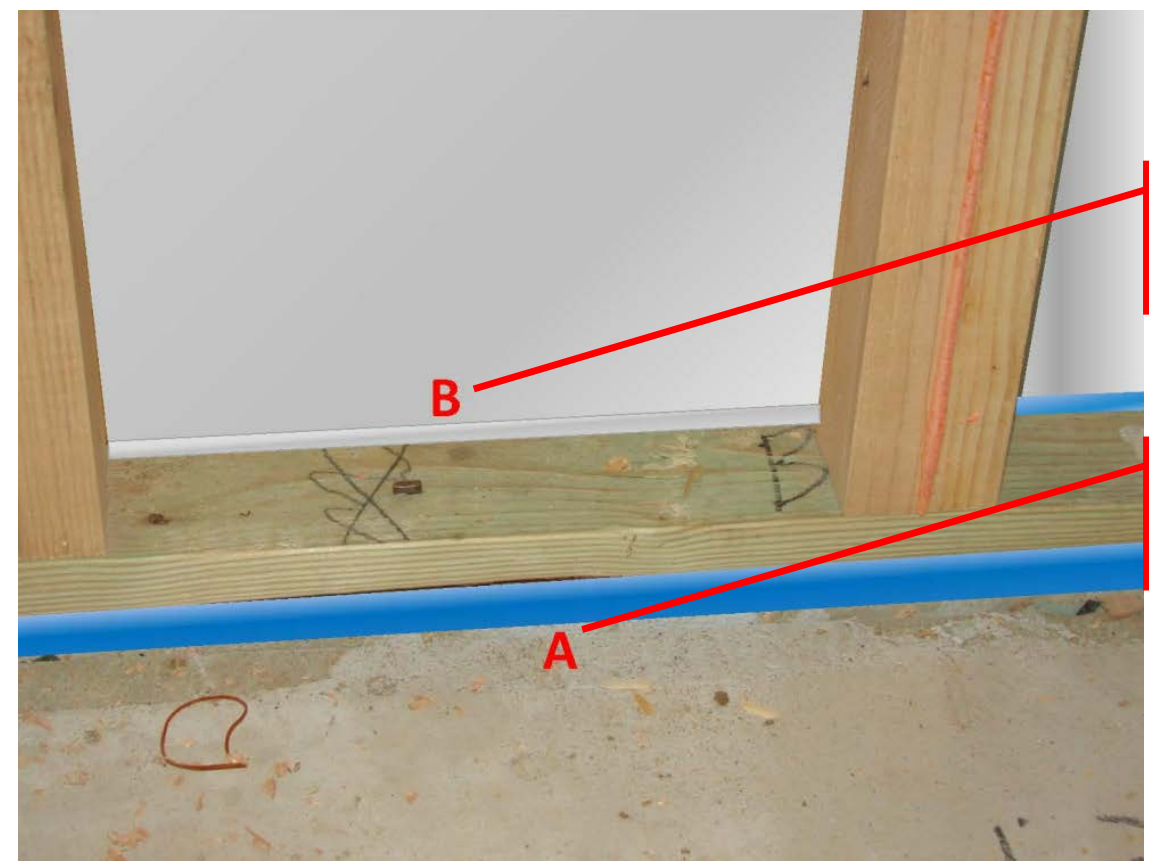

B: Gypsum board to sill plate (acrylic latex caulk)

Figure 9. Wall bottom plate air sealing details

\subsection{3 "Improved" Package of Air Sealing Details: Area Separation Walls}

Several details at the area separation walls were sealed using expanding single-component polyurethane foam sealant. Holton and Prahl (2005) and Rudd and Prahl (2014a) observed that these air sealing details at the area separation wall do not nominally meet code, but that acceptance is up to the local building official/authority having jurisdiction. The local building officials at this site had no issues with these air sealing details.

At the area separation wall penetration into the vented (unconditioned) attic, the 1-in. wide cavity was sealed or "capped" with expanding foam (Figure 10 and Figure 11). The complexity (multiple connections) of this detail increases the risk of air barrier failures at this location. 


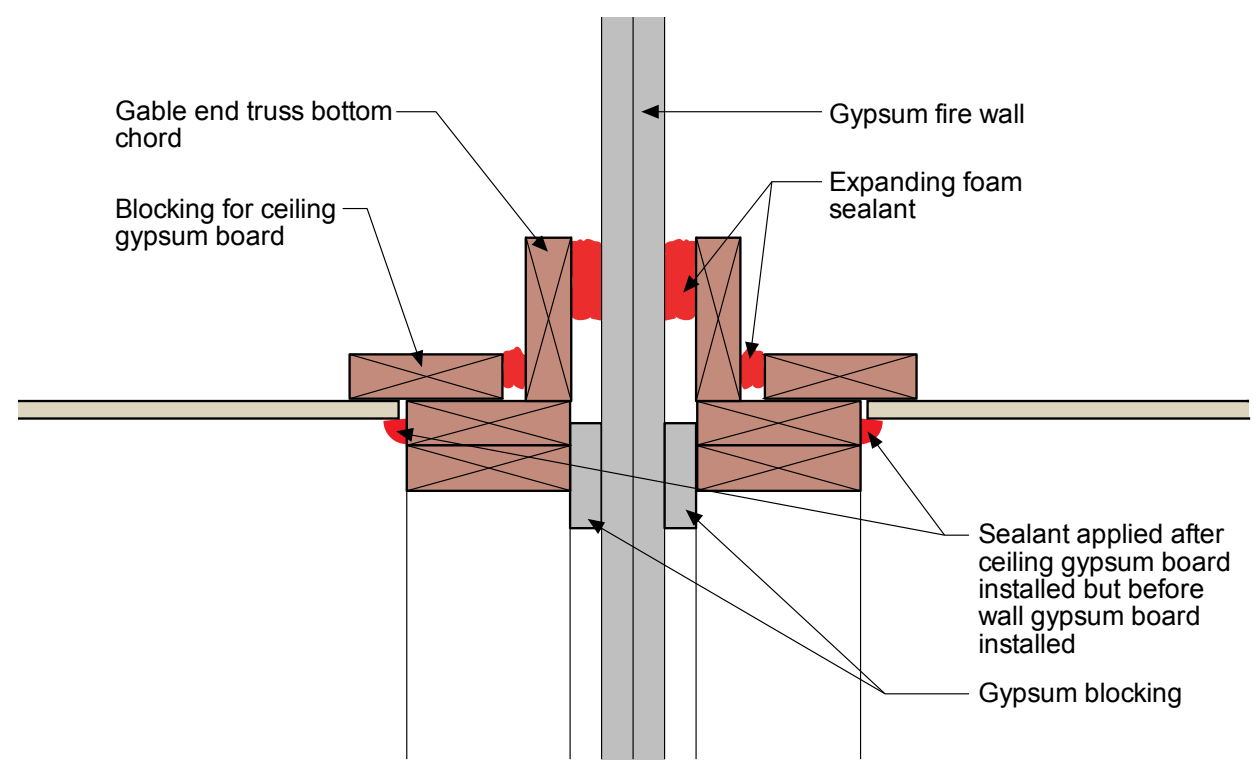

Figure 10. Vertical section detail of fire separation/demising wall at penetration to vented attic
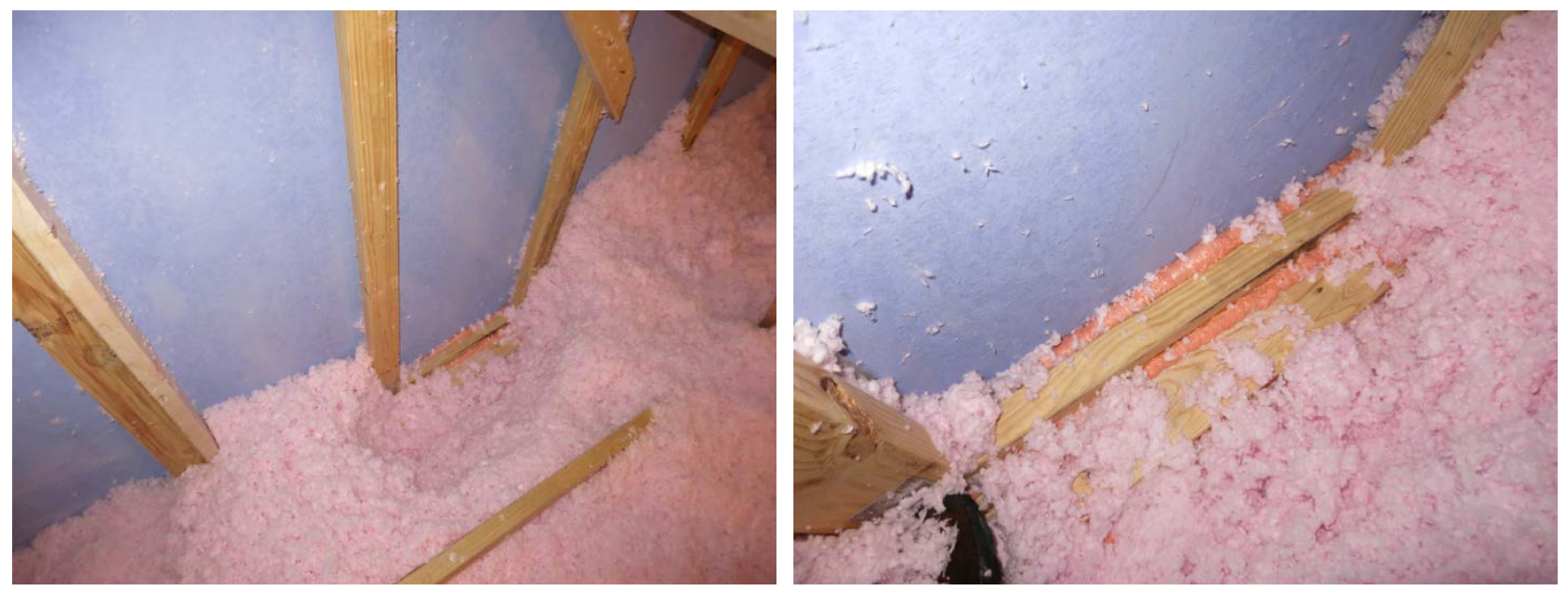

Figure 11. Wall top plate seal at fire separation/demising wall in attic

At the garage (unconditioned space), the area separation wall's top plate was sealed with expanding foam, per Figure 12. The uncapped soffit is a potential draftstopping failure, connecting the HVAC/plumbing soffit to the area separation wall cavity. 


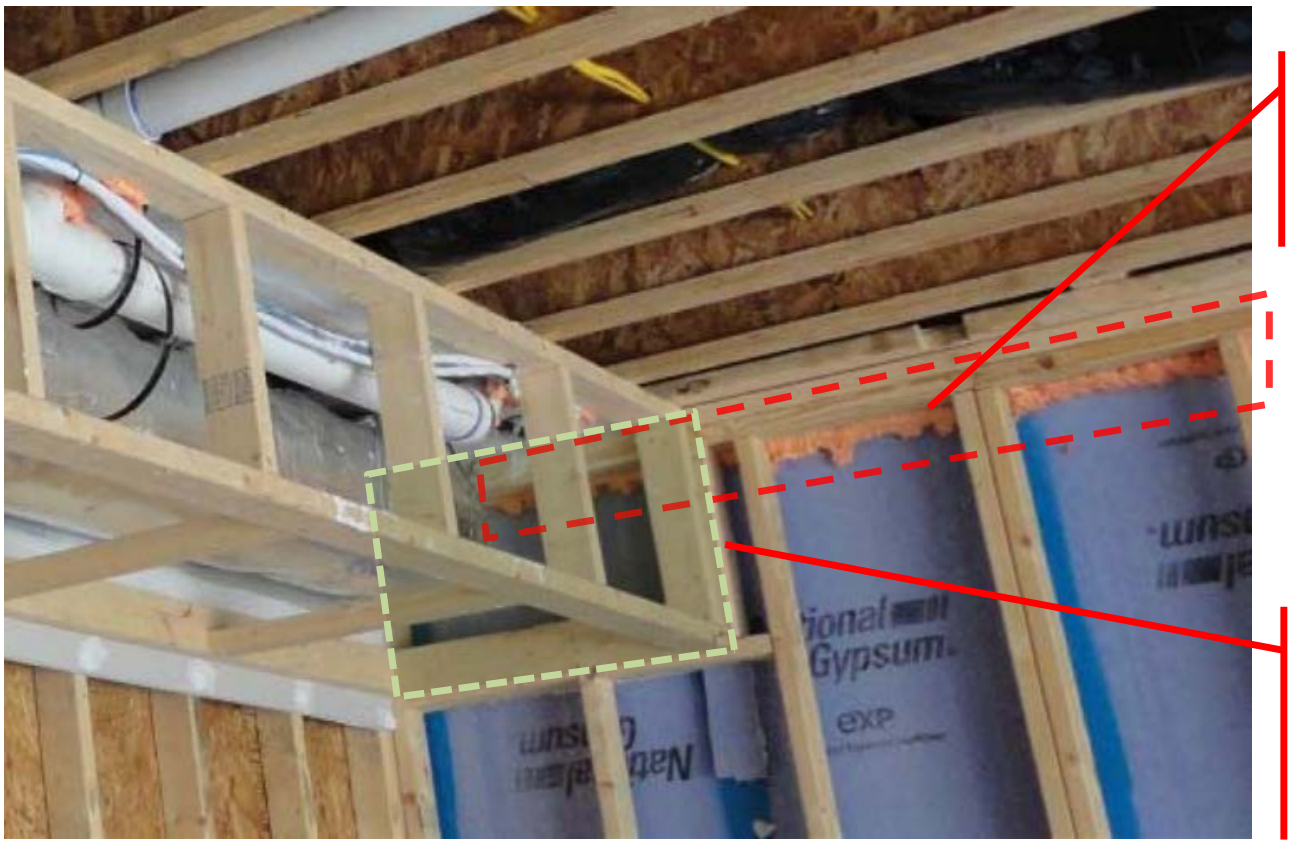

Expanding foam at top plate to area separation wall

Figure 12. Expanding foam at garage, top plate to area separation wall

\subsection{4 “Improved" Package of Air Sealing Details: Adhered Tape Details}

At the area separation wall, tape was applied to the joints of the gypsum panels and the OSB structural sheathing, thus "capping" the layers, as shown by blue tape in Figure 13 and Figure 15.

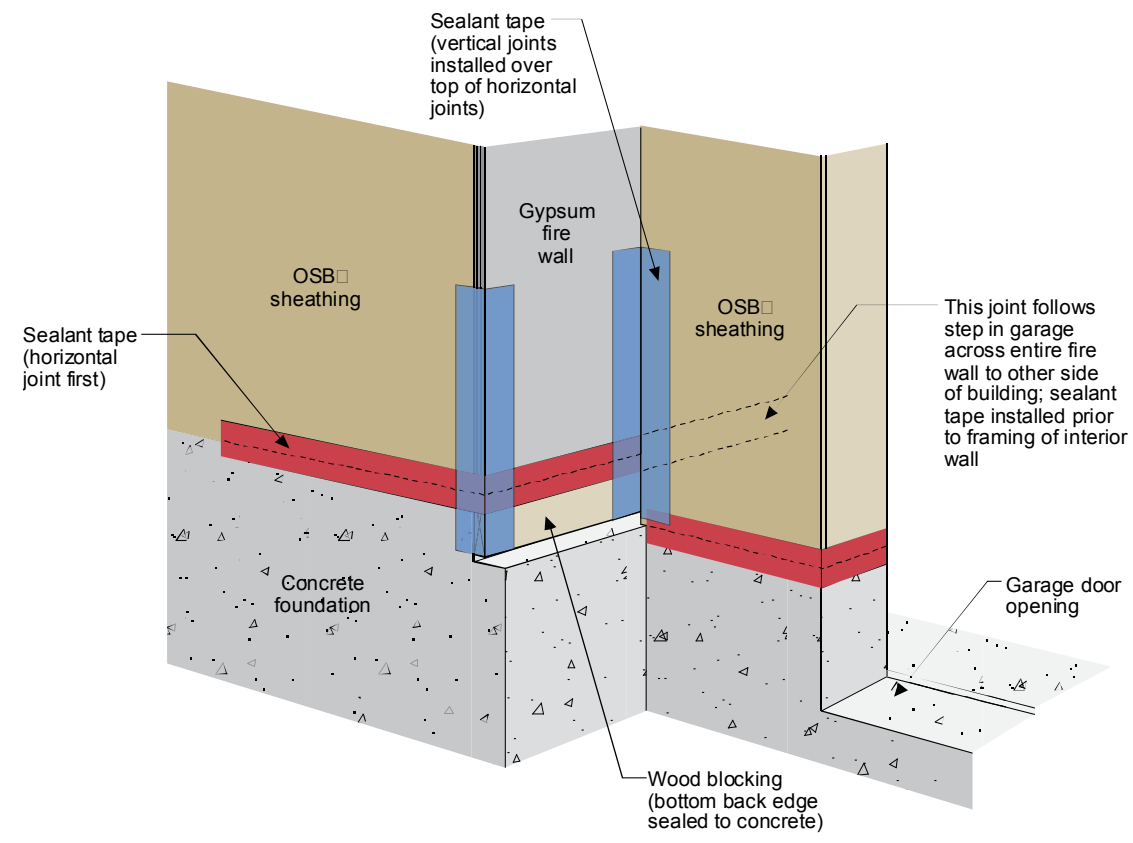

Figure 13. Sealant tape installed at area separation wall, sheathing-to-foundation connection

The gap between the wall sheathing and the foundation was addressed by taping the joint, shown as red tape in Figure 13 and Figure 15; this joint can be a significant source of air leakage. Some 
adhesion issues were discovered when applying tape to the concrete slab edge; a primer was required for good results using butyl-based flashing tape.

A similar sheathing-to-foundation detail was used where a wood ledger is added at the base of the area separation wall, to address a height offset between units (Figure 14 and Figure 15)

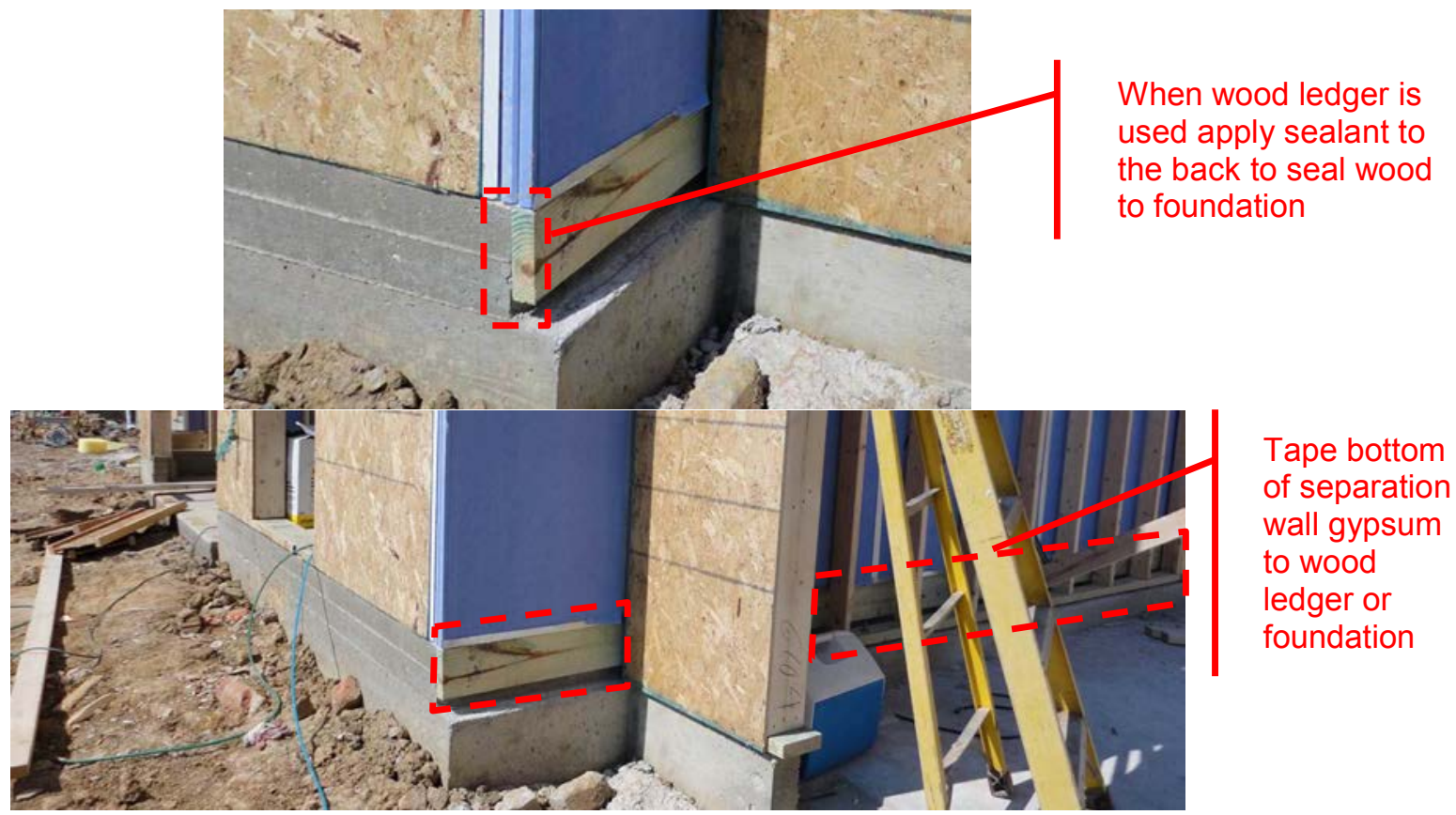

Figure 14. Wood ledger condition at area separation wall

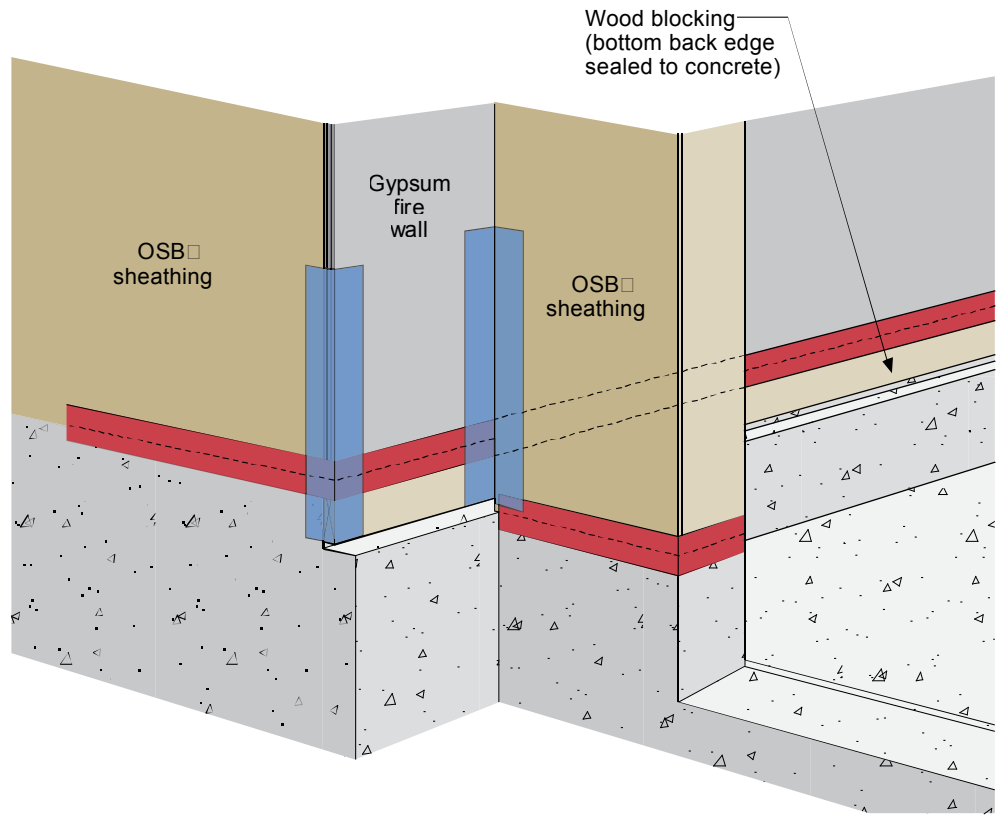

Figure 15. Sealant tape at area separation wall, sheathing-to-foundation connection 
The exterior sheathing was taped to the wall top plate before the installation of the roof trusses, thus creating an air barrier connection (Figure 16).
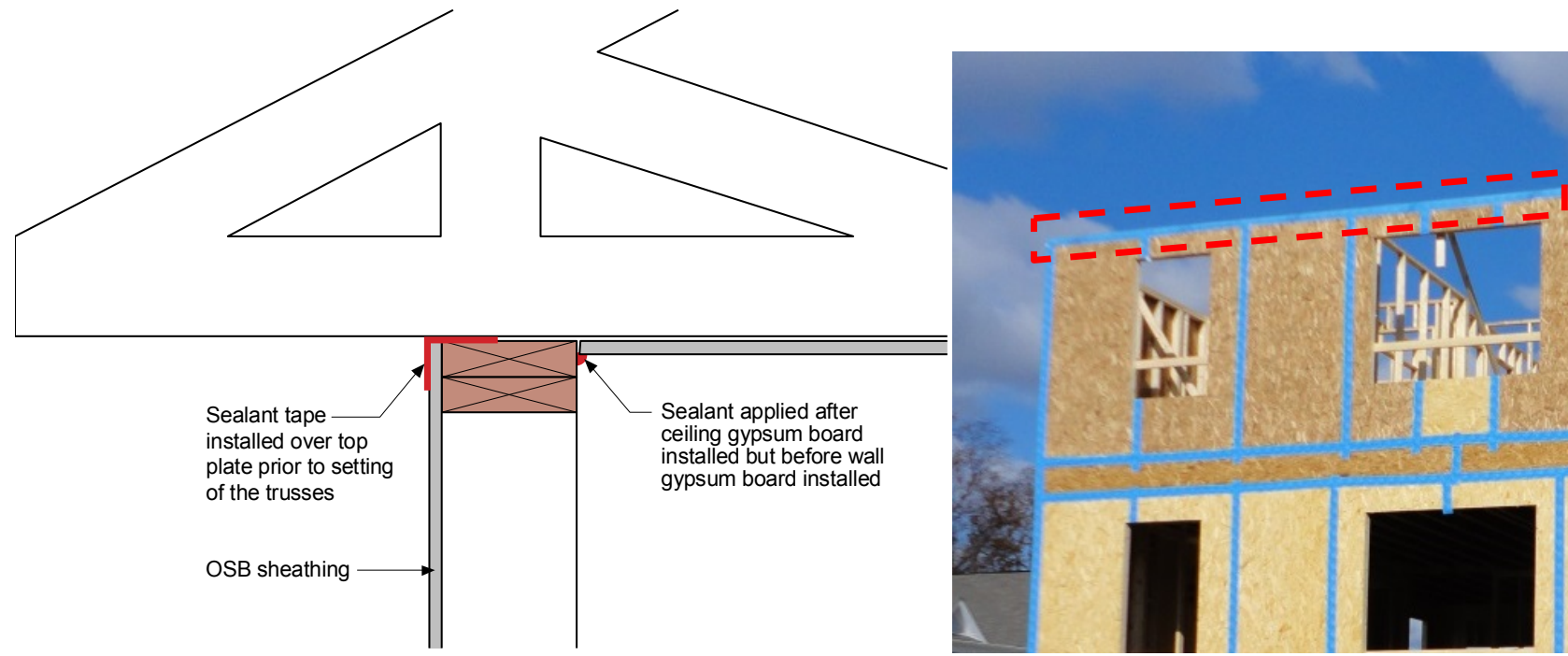

Figure 16. Tape air barrier connection at wall top plate, prior to installation of roof trusses

\subsubsection{Taped Exterior Sheathing}

In two units (6700 and 6702), all sheathing seams were taped, as shown in Figure 17; this resulted in a monolithic air barrier at the field of the wall, at the structural sheathing.
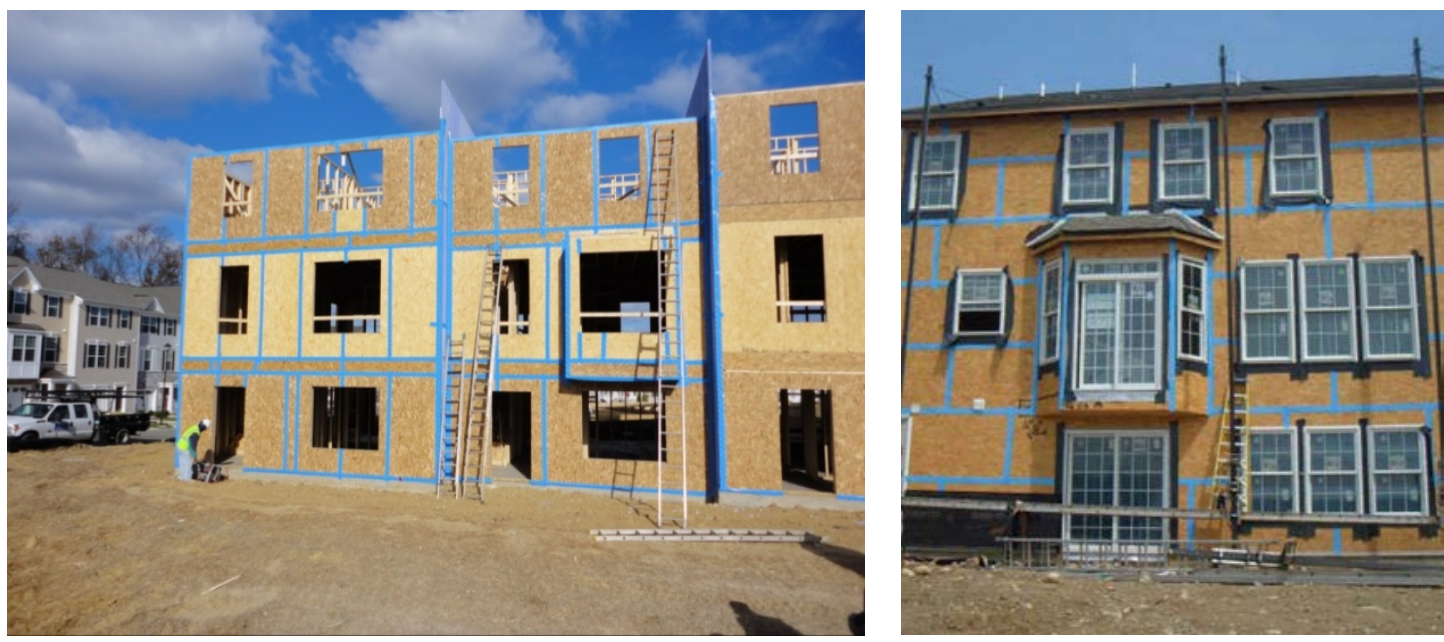

Figure 17. Taped seams of exterior sheathing and gypsum fire separation wall

\subsection{Previous Field Tests}

Air leakage testing was conducted on buildings similar to the test units, from previous construction at Villages at Pepper Mill. This previous construction had conventional detailing, and did not include the "improved" or taped sheathing details covered in Sections 3.3.1 through 3.3.5. The results of previous (unguarded) testing are shown in Table 2. The average air leakage 
was $4.8 \mathrm{ACH} 50( \pm 0.6$ one standard deviation $)$, or $0.27 \mathrm{CFM} 50 / \mathrm{ft}^{2}$ enclosure $( \pm 0.03$ one standard deviation), based on eight samples $(\mathrm{n}=8)$.

Table 2. Summary of Previous Air Leakage Testing at Villages at Pepper Mill

\begin{tabular}{c|c|c|c|c|c}
\hline $\begin{array}{c}\text { Building/ } \\
\text { Lot }\end{array}$ & $\begin{array}{c}\text { Surface } \\
\text { Area* }\end{array}$ & Volume & CFM50 & ACH50 & $\begin{array}{c}\text { CFM50/ft } \\
\text { Enclosure }\end{array}$ \\
\hline $\mathbf{1 4 0 7 8}$ & 4865 & 17026 & 1177 & 4.1 & 0.24 \\
$\mathbf{1 4 0 7 9}$ & 4350 & 14376 & 1055 & 4.4 & 0.24 \\
$\mathbf{1 4 0 8 0}$ & 4350 & 14376 & 1123 & 4.7 & 0.26 \\
$\mathbf{1 4 0 8 1}$ & 4865 & 17026 & 1362 & 4.8 & 0.28 \\
$\mathbf{1 5 0 8 2}$ & 4865 & 17026 & 1336 & 4.7 & 0.27 \\
$\mathbf{1 5 0 8 3}$ & 4350 & 14376 & 1320 & 5.5 & 0.30 \\
$\mathbf{1 5 0 8 4}$ & 4350 & 14376 & 1396 & 5.8 & 0.32 \\
$\mathbf{1 5 0 8 5}$ & 4865 & 17026 & 1329 & 4.7 & 0.27 \\
Average & & & 1262 & 4.8 & 0.27 \\
\hline Standard Deviation & & & 126 & 0.6 & 0.03 \\
\hline
\end{tabular}

* This conversion assumes all enclosure surface area, including adiabatic walls.

The builder reported that a similar development in Maryland with more stringent code enforcement (The Pointe at Arundel Preserve) was regularly achieving 3.2 ACH50, but this required multiple return trips by the air sealing contractor. That development used a sprayapplied latex air sealing compound, which was not used at Pepper Mill. 


\section{Field Air Leakage Testing and Results}

The field testing work of the five-unit building was conducted in several phases over 2 days in February 2014:

- On the first day, individual units were tested for air leakage in detail, using unguarded or nonnulled testing. This was done by a single tester to understand the major air leakage locations of the units and the range of air leakage measurements.

- On the second day, the building was set up for a "nulled" or "guarded" (pressure neutralization) test, which brought adjacent units to the same test pressure(s) simultaneously. Fans were installed in all units. This testing eliminates the pressure difference between adjacent units, and therefore only ostensibly measures leakage to the exterior. These methods, when applied to multifamily buildings, are discussed by Genge (2007), Finch et al. (2009), NRCERT (2012), and Griffiths (2012), and others. Simultaneous testing was controlled and recorded by TECLOG3 software from TEC. Two sets of tests were run:

○ The units were again individually tested (unguarded/nonnulled test) to ensure that the results were basically consistent with the previous day's measurements.

$\circ$ The units were then all simultaneously tested in a guarded/nulled test. A multipoint test (multiple test pressure) was used, bringing the test pressures down in parallel in all units.

During all this testing, air leakage pathways were identified via observations, differential pressure diagnostics, and infrared thermography. The test building had units ready for sale, so no intrusive disassembly could be conducted to pinpoint the source of air leakage. However, a building adjacent to the test building was still in frame; it was examined to correlate leakage issues with construction details.

\subsection{Individual Unit Air Leakage Testing (Day 1)}

The first day's testing was intended to capture the range of leakage in the units (for test equipment placement), to understand the major air leakage locations, and to become familiar with the site before the full team performed multifan testing. The testing was unguarded; the windows in adjacent units were left closed. Results are shown in Table 3, with short descriptors of the air sealing details; full detailed test results are provided in Appendix B.

Table 3. Air Leakage Testing Results From Individual Unit Testing (Day 1)

\begin{tabular}{c|c|c|c|c|c|c}
\hline Unit & Notes & $\begin{array}{c}\text { Surface } \\
\text { Area }\end{array}$ & Volume & CFM50 & ACH50 & $\begin{array}{c}\text { CFM50/ft } \\
\text { enclosure }^{2}\end{array}$ \\
\hline $\mathbf{6 7 0 0}$ & End-improved + taped & 4865 & 17026 & 1115 & 3.9 & 0.23 \\
$\mathbf{6 7 0 2}$ & Mid-improved + taped & 4350 & 14376 & 1408 & 5.9 & 0.32 \\
$\mathbf{6 7 0 4}$ & Mid-conventional & 4350 & 14376 & 1271 & 5.3 & 0.29 \\
$\mathbf{6 7 0 6}$ & Mid-improved & 4350 & 14376 & 1307 & 5.5 & 0.30 \\
$\mathbf{6 7 0 8}$ & End-improved & 4865 & 17026 & 1117 & 3.9 & 0.23 \\
\hline
\end{tabular}


All tests were run with a TEC Minneapolis Duct Blaster Series B Fan. Test images are shown in Figure 18.
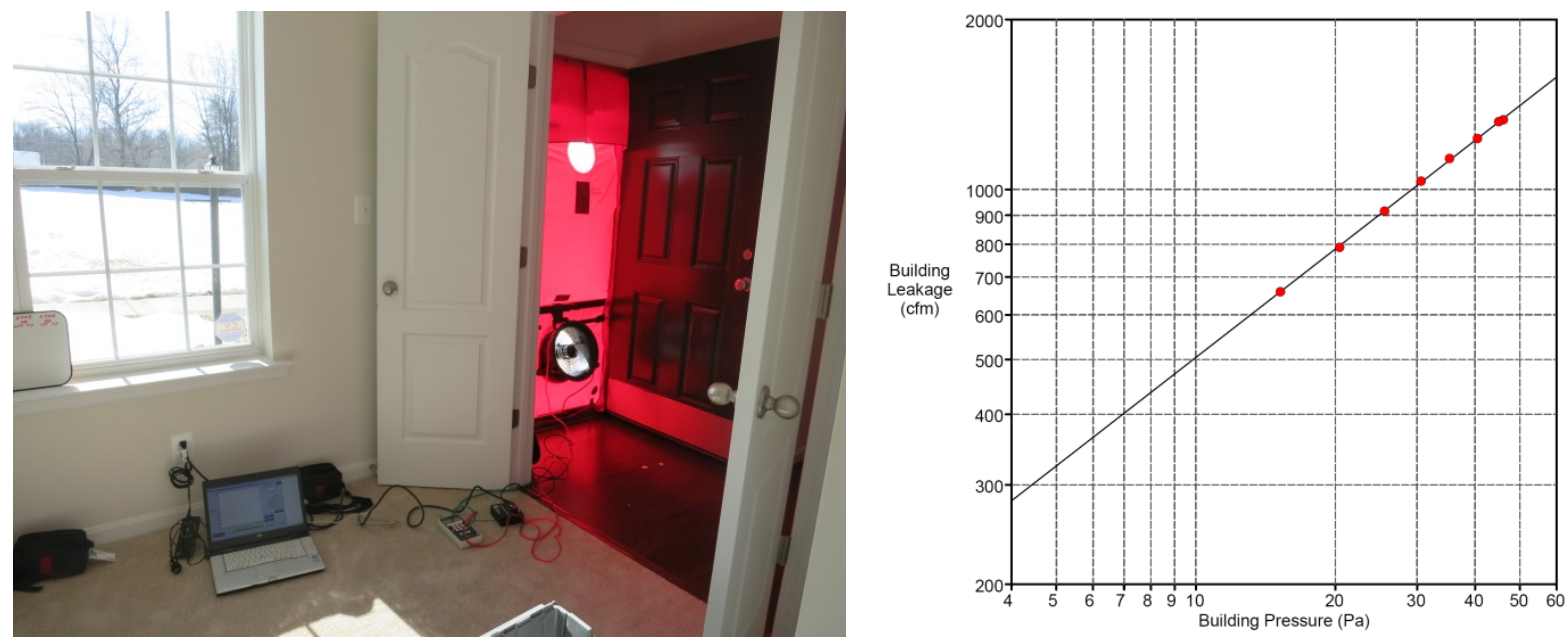

Figure 18. Individual unit air leakage testing and multipoint test results

Key findings from this initial testing included:

- None of the units tested below 3 ACH50 (2012 IECC target).

- The end units $(6700 / 6708)$ had lower air leakage than the middle units, both in terms of normalized metrics (ACH50 and CFM50/ $\mathrm{ft}^{2}$ enclosure), and in absolute terms (CFM50). For reference, the end units are larger (12\% greater surface area, 18\% greater volume).

- The taped/improved middle unit (6702) had higher normalized air leakage than previous test results (5.9 ACH50). In comparison, middle units in previous tests ranged from 4.4 to $5.8 \mathrm{ACH} 50$.

- No apparent improvement in airtightness was associated with the taped sheathing detail (6700 and 6702). If airtightness increased because of the "improved" details, the difference was overwhelmed by the additional attic air sealing in the "conventional" unit (6704), as described in Section 3.3 or other geometry/detail differences.

- The end units are lower than $0.25 \mathrm{CFM} 50 / \mathrm{ft}^{2}$ enclosure; the middle units are noticeably higher ( $\sim 0.30 \mathrm{CFM} 50 / \mathrm{ft}^{2}$ enclosure), which suggests that leakage might be ascribed to the area separation wall (two area separation walls for middle units, versus one for the end units).

\subsection{Multifan Testing (Day 2): Overview}

In the second day of testing, test fans were installed in all units (Figure 19), to perform guarded, nulled, or pressure neutralized testing. The tests included individual unit testing (unguarded/ nulled test, or total leakage), followed by a nulled test (leakage to exterior). Based on the results from the previous day's testing, TEC Minneapolis Duct Blaster fans were installed at two end units and a middle unit; the remaining units were tested with higher capacity TEC Minneapolis Blower Door fans. Appendix A provides a full list of equipment (with ranges and accuracy). 


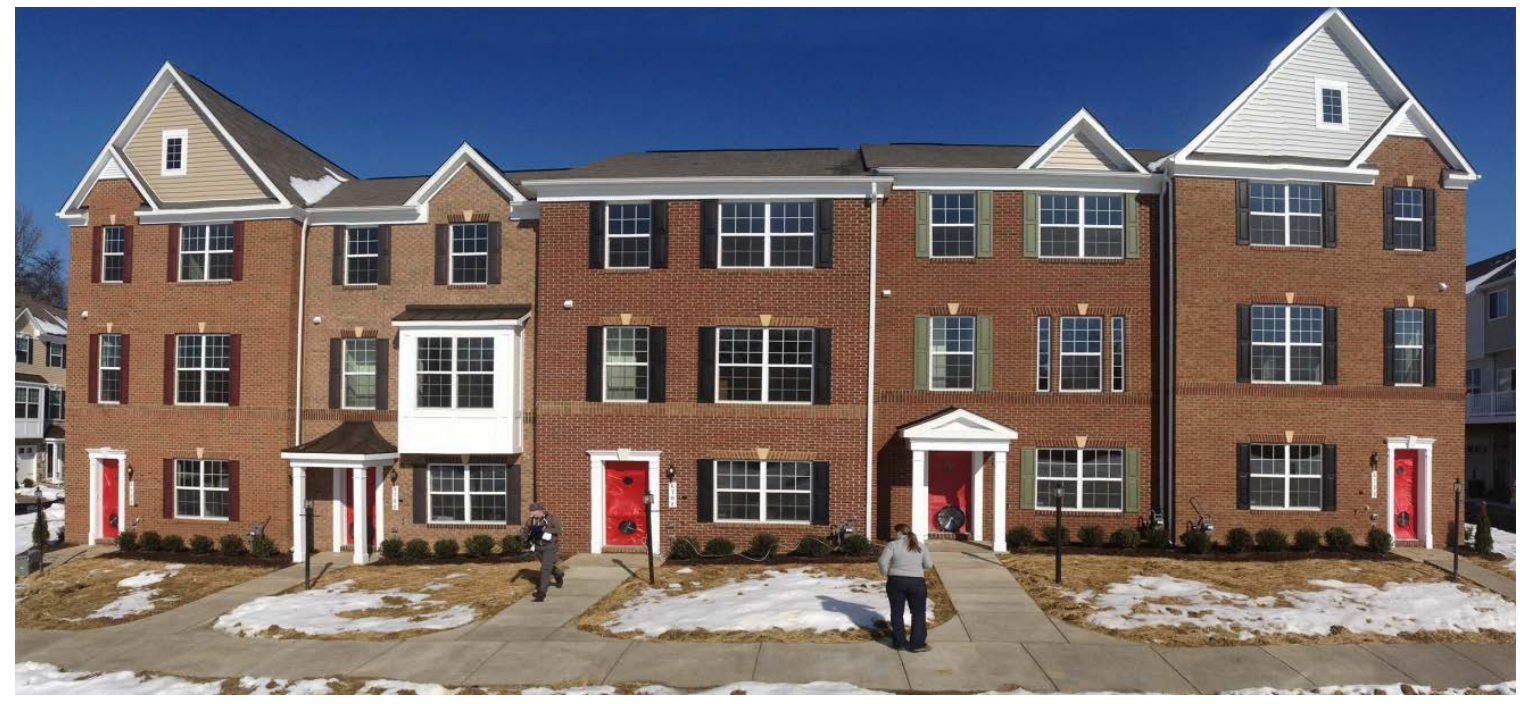

Figure 19. Setup for multifan air leakage testing (Day 2)

The simultaneous testing was controlled and recorded by TEC's TECLOG3 software, which allowed for control of all fans from a central point, via wired connections. The central control location was Unit 6504, as shown in Figure 20. However, field test personnel were required at all units, to configure fans and ensure that test anomalies were not occurring.

Wind speeds were higher on Day 2 ( $15 \mathrm{mph}$ versus 5-10 $\mathrm{mph})$; therefore, the outside pressure measurements were located in the shielded garages instead of at the front elevation.
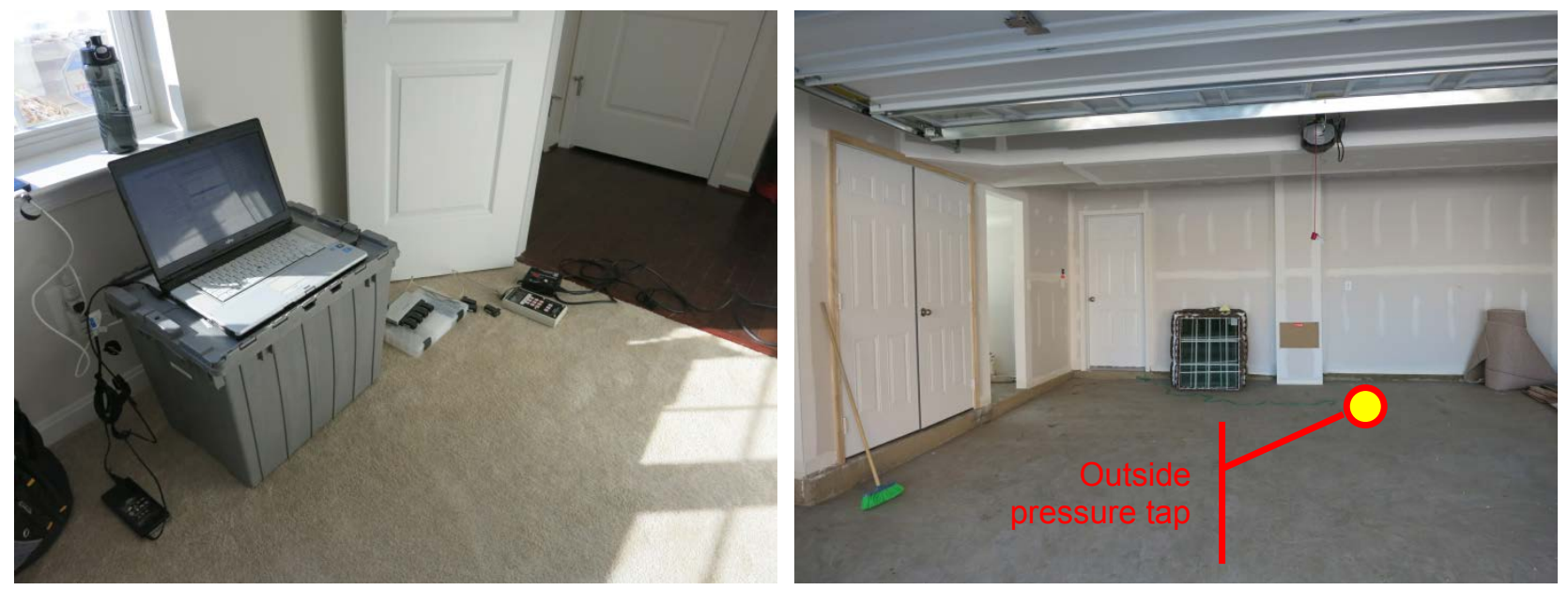

Figure 20. Multifan test setup, outside pressure tap in garage

During the Day 2 tests, all outside ventilation air intakes were taped off at the exterior hood (Figure 21). This was done because Day 1 testing revealed noticeable air leakage coming from some ductwork systems (especially at the returns). The likely explanation was a malfunctioning motorized damper on the outside air duct (Figure 21); however, the damper would have had to be disassembled to ascertain its position. Given that the focus of this research is enclosure leakage, the ventilation ducts were removed from the experiment with this sealing. 

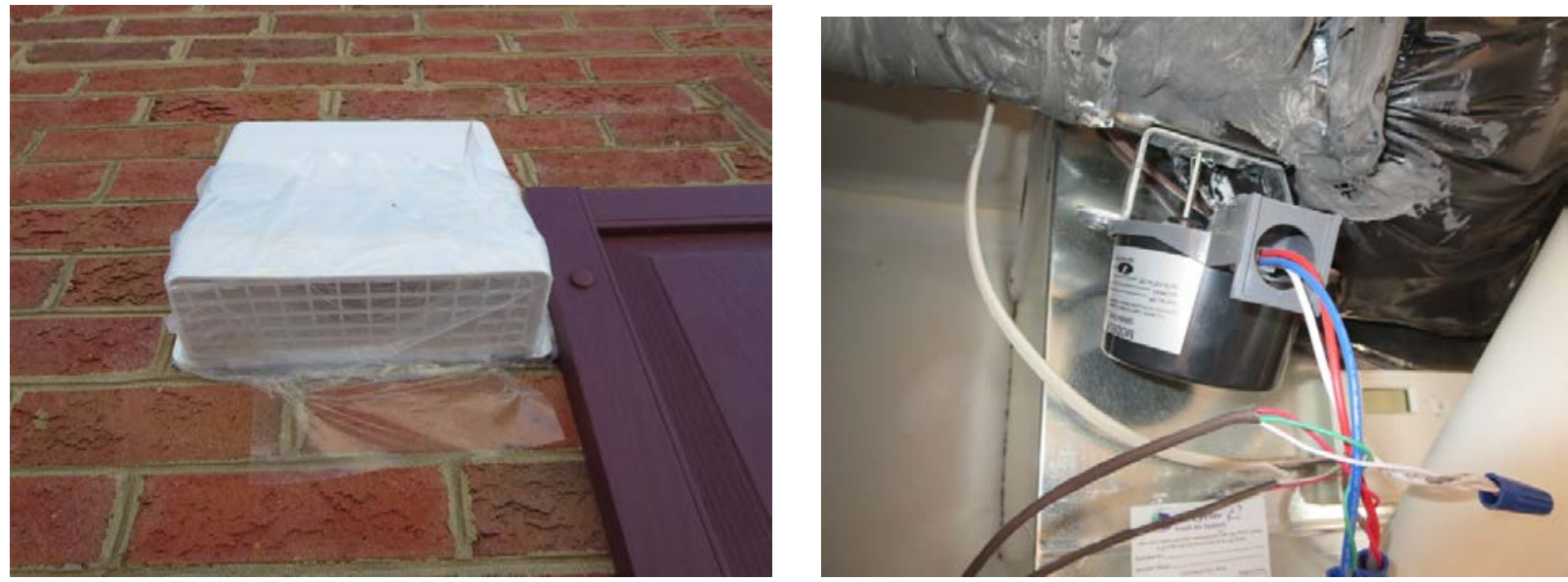

Figure 21. Outside ventilation air intake; motorized damper at air handler

\subsection{Multifan Testing (Day 2): Nonnulled Testing}

After the fans were set up, units were individually tested in unguarded/nonnulled tests, as a comparison with the previous day's testing. Day 1 testing was all conducted with a single fan, which was moved from unit to unit; Day 2 testing was conducted with five fans. During each unit test, the adjacent units were opened to the exterior (an open window) to relieve pressure and avoid "serial leakage" effects (leakage to the exterior constricted by adjacent unit airtightness). The Day 2 results are shown in Table 4, with comparisons to Day 1 tests. Detailed results are shown in Appendix C.

Table 4. Air Leakage Testing Results From Individual Unit Testing (Day 2), With $\Delta$ From Day 1 Tests

\begin{tabular}{c|c|c|c|c|c|c}
\hline Unit & Notes & CFM50 & ACH50 & $\begin{array}{c}\text { CFM50/ft } \\
\text { Enclosure* }^{*}\end{array}$ & A CFM50 & $\begin{array}{c}\Delta \text { CFM50 } \\
\%\end{array}$ \\
\hline $\mathbf{6 7 0 0}$ & End-improved + taped & 1085 & 3.8 & 0.22 & -30 & $-3 \%$ \\
$\mathbf{6 7 0 2}$ & Mid-improved + taped & 1329 & 5.5 & 0.31 & -79 & $-6 \%$ \\
$\mathbf{6 7 0 4}$ & Mid-conventional & 1255 & 5.2 & 0.29 & -16 & $-1 \%$ \\
$\mathbf{6 7 0 6}$ & Mid-improved & 1330 & 5.6 & 0.31 & +23 & $+2 \%$ \\
$\mathbf{6 7 0 8}$ & End-improved & 1113 & 3.9 & 0.23 & -4 & $0 \%$ \\
\hline
\end{tabular}

* This conversion assumes all enclosure surface area, including adiabatic walls.

Although these two tests are not directly comparable (sealed versus unsealed outside air ducts, adjacent unit windows open/closed), the results between the tests are basically consistent. There was a maximum of a $6 \%$ difference, with an average of $2 \%$ difference (absolute value). This can be compared with the overall accuracy of the fan and gauge combination ( $\pm 3 \%$ of reading; see Appendix A).

\subsection{Multifan Testing (Day 2): Nulled Testing}

After confirming repeatability of the tests with the installed equipment, the five units were tested in parallel in a nulled, guarded, or pressure neutralized test, nominally eliminating air leakage between units. TEC provides two options for this type of multifan testing: 
- A “calm day" approach, where each unit's pressure is referenced to a single ganged outdoor pressure tap, using methods shown by NRCERT (2012). A common/ganged outdoor pressure tap will result in more reliable unit-to-unit pressure differences, even if the outside pressure is fluctuating badly. This is the most commonly used approach.

- A "windy day" approach, where one unit is chosen as a "primary" unit, with four measurements of the primary unit with respect to outside (four cardinal directions). The nonprimary units are then pressurized/depressurized to zero with respect to the primary unit. It is a more complex, but also more robust, test method.

The "calm day" approach was used here; the results are shown in Table 5, with the difference relative to individual unit (unguarded) tests from Table 4. Detailed results are shown in Appendix C.

Table 5. Air Leakage Testing Results From Nulled Testing, With $\Delta$ From Individual Tests

\begin{tabular}{|c|c|c|c|c|c|c|}
\hline Unit & Notes & CFM50 & ACH50 & $\begin{array}{l}\text { CFM50/ft } \\
\text { Enclosure* }\end{array}$ & $\triangle$ CFM50 & $\begin{array}{c}\Delta \text { CFM50 } \\
\%\end{array}$ \\
\hline 6700 & End-improved + taped & 953 & 3.4 & 0.20 & -132 & $-12 \%$ \\
\hline 6702 & Mid-improved + taped & 1057 & 4.4 & 0.24 & -271 & $-20 \%$ \\
\hline 6704 & Mid-conventional & 1004 & 4.2 & 0.23 & -250 & $-20 \%$ \\
\hline 6706 & Mid-improved & 1085 & 4.5 & 0.25 & -245 & $-18 \%$ \\
\hline 6708 & End-improved & 989 & 3.5 & 0.20 & -125 & $-11 \%$ \\
\hline
\end{tabular}

* This conversion assumes all enclosure surface area, including adiabatic walls.

A graph of the unit pressures from TECLOG3 software is shown in Figure 22.

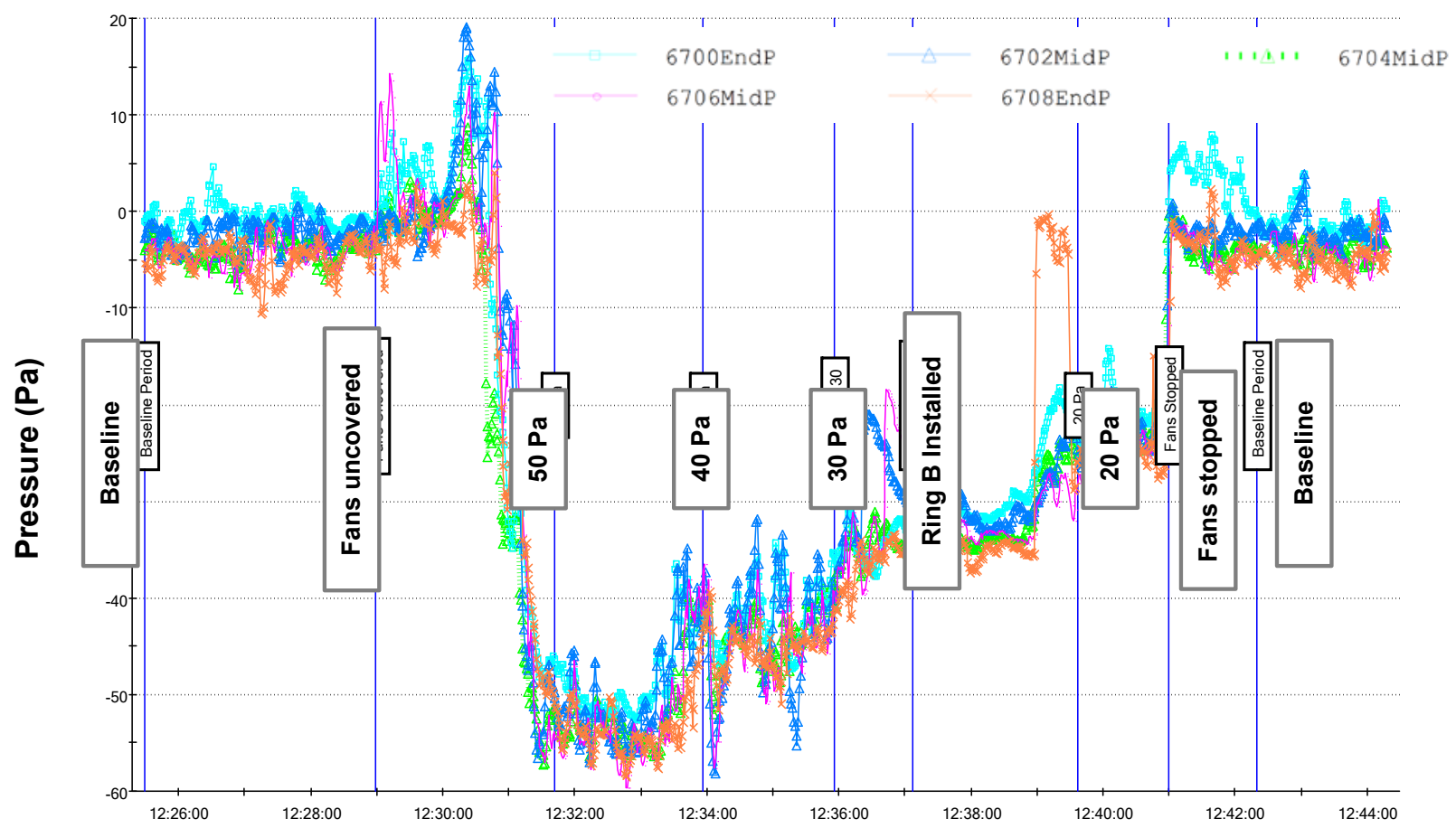

Figure 22. TECLOG3 unit pressures for multipoint nulled test of five units 
The graph shows the multiple test pressures (nominally 50, 40, 30, and $20 \mathrm{~Pa}$ ). Baseline measurements were taken at the beginning and end of testing, and used to normalize test data. The test was interrupted at lower pressures to reconfigure fans (e.g., ring replacement in Unit 6708 at $30 \mathrm{~Pa}$ ).

Significant variations in unit pressures occurred at each measurement point $( \pm 5 \mathrm{~Pa}$ or higher typical variation), likely caused by windy outdoor conditions. Given the measurement scatter, the software's statistical sampling feature was used to generate average pressures and flows for periods of interest. The "windy day" approach may have given better results, but the testing schedule did not allow for reconfiguration and retesting of the units.

Conclusions from the nulled/guarded testing included:

- Even with the nominal elimination of unit-to-unit leakage, none of the units reached the 3 ACH50 target. The end units were closest at 3.4-3.5 ACH50. The middle units reached 4.2-4.5 ACH50.

- The reduction in leakage caused by nulling is roughly $10 \%$ at the end units $(11 \%-12 \%)$, and roughly $20 \%$ at the middle units. This is consistent with the number of area separation walls (one versus two). This reduction is less than the $22 \%-27 \%$ reported by Klocke et al. (2014), but this might be a function of the townhomes' geometry difference versus mid- or high-rise multifamily apartment buildings (more common walls/ceilings/floors).

- In terms of CFM50, the reduction was roughly 130 CFM50 for the end units and roughly 250 CFM50 for the middle units. In terms of equivalent leakage area (EqLA at $10 \mathrm{~Pa}$ ); these reductions are $13 \mathrm{in.}^{2}$ and $26 \mathrm{in.}^{2}$, respectively.

- The surface area-normalized leakage metrics showed that the middle units $(0.24$ CFM50/ $\left.\mathrm{ft}^{2}\right)$ were leakier than the end units $\left(0.20 \mathrm{CFM} 50 / \mathrm{ft}^{2}\right)$. One explanation is that the greater leakage of the middle units is not simply a function of the area separation walls. Another possible explanation is that the nulling did not completely eliminate leakage through the area separation walls (i.e., eliminate unit-to-unit flow), because the wall cavity is connected to exterior. The latter explanation is consistent with pressure diagnostics performed on the area separation wall cavity, covered in Section 4.8.

\subsection{Air Leakage Locations: Overview}

The air leakage results (greater than 3 ACH50 for all units) were disappointing, given the additional air sealing measures being tested at this building. During this testing, the units were examined more closely for the location of air leakage issues. This was done by depressurizing units (typically to $-50 \mathrm{~Pa}$ ) and searching for cold surfaces (exterior air infiltration) with an infrared camera. The units were initially surveyed with the infrared camera (before depressurization) to avoid confusing air leakage with thermal bridging/cold surfaces. The outdoor temperature was about $32^{\circ} \mathrm{F}$ during these observations.

Zone pressure diagnostics were used to see how well interstitial spaces were connected to the unit versus exterior/adjacent units. This included interstitial measurements of the area separation wall. 
The units were ready for sale, so no intrusive disassembly could be done to further pinpoint air leakage. A useful experiment would have been incremental air sealing of leakage details and testing, but access was not available for this work.

The air leakage observations are broken into two sections: details that would occur in conventional, single-family construction (Section 4.6) and details that are related to the area separation wall (Section 4.7). The leakage sites shown here were typically observed in multiple units, although some infrared photos highlight the more extreme cases.

The builder has used a spray-applied latex sealant (applied to the interior of the stud bays) in other projects; however, it was not used here. Some of the leaks seen here would have been solved by using this product, resulting in better overall airtightness.

\subsection{Air Leakage Locations: Conventional Details}

Some of the air leakage issues described in this section are keyed to locations shown in Figure 23. The floor plan shows a middle unit, which captures most of the important locations.
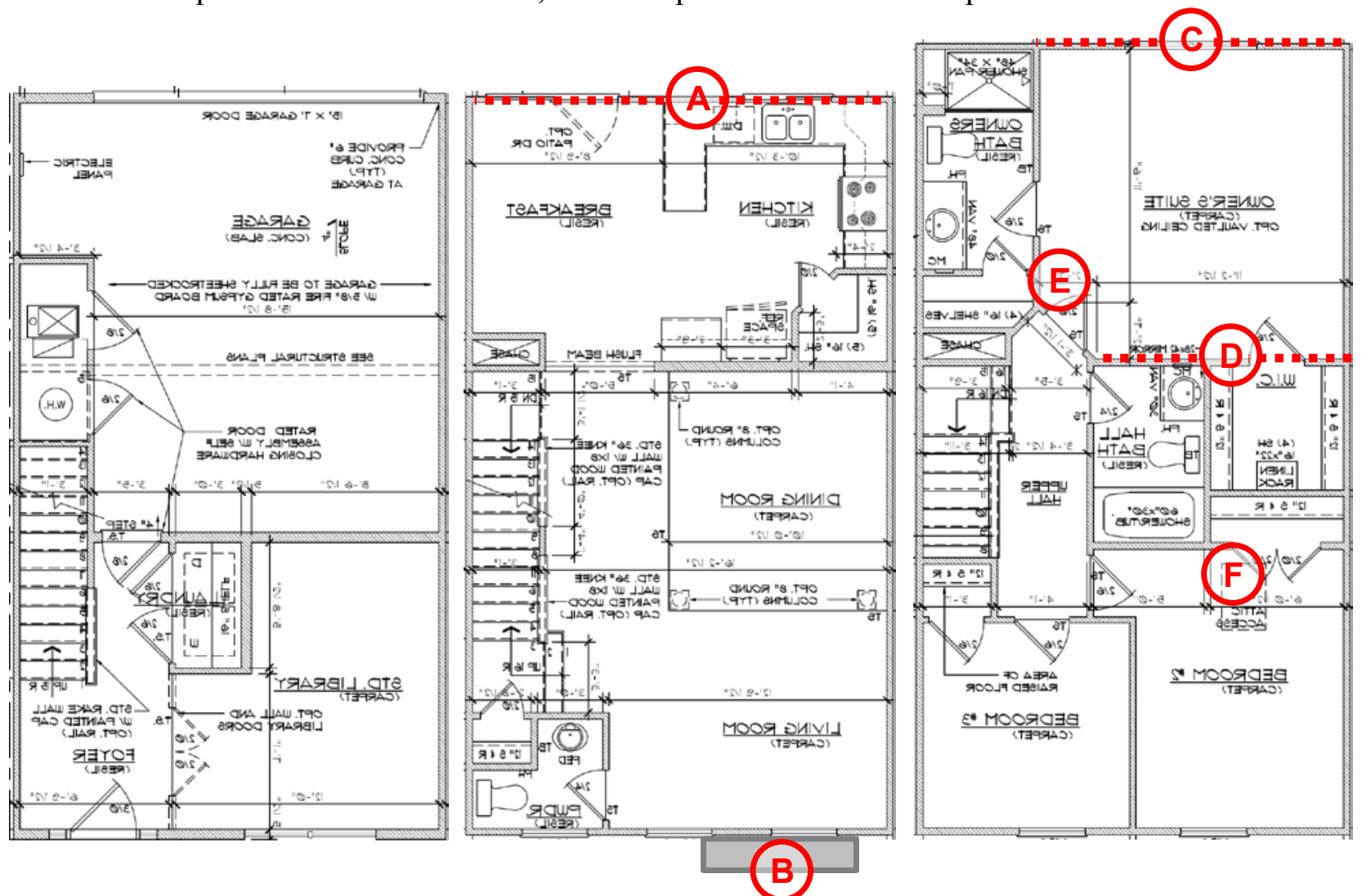

Figure 23. Air leakage location infrared image key, middle unit

One consistent issue arose at the second- to third-floor ceiling/floor assembly (across several units); this is shown at a rear second-floor kitchen in Unit 6704 (conventional construction) in Figure 24 and Figure 25 (keyed to "A" in Figure 23). Air is entering the floor framing cavity from the exterior at the third-floor overhang detail. 

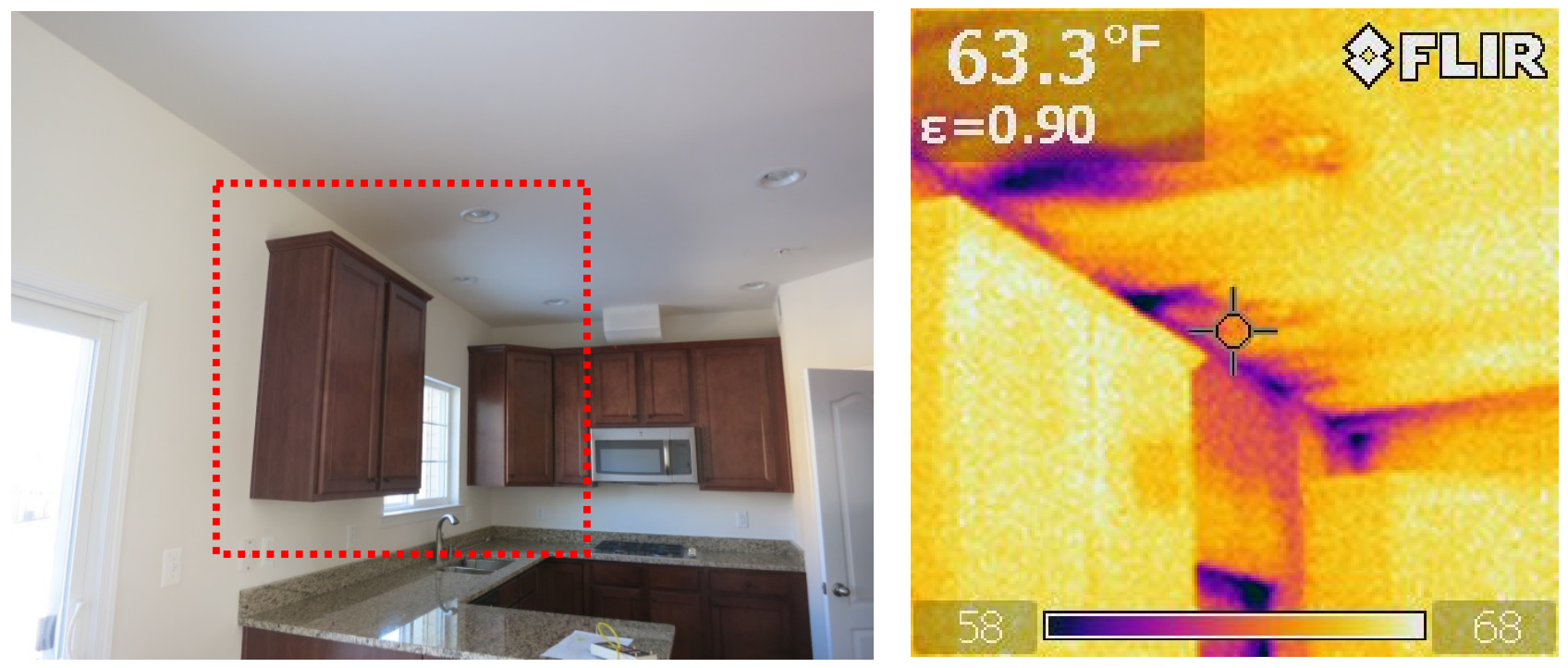

Figure 24. Rear second-floor kitchen, Unit 6704 (middle)

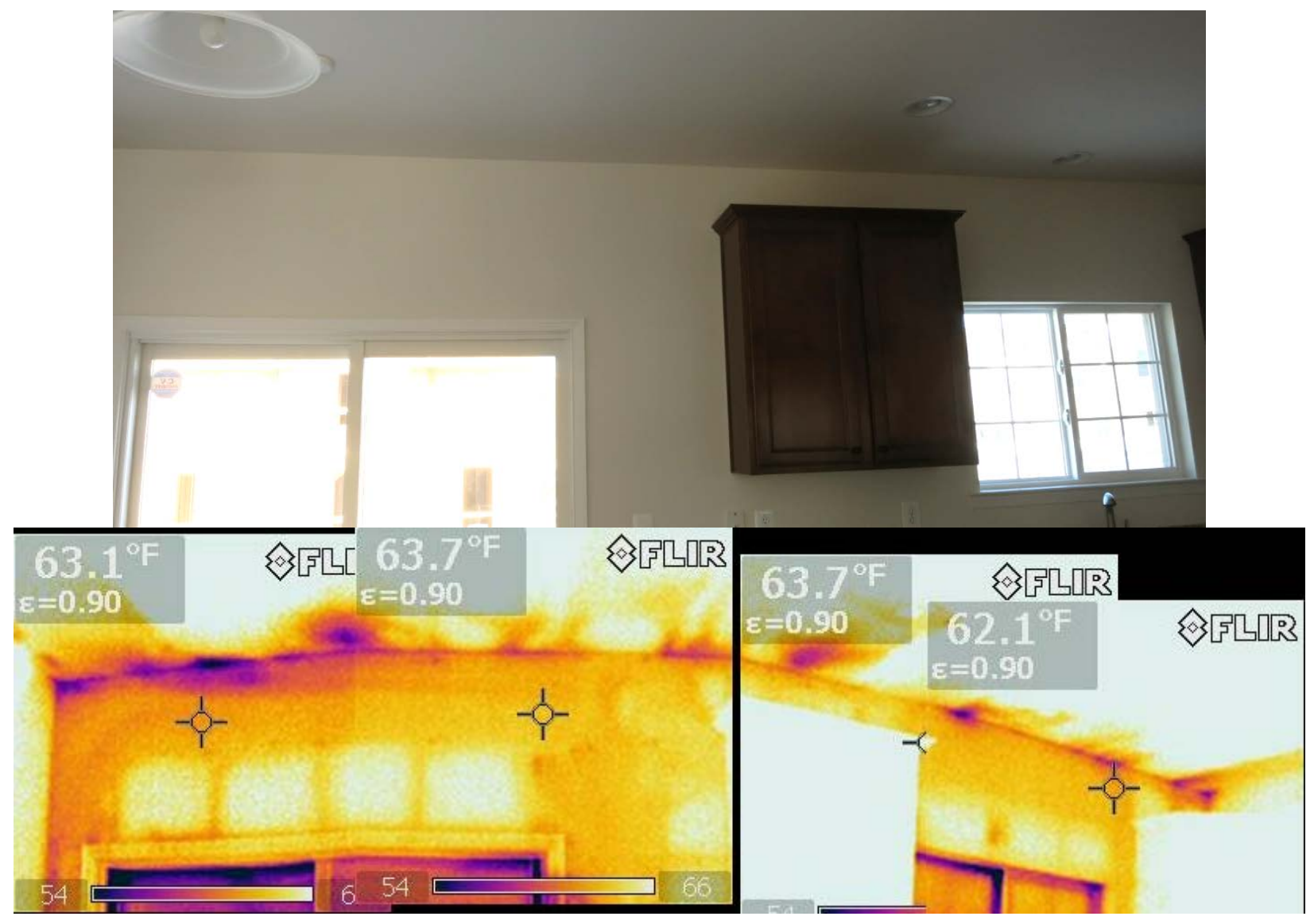

Figure 25. Rear second-floor kitchen/dining area, Unit 6704 (middle) 
Figure 26 shows the construction of this detail on the adjacent building in frame. The underside of the overhang was sheathed with OSB, but large sheathing gaps were common. No visible blocking detail separated the overhang floor cavity from the main floor cavity.
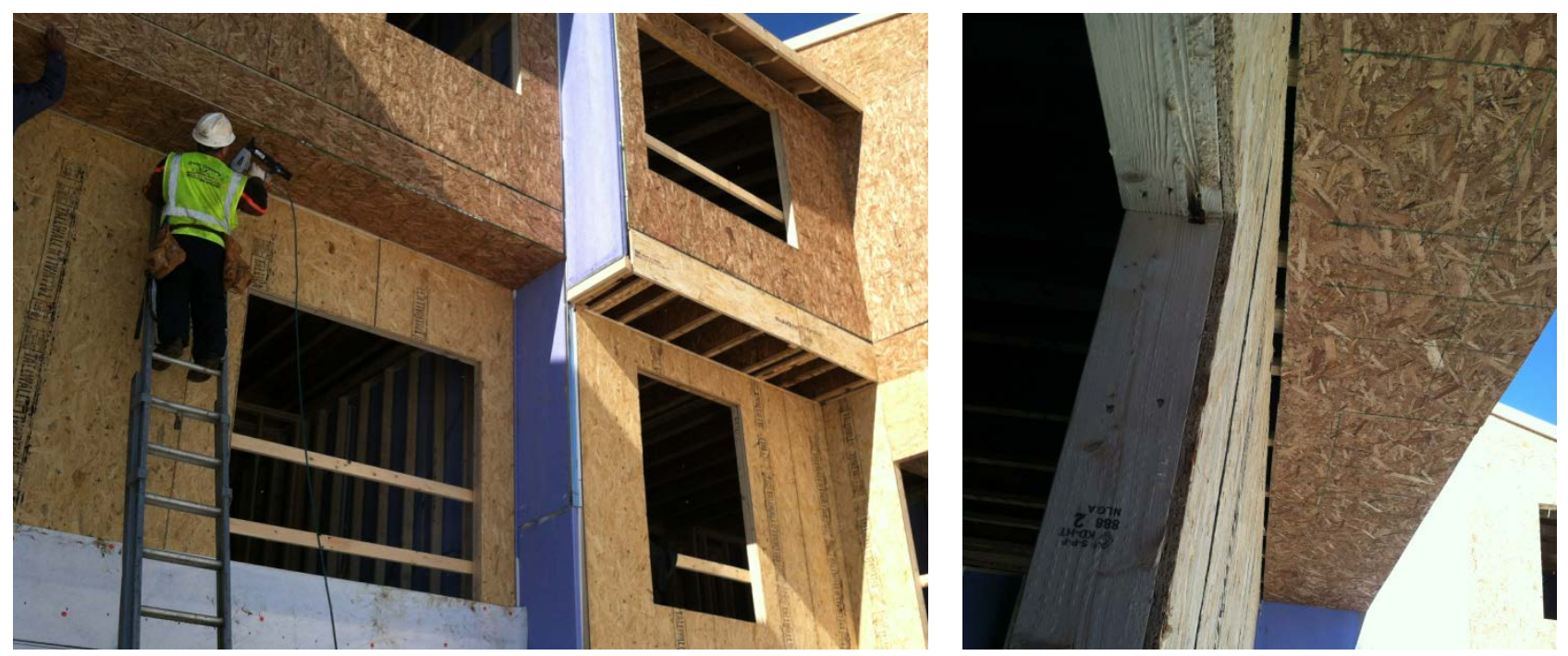

Figure 26. Overhang detail in framed building, showing gap in sheathing at inside corner

Surprisingly, this leakage was even seen in one of the two taped sheathing units (6700), albeit in a much reduced form. A possible explanation is shown in Figure 27: although the flat sheathing seams were taped, the inside and outside corners of the overhanging bay were left untaped.

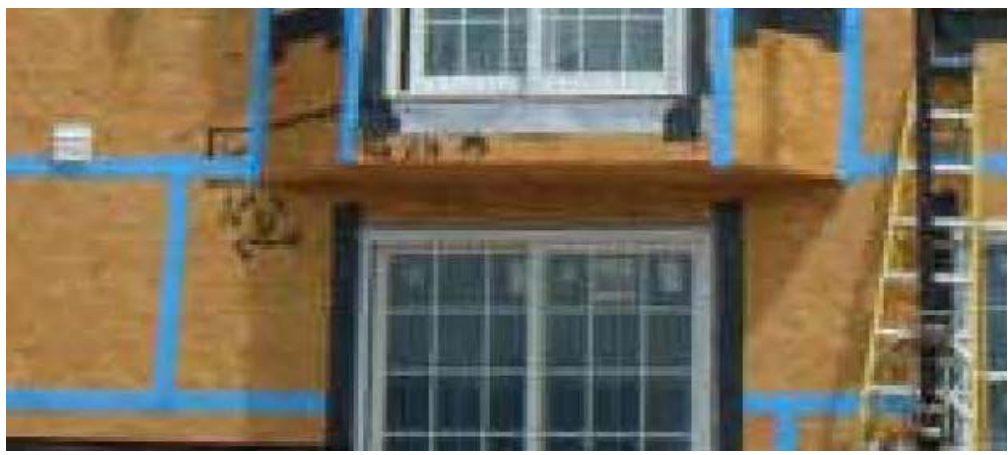

Figure 27. Overhang detail at taped sheathing condition

An exterior infrared image of the overhang (Figure 28) shows warmer surface temperatures (outdoor temperature $30^{\circ} \mathrm{F}$ and rising). This might be due to air leakage, but the overhang surface is shielded from night sky radiation, which might increase its temperature.

The projecting bay at the front of Unit 6702 (middle, improved, and taped) had significant air leakage at the ceiling, visible at the framing (Figure 29; keyed to "B" in Figure 23). An exterior view of the bay is seen in Figure 30. The metal roof of the bay does not appear to be vented; no further investigation or disassembly was done. 

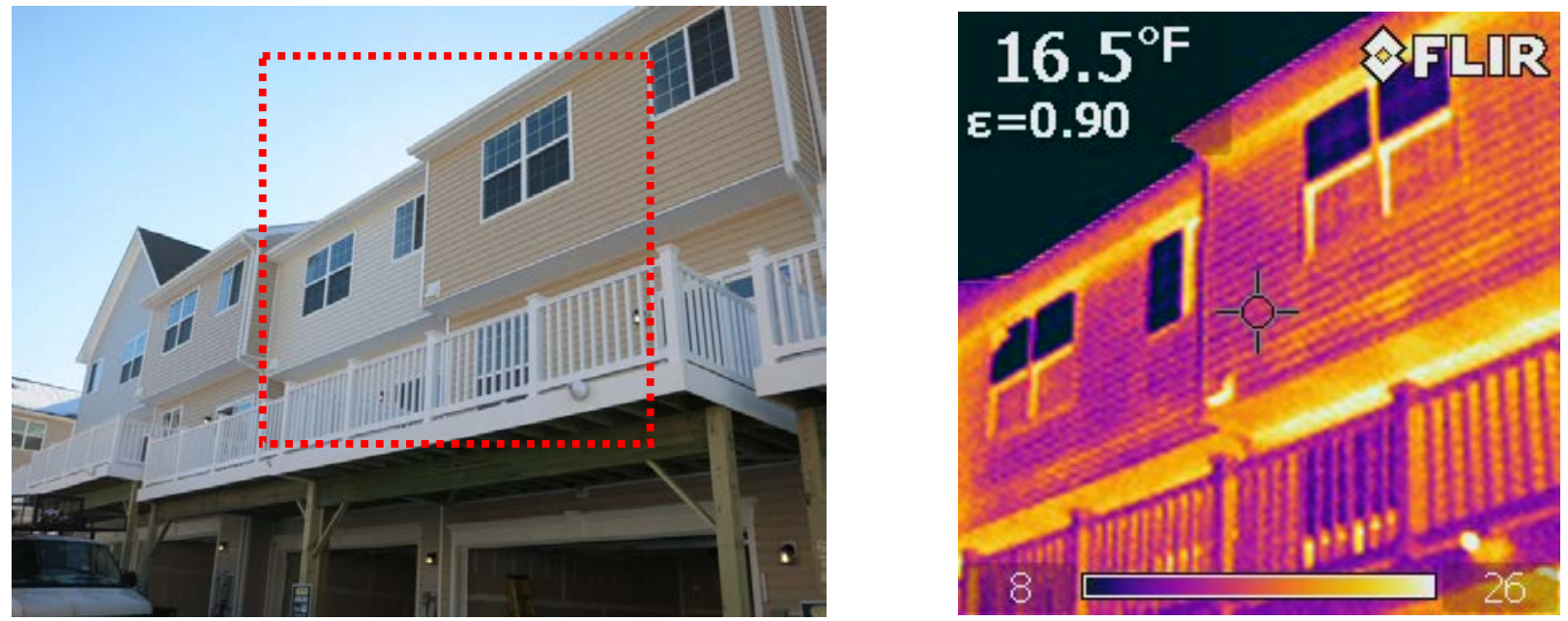

Figure 28. Rear overhang infrared image, units 6702 and 6704 (taped and conventional)
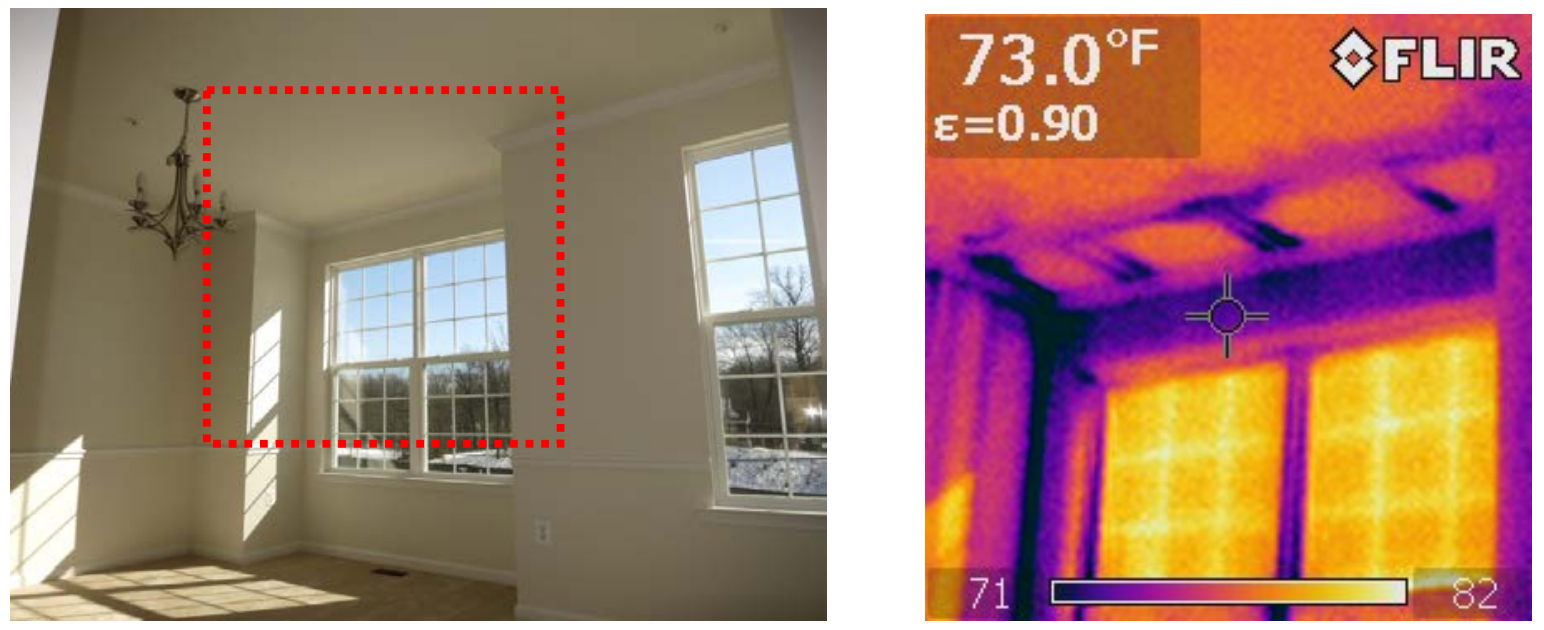

Figure 29. Front bump out bay detail at unit 6702

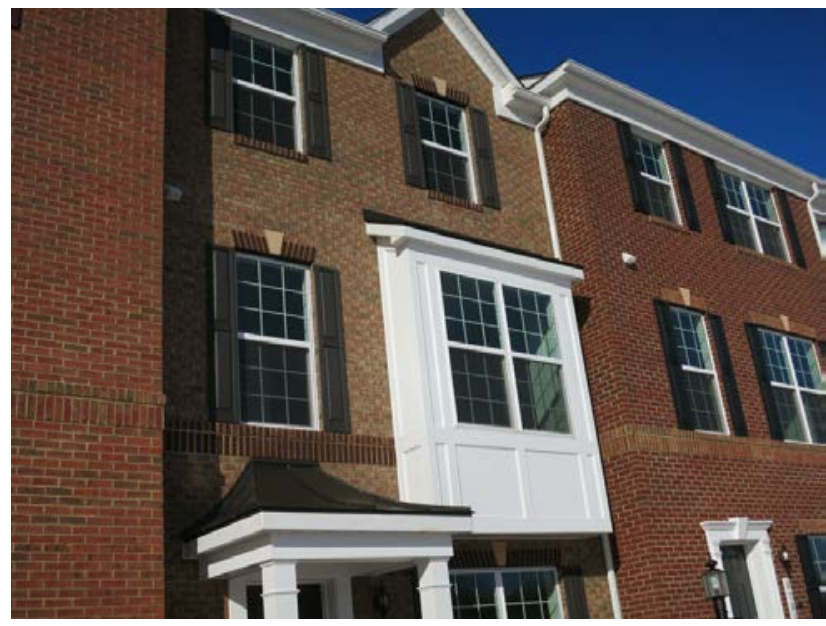

Figure 30. Front bump out bay detail at unit 6702 
Air leakage was seen in multiple units at the baseboard at exterior walls (Figure 31).
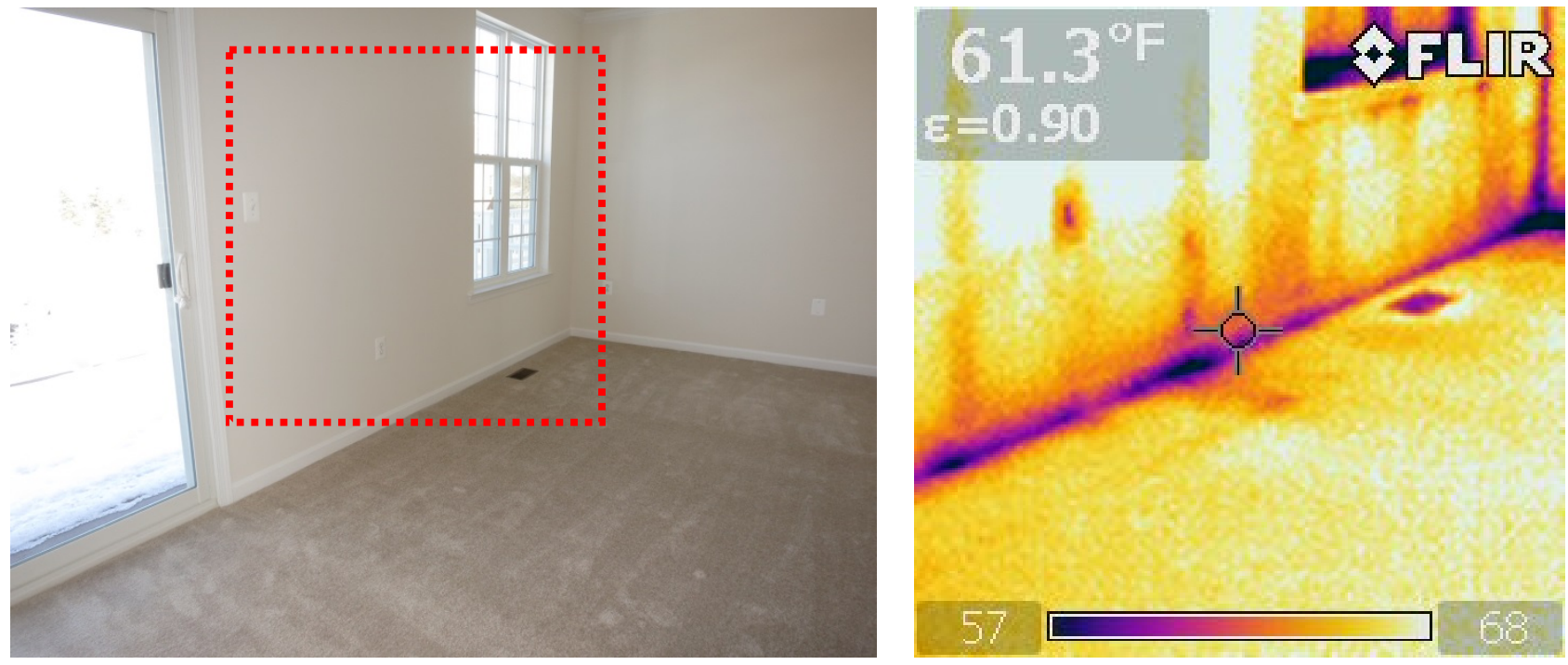

Figure 31. Air leakage at first-second floor/ceiling assembly, Unit 6702

Leakage was consistently seen at the top (third)-floor roof-wall connection, often at the rear of the units (keyed to " $\mathrm{C}$ " in Figure 23). The rear of the building has some type of cross-framing detail (possibly horizontal strapping or resilient channel); the leakage might be due to insufficient sealing of the top of the cavity. The fact that the leaks coincide with the roof trusses (where access and visibility would be limited) is consistent with this theory.

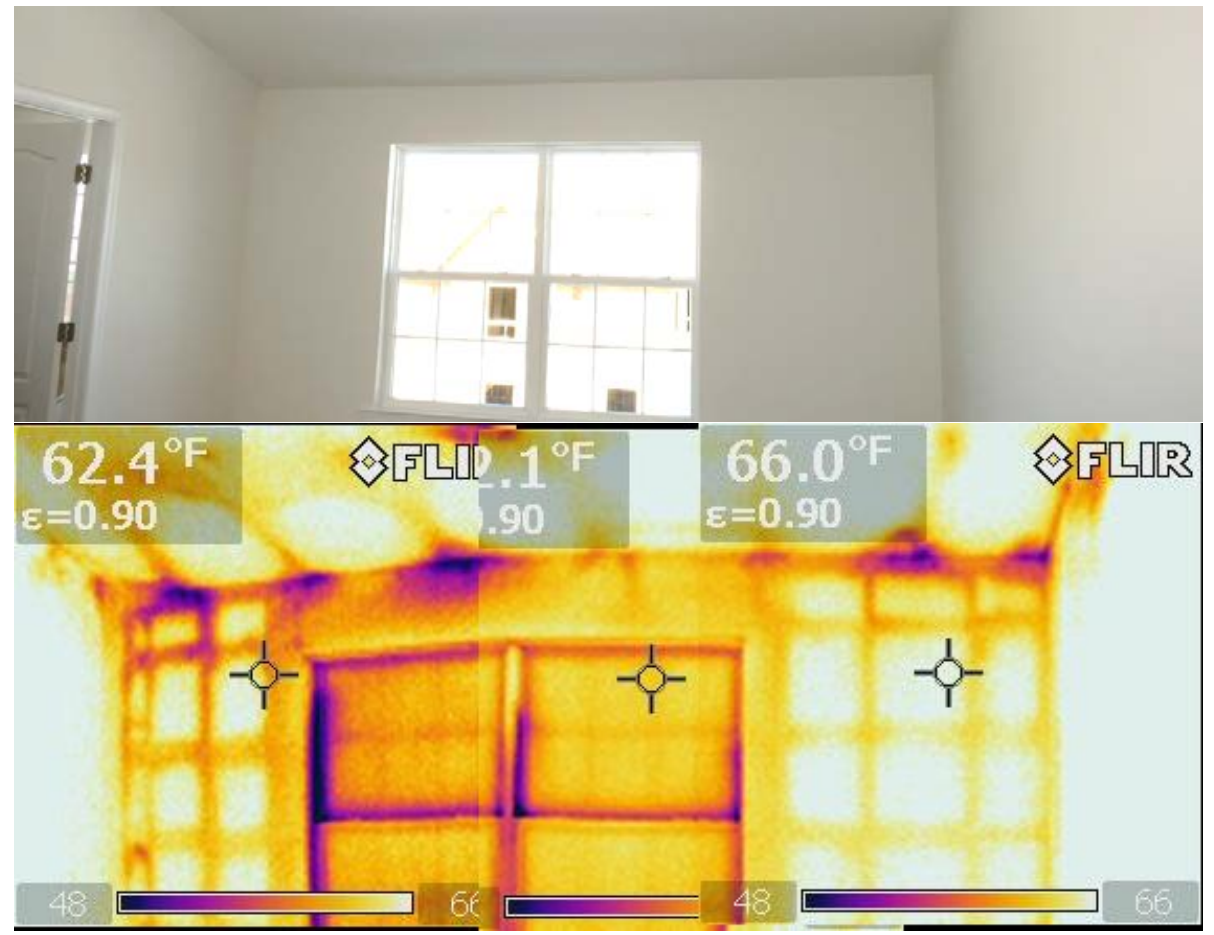

Figure 32. Rear wall/vaulted ceiling leakage, Unit 6706 
Issues were also seen in the vaulted ceiling (Figure 33).
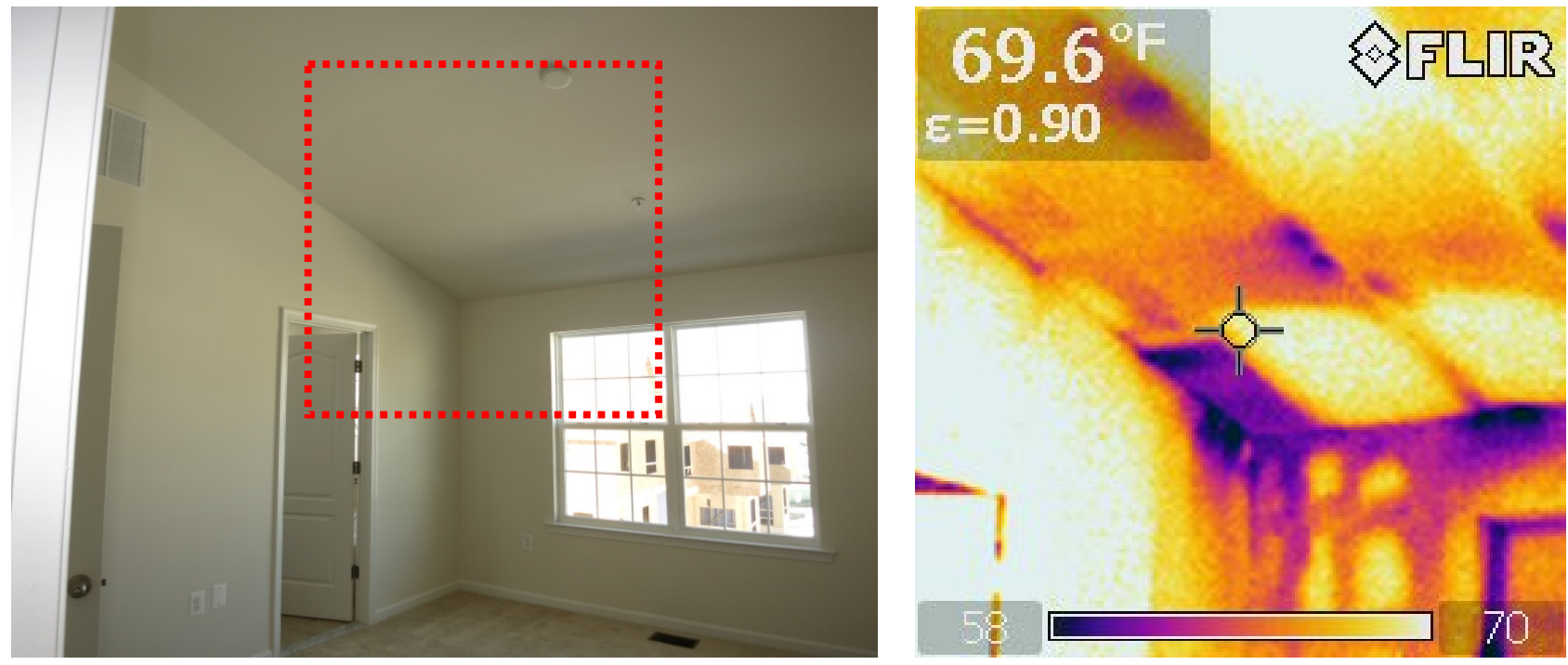

Figure 33. Vaulted ceiling air leakage, Unit 6706

At several interior walls under the vented/unconditioned attic, noticeable air leakage was visible at the top plate (Figure 34 and Figure 35, keyed to "D" in Figure 23). Unfortunately, this indicates that the interior top plate detail (Figure 8) was not executed correctly or consistently.
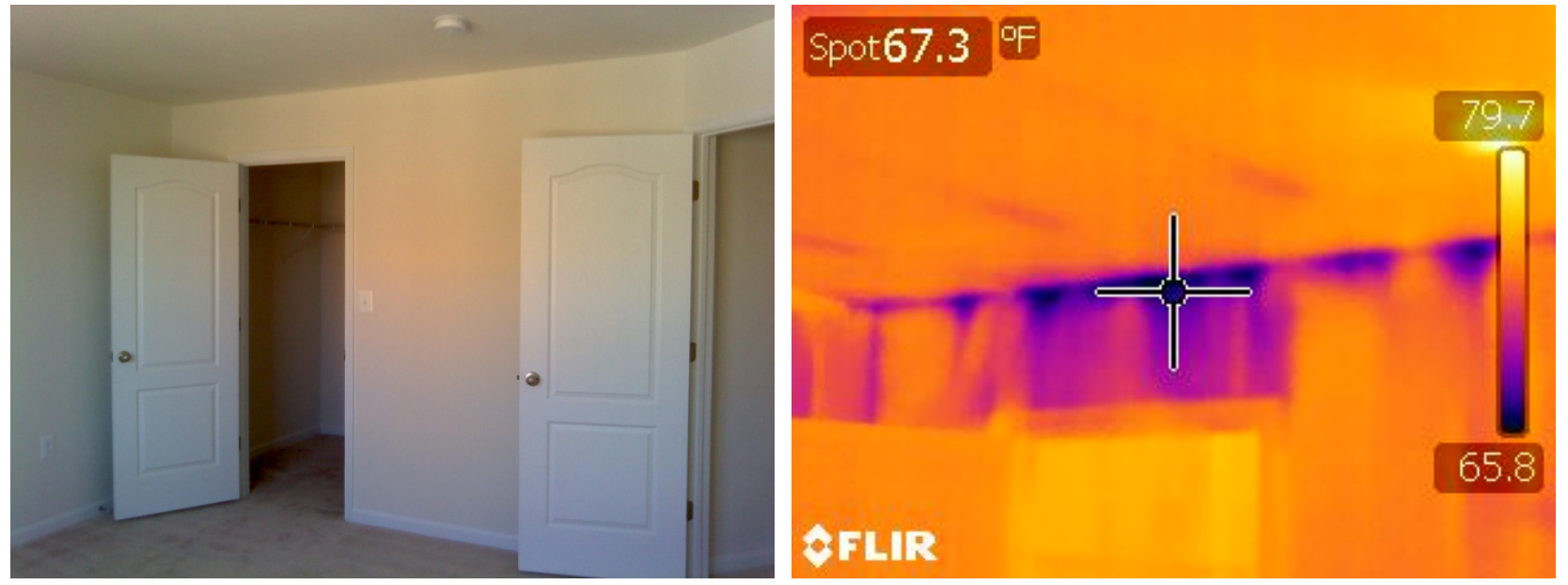

Figure 34. Interior wall under attic (third floor), Unit 6702 

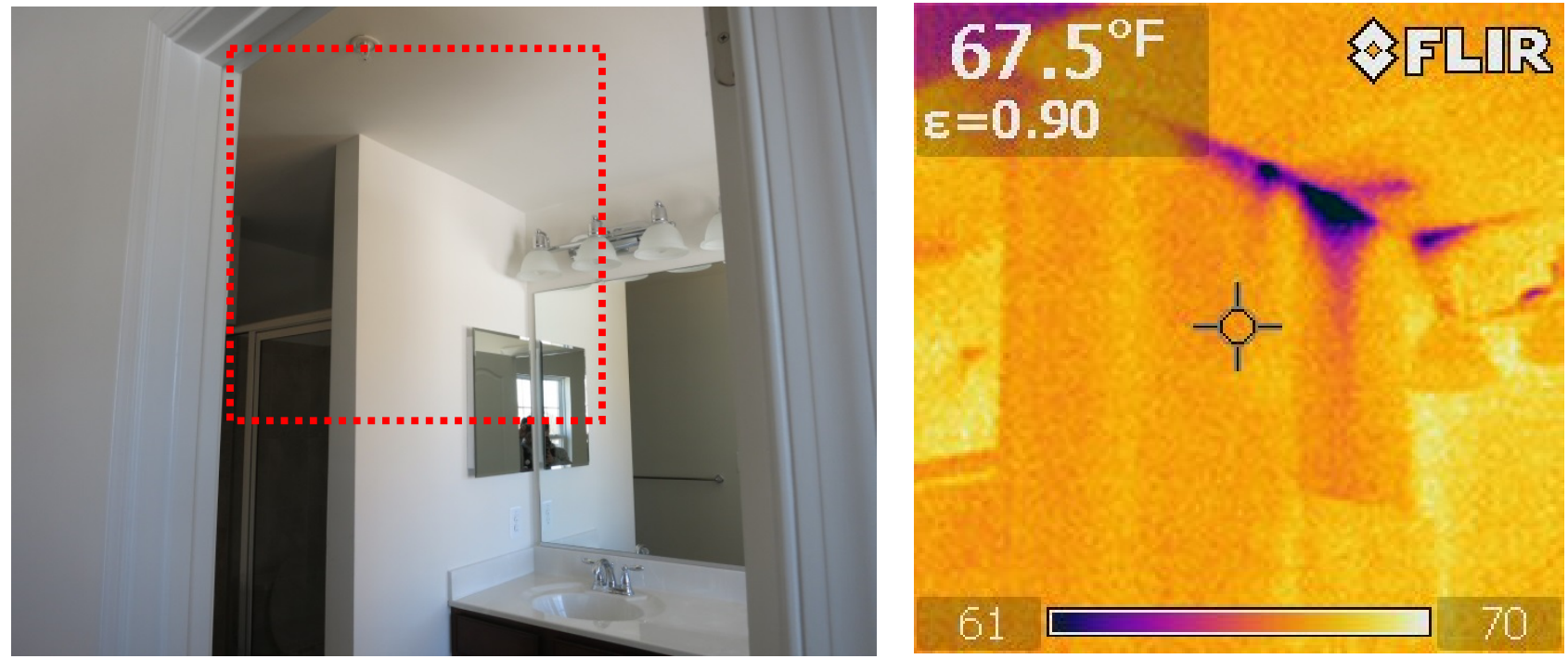

Figure 35. Interior wall under attic (third floor), Unit 6702

The transitions from vaulted ceilings to flat attics were good in some cases, but poor in other cases (Figure 36; keyed to "E" in Figure 23). The attic sides of the knee walls were sheathed with thin profile sheathing (Figure 37), but apparently, some air sealing details were not executed correctly.

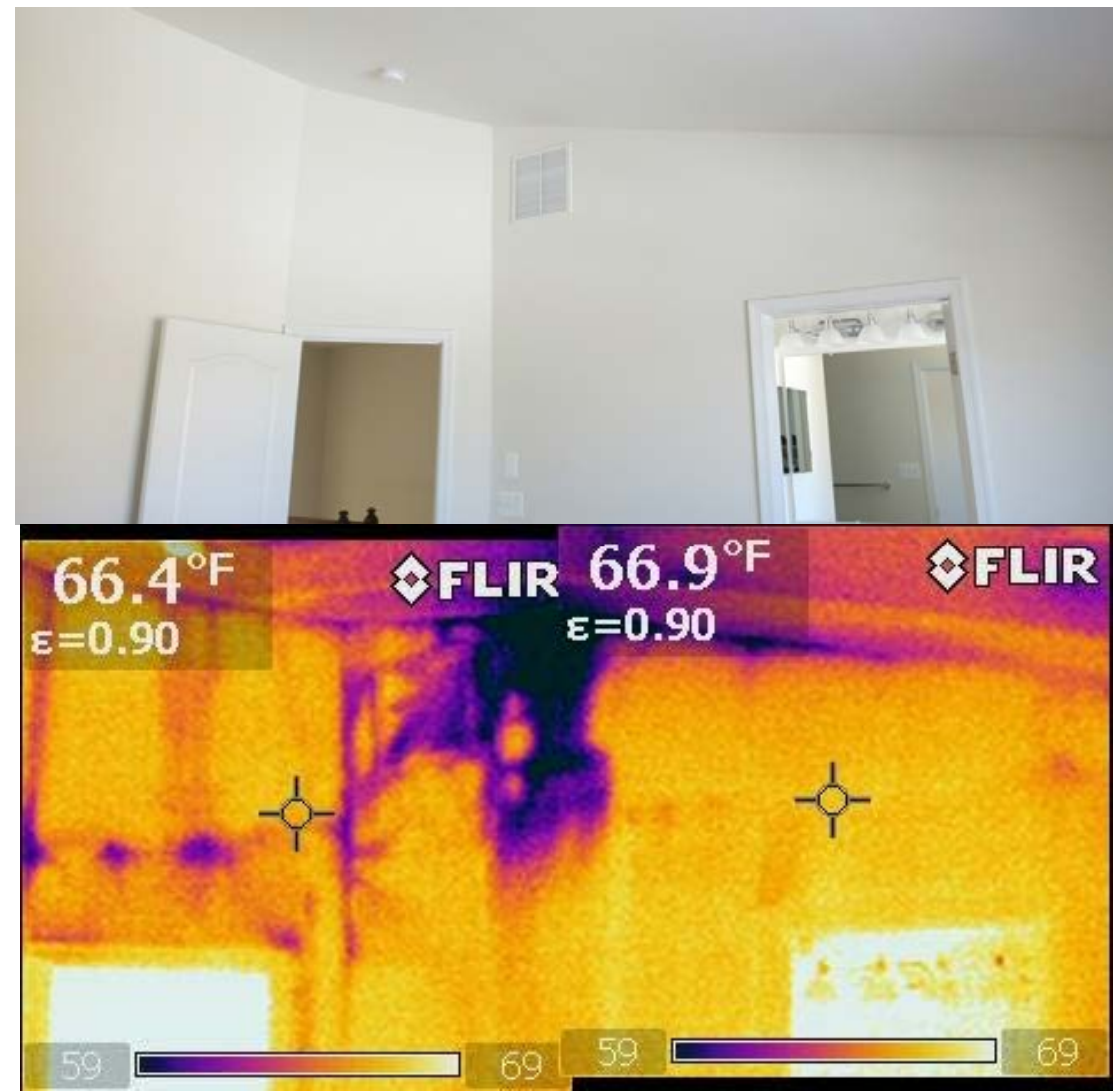

Figure 36. Return duct air leakage and attic knee wall leakage (Unit 6704) 


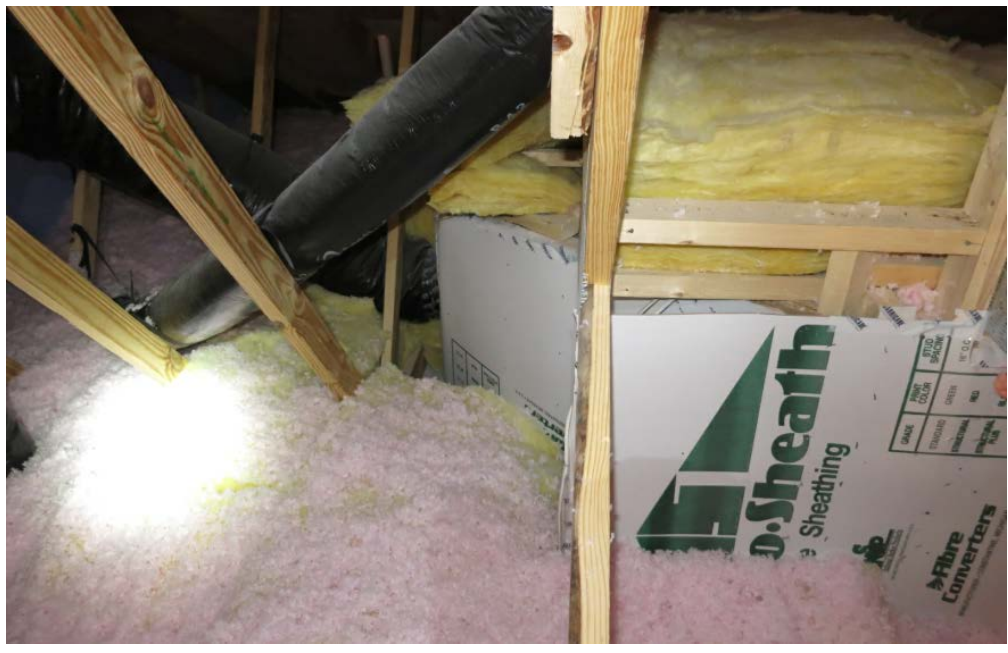

Figure 37. Attic knee wall condition and sheathing (Unit 6704)

Windows and doors were noticeable sources of air leakage. Air leakage occurred in the window units at the sash to frame interface (often worst at the corners), as shown in Figure 38. At a sliding glass door, an interior weep hole at the sill track was a distinct air leakage point (Figure 39 and Figure 40), which is a flaw in the design of the unit.

The window-to-wall connection was also a source of air leakage in some cases, as evidenced by the leakage plume coming from the stool casing below the window sill (Figure 41).

Similarly, the door to the garage showed air leakage at both the unit (door jamb gasket) and at the frame-to-wall connection (Figure 42).
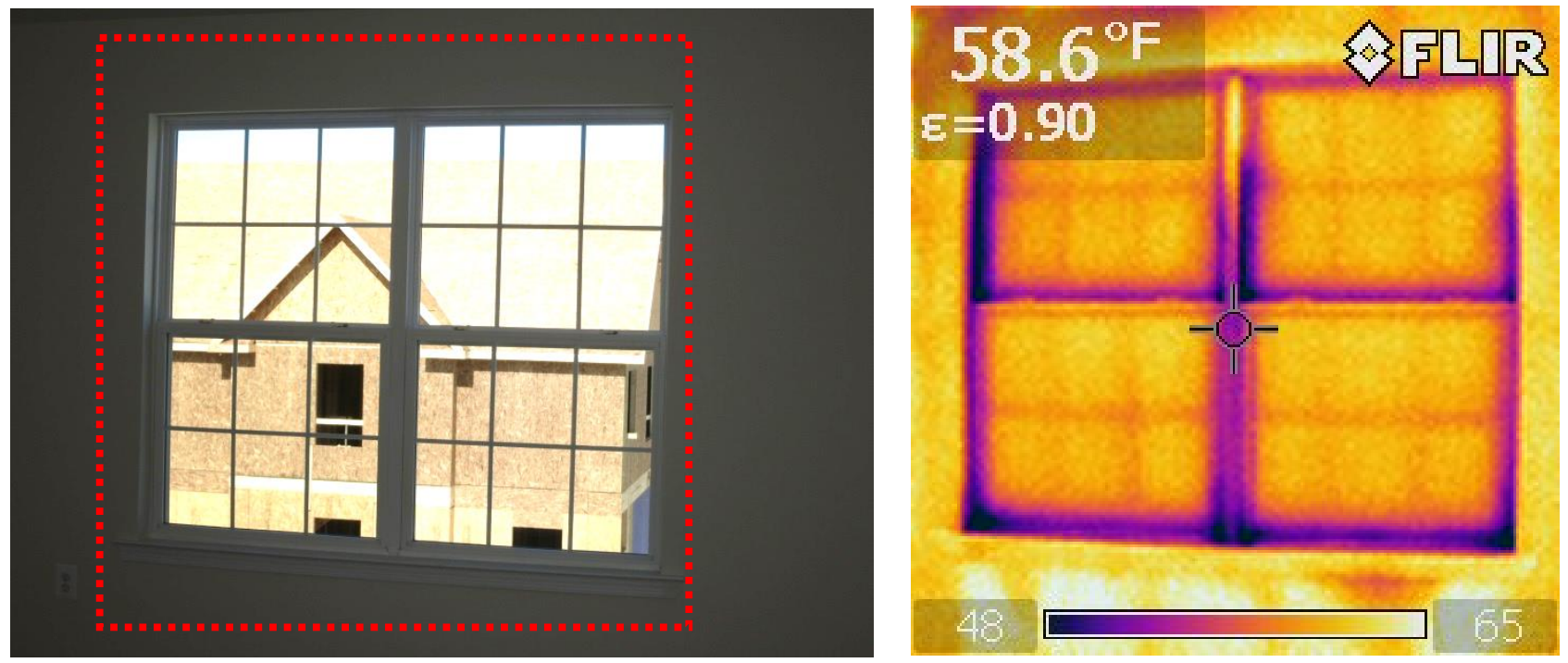

Figure 38. Window air leakage (window unit, sash-to-frame) 

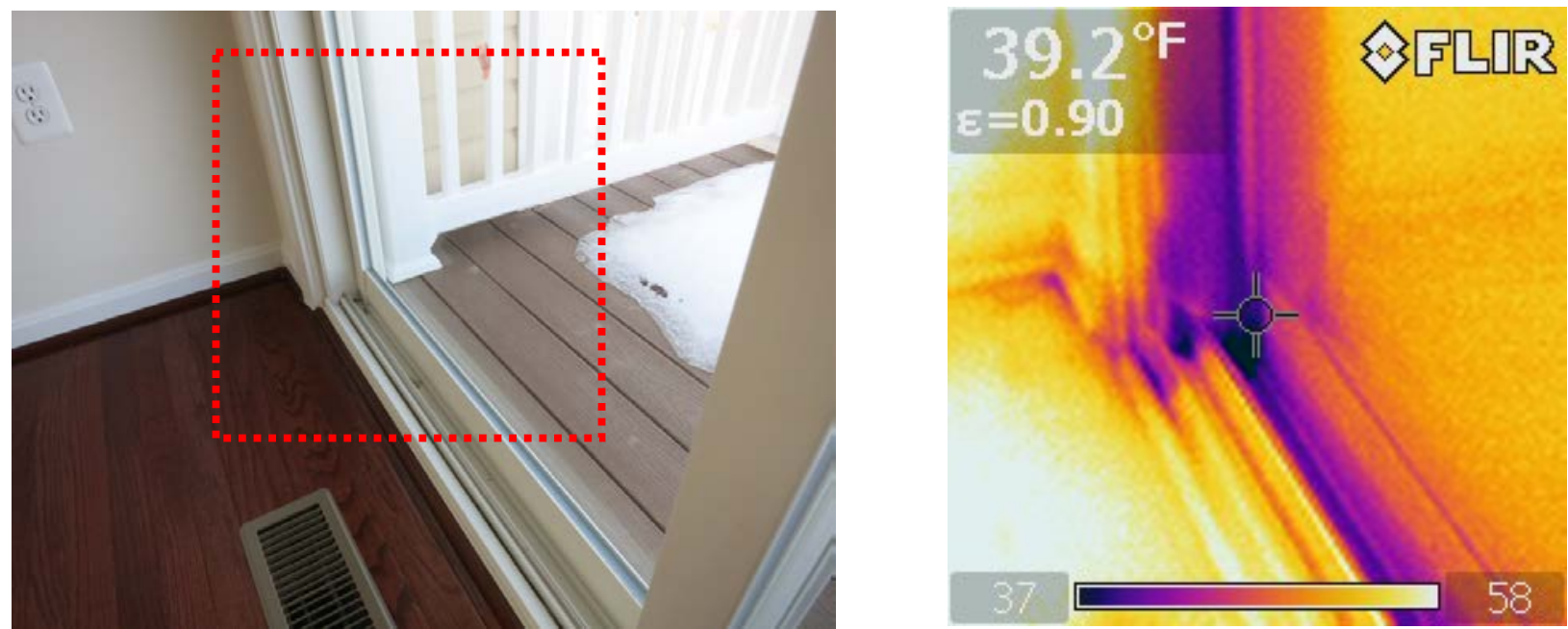

Figure 39. Sliding glass door air leakage at weep hole (door unit)

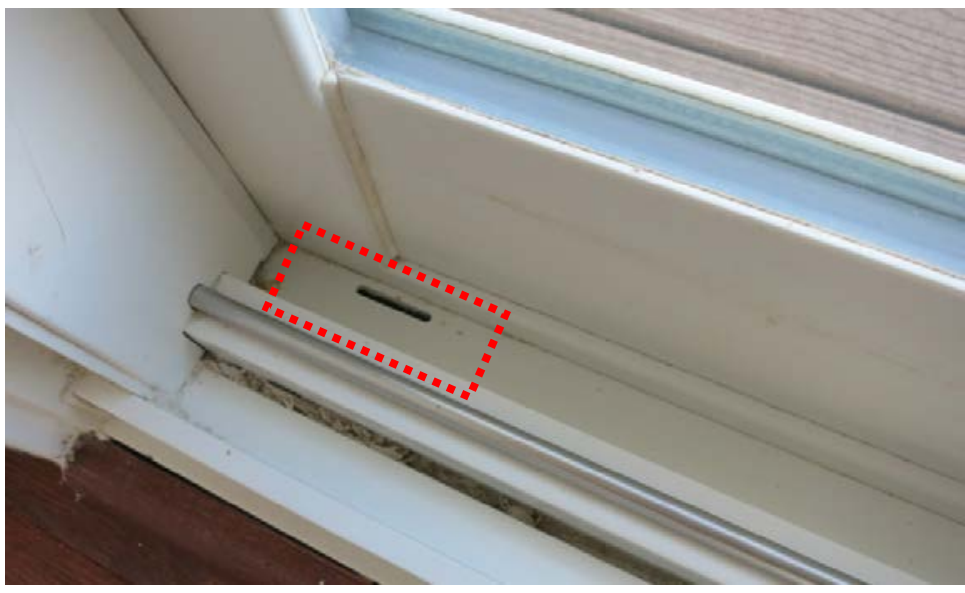

Figure 40. Sliding glass door air leakage at weep hole (door unit)
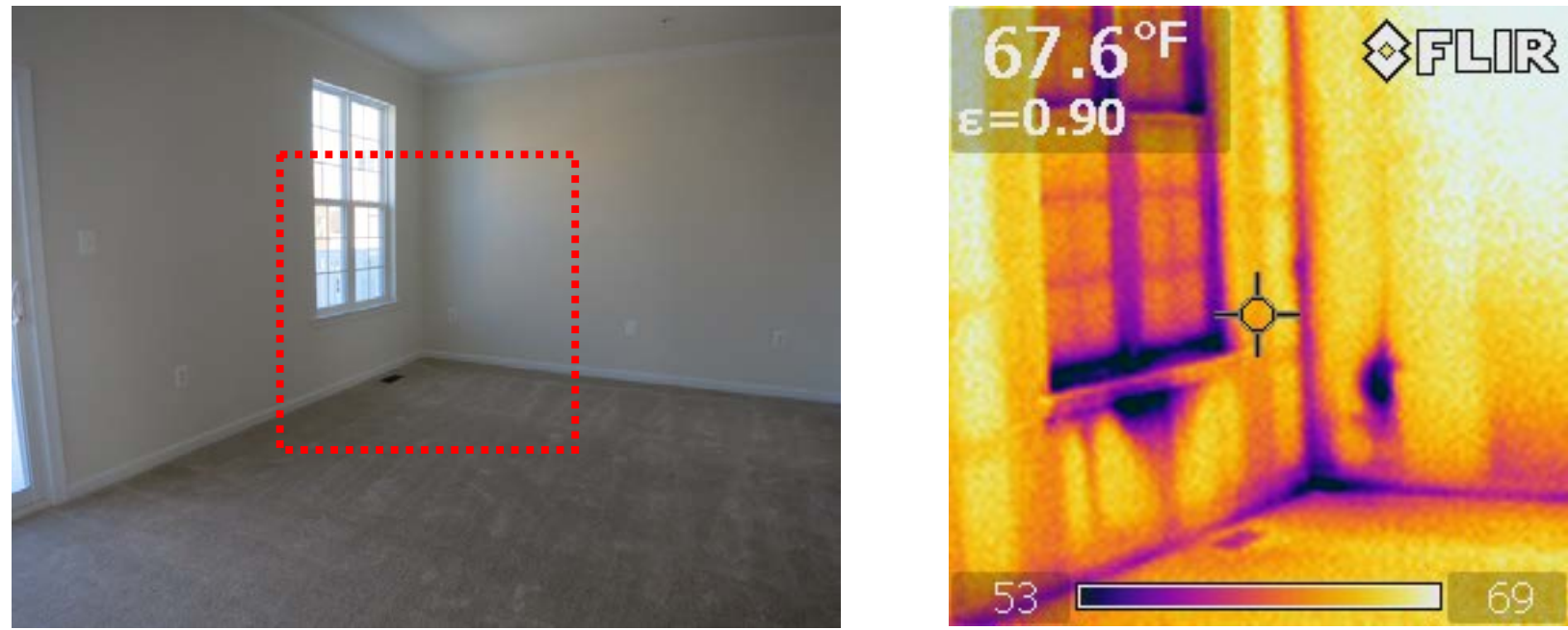

Figure 41. Window air leakage (window-to-wall connection at sill), Unit 6706 

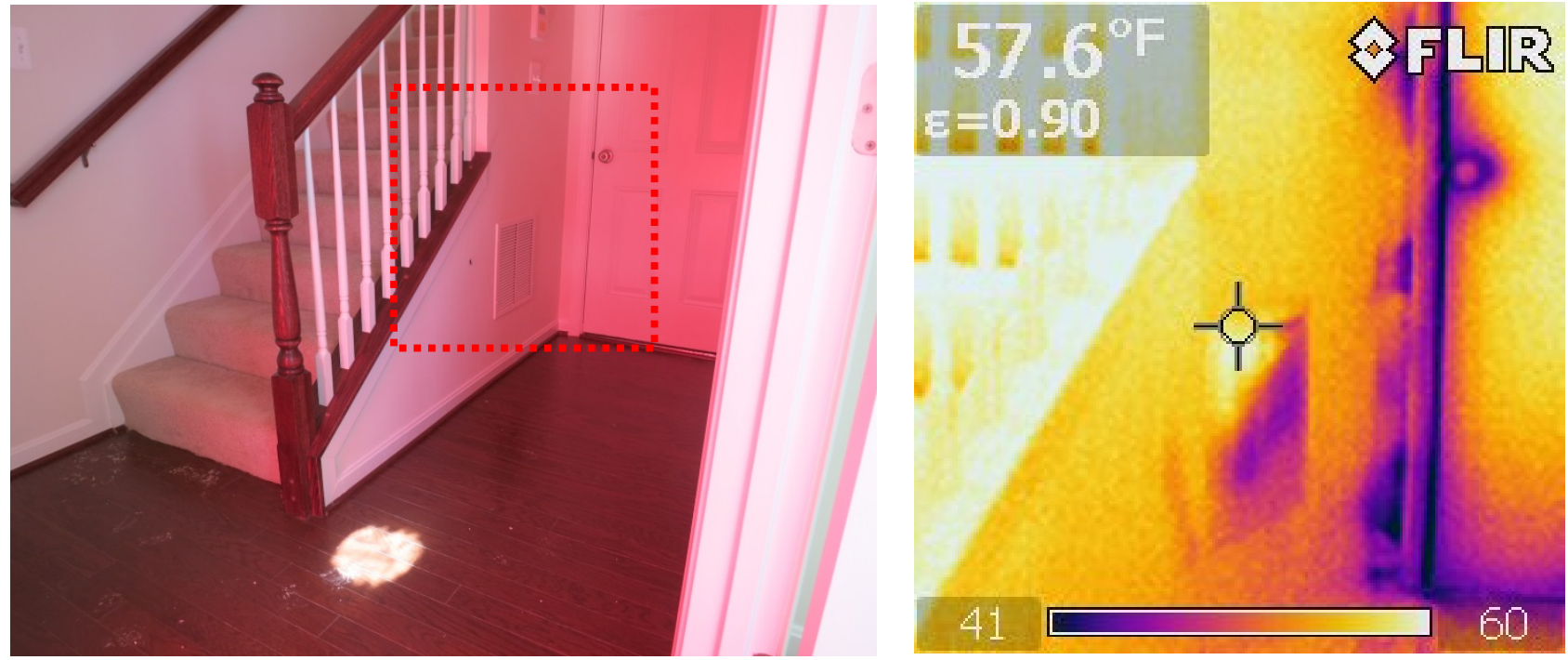

Figure 42. Air leakage at door (door jamb gasket and frame-to-wall connection)

The attic hatch showed air leakage plumes (Figure 43, keyed to " $F$ " in Figure 23), despite the presence of a bulb gasket. The hatch was insulated with a 10-in. block of expanded polystyrene foam ( R-40); however, it was evidently not sufficient to compress the gasket fully. The units were depressurized in this test, which would tend to pull the hatch downward. Apparently, some type of mechanical clamping may be required for a good seal.
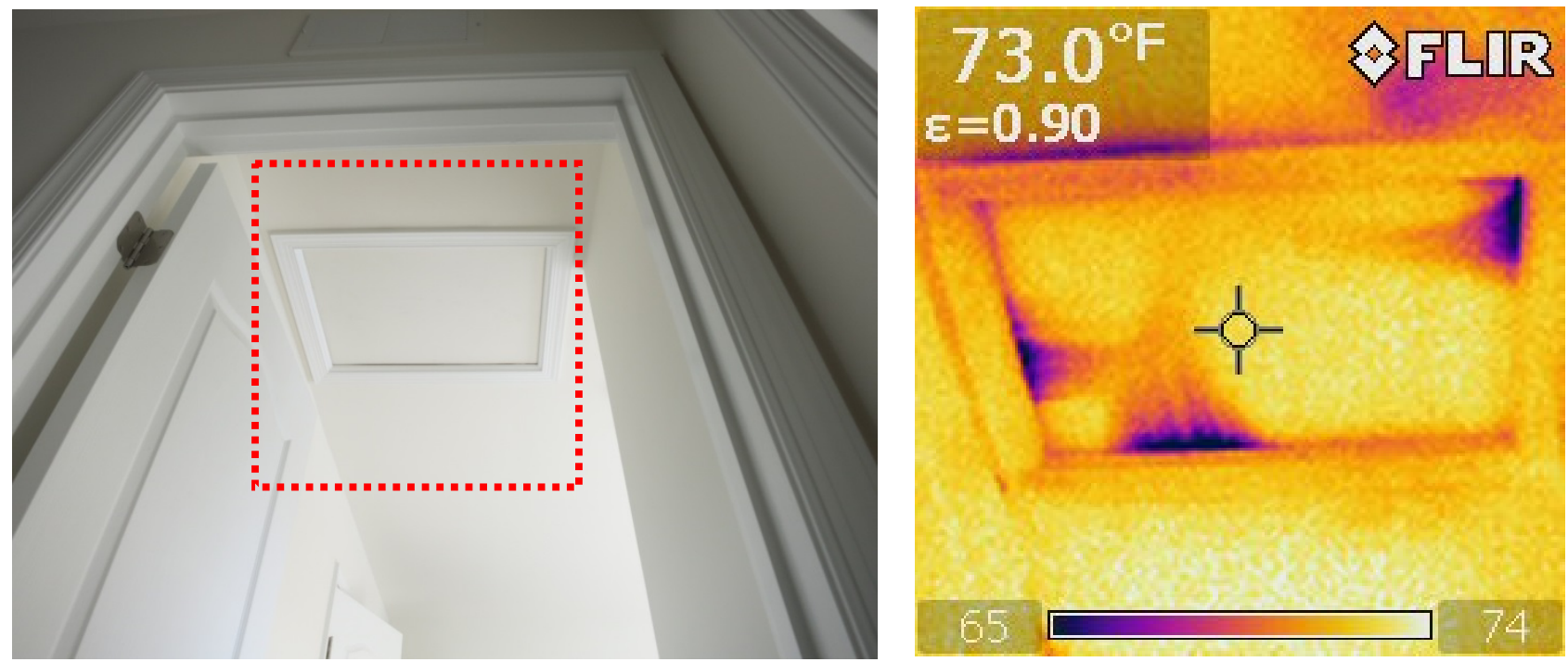

Figure 43. Attic hatch air leakage

Various mechanical systems were also a source of air leakage. Air leakage was evident at the air handler returns, which was linked with incorrectly operating motorized dampers in the outside air supply ventilation duct (see Figure 21). 
The bathroom exhaust fans were also leakage sources, both through the fan (i.e., flapper not sealing correctly), and around the fan unit (gaps between the fan body and ceiling gypsum board).
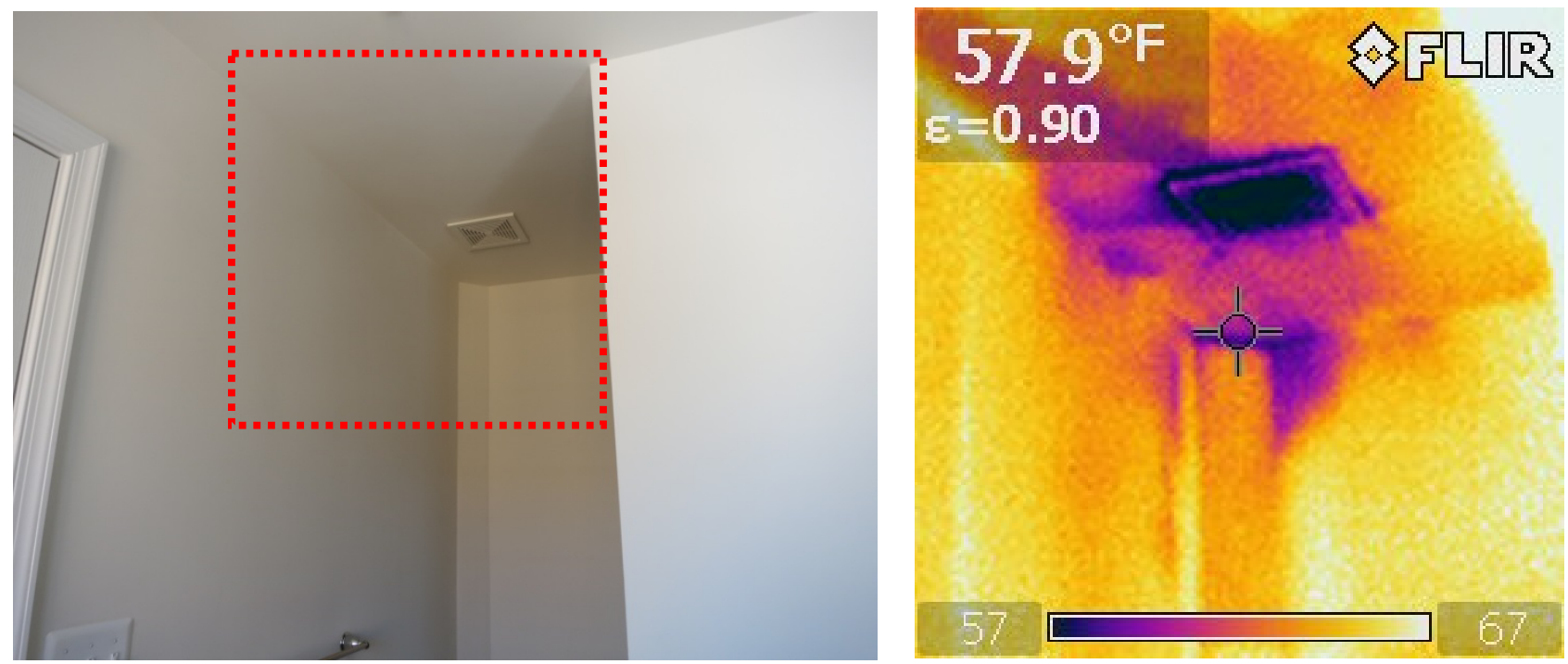

Figure 44. Exhaust fan air leakage (through unit and around unit)

Similarly, the microwave oven/range hood was a source of leakage in some cases (Figure 45).
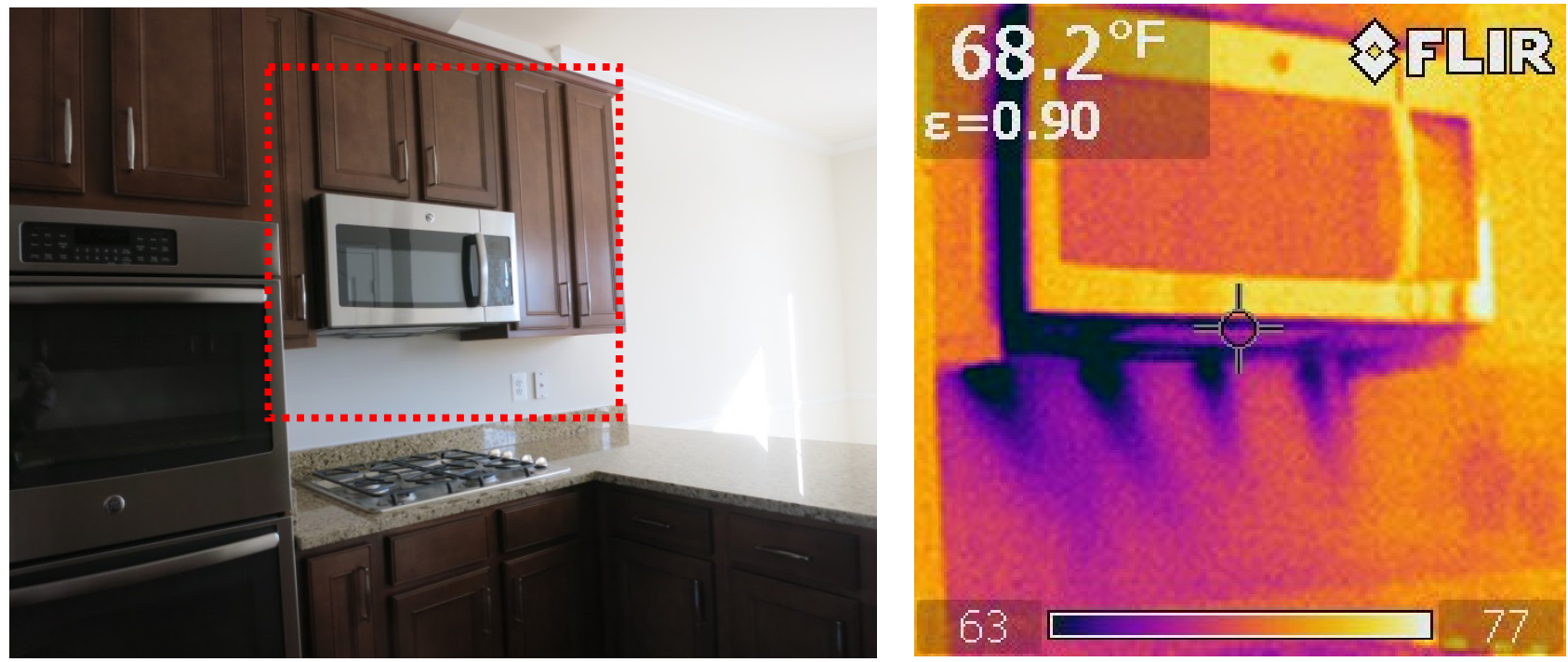

Figure 45. Microwave/range hood air leakage (through unit and around unit)

Leakage was observed around recessed lighting below the unconditioned attic (Figure 46). Similarly, electrical fixtures and box covers had similar leakage issues (see Figure 33, showing vaulted ceiling). 

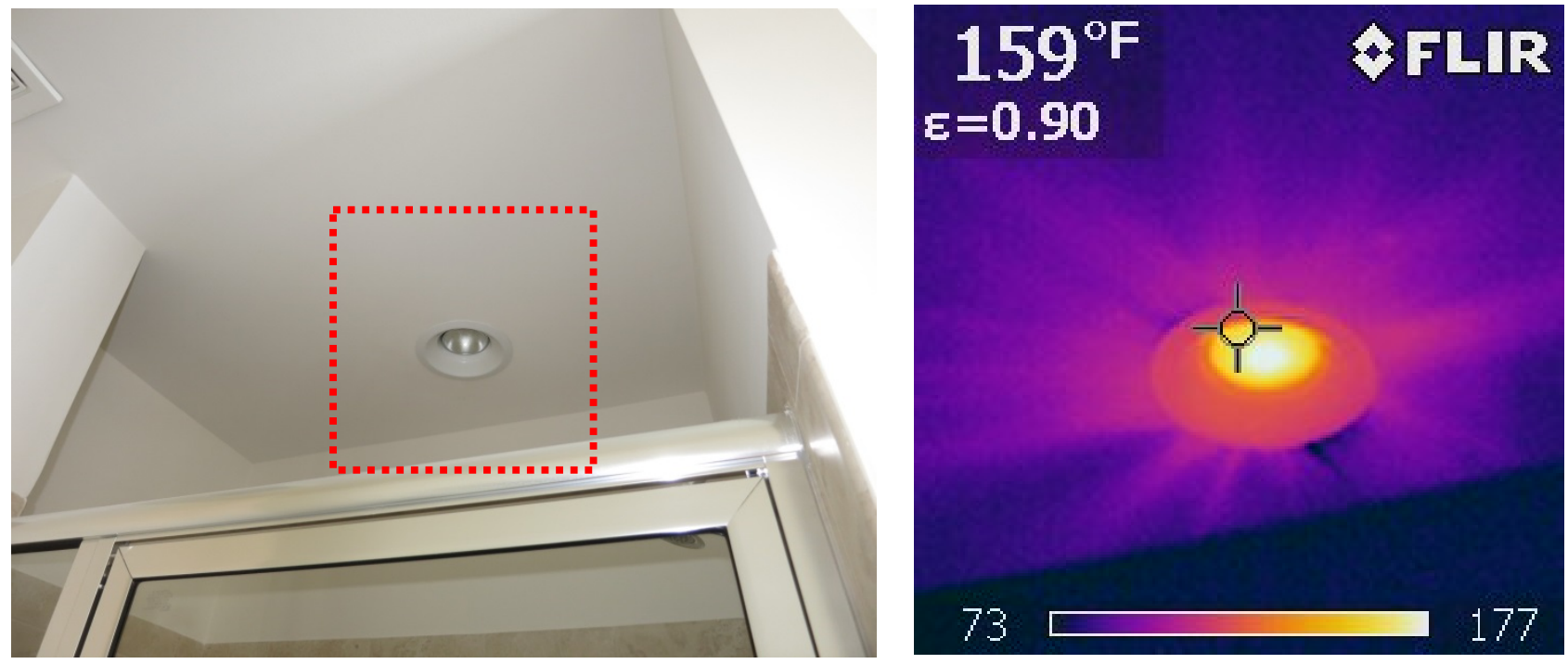

Figure 46. Bathroom recessed light air leakage (around unit/trim ring)

\subsection{Air Leakage Locations: Area Separation Wall Details}

Several of the observed air leaks were associated with details at the area separation walls/ demising walls. A plan of two adjacent middle units is shown in Figure 47, providing a map of some of the following observations. These area separation wall air leaks were found in multiple units; the plan in Figure 47 is meant to show typical connections between two middle units.

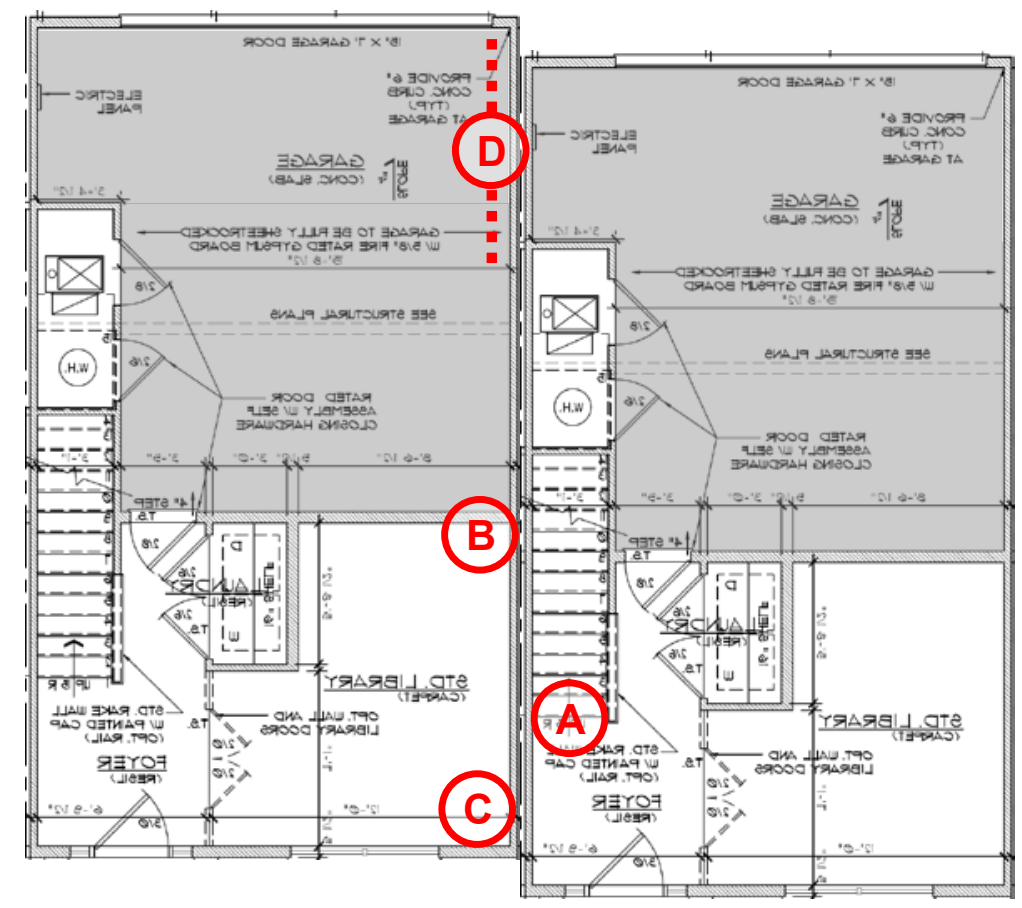

Figure 47. Plan of two adjacent middle units (first floor), with key locations highlighted 
During depressurization, noticeable amounts of leakage came out of the stair carpeting joints (location A), at the tread-to-riser connection (Figure 48). Given the geometry, this is due to leakage at the area separation wall, the garage mechanical room (and systems), or interactions between these two details.
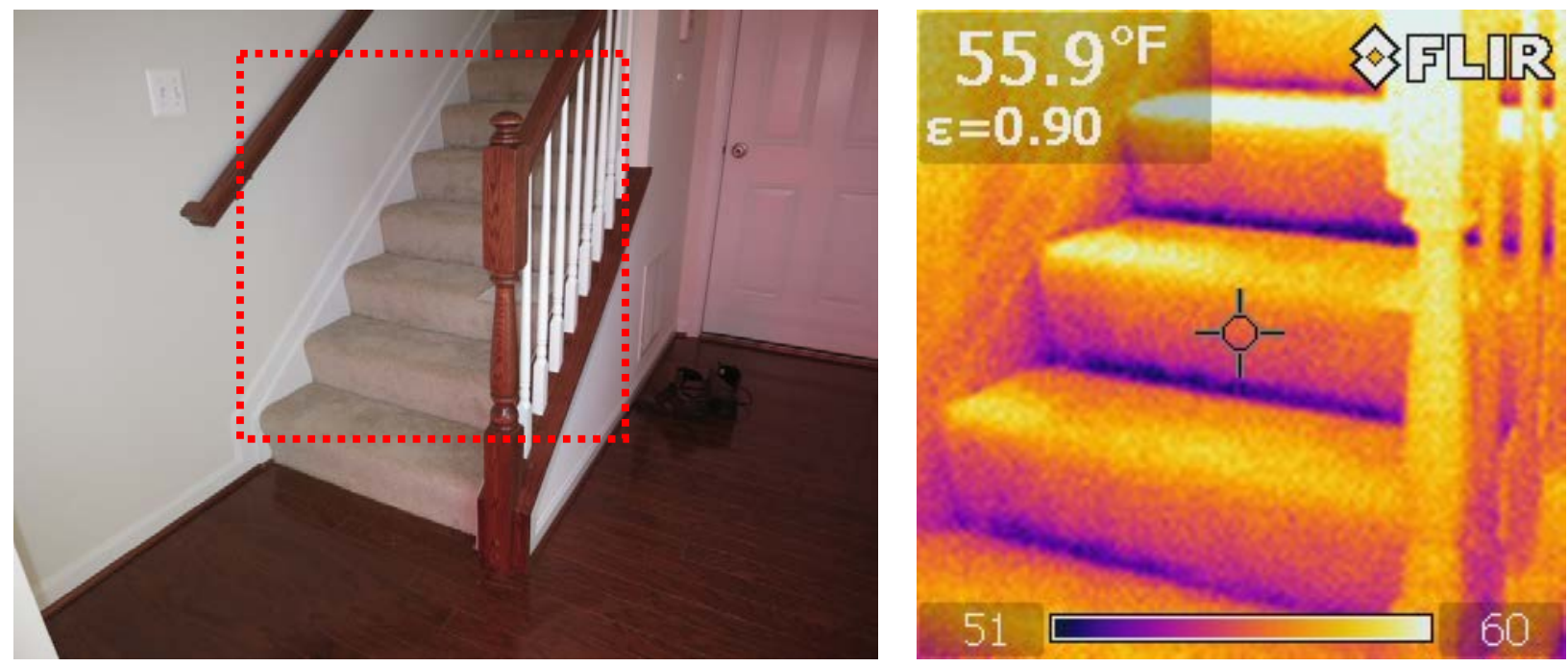

Figure 48. Air leakage at stair tread-to-riser joints, location (A)

A pressure measurement was taken at the space under the stairs; when the unit was depressurized to $50 \mathrm{~Pa}$, the stairs were at $24 \mathrm{~Pa}$ with respect to the interior. In other words, the area under the stairs is $50 \%$ interior and $50 \%$ exterior, indicating significant leakage to the exterior.
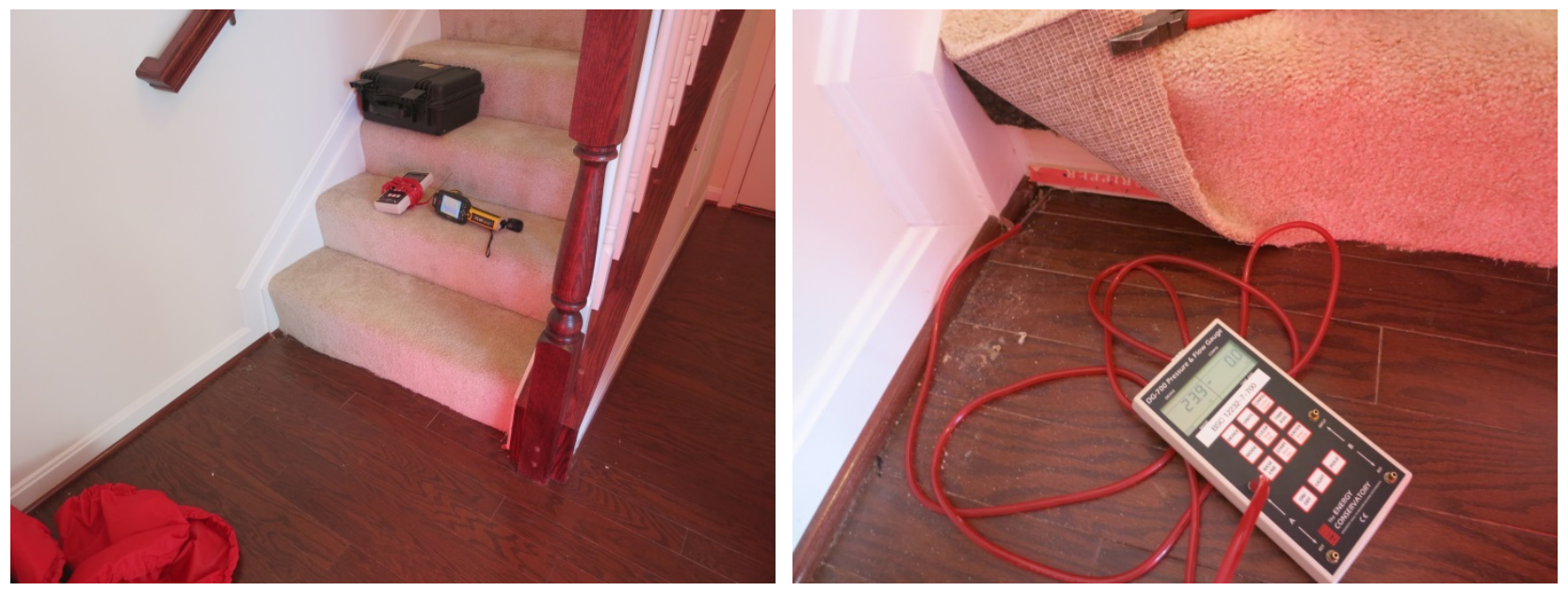

Figure 49. Measurement of pressure difference under stairs, location A

Similar issues were seen at the top of the stairs, at the landing between the first and second floors (Figure 50). 

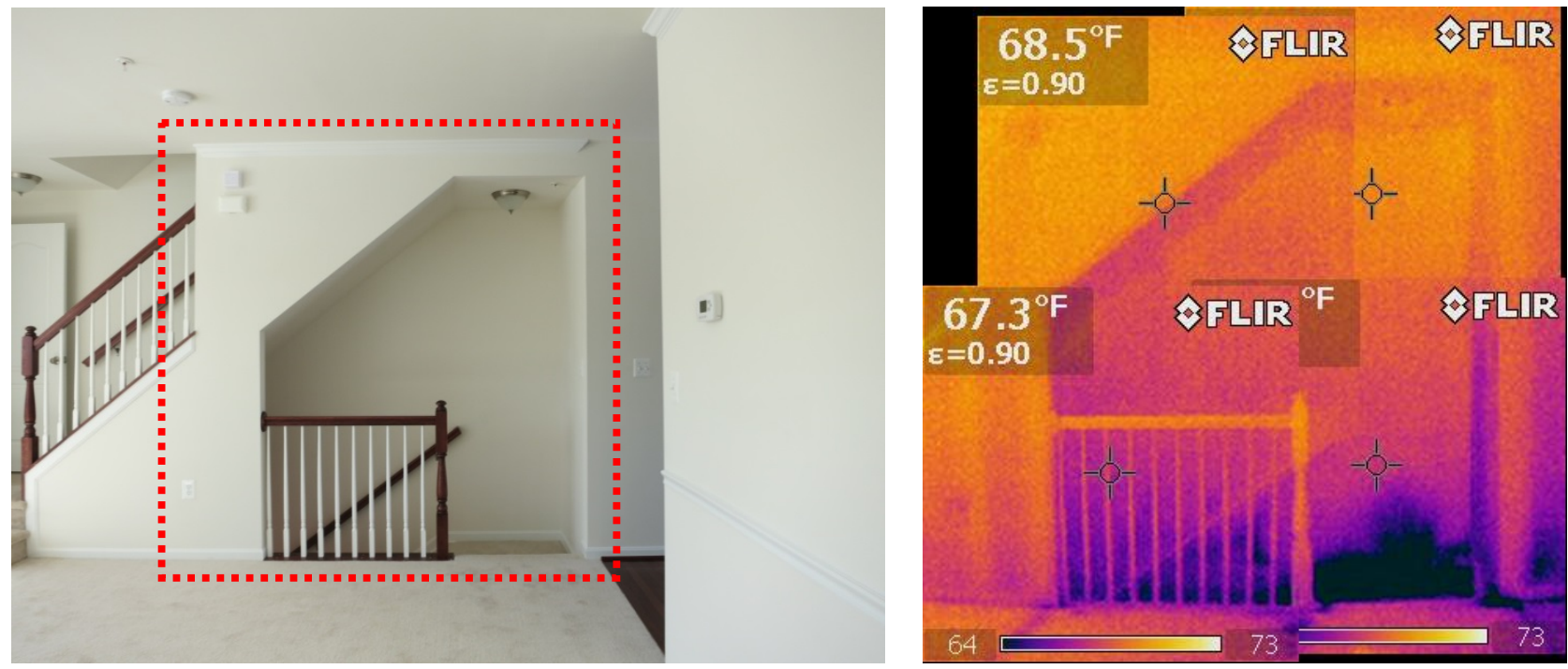

Figure 50. Air leakage at stair landing (first-to-second floor)

The wall between the garage and the first-floor conditioned space forms a tee wall intersection at the area separation wall (location B, Figure 47). Air leakage from the garage into the area separation wall cavity was seen during depressurization (Figure 51).
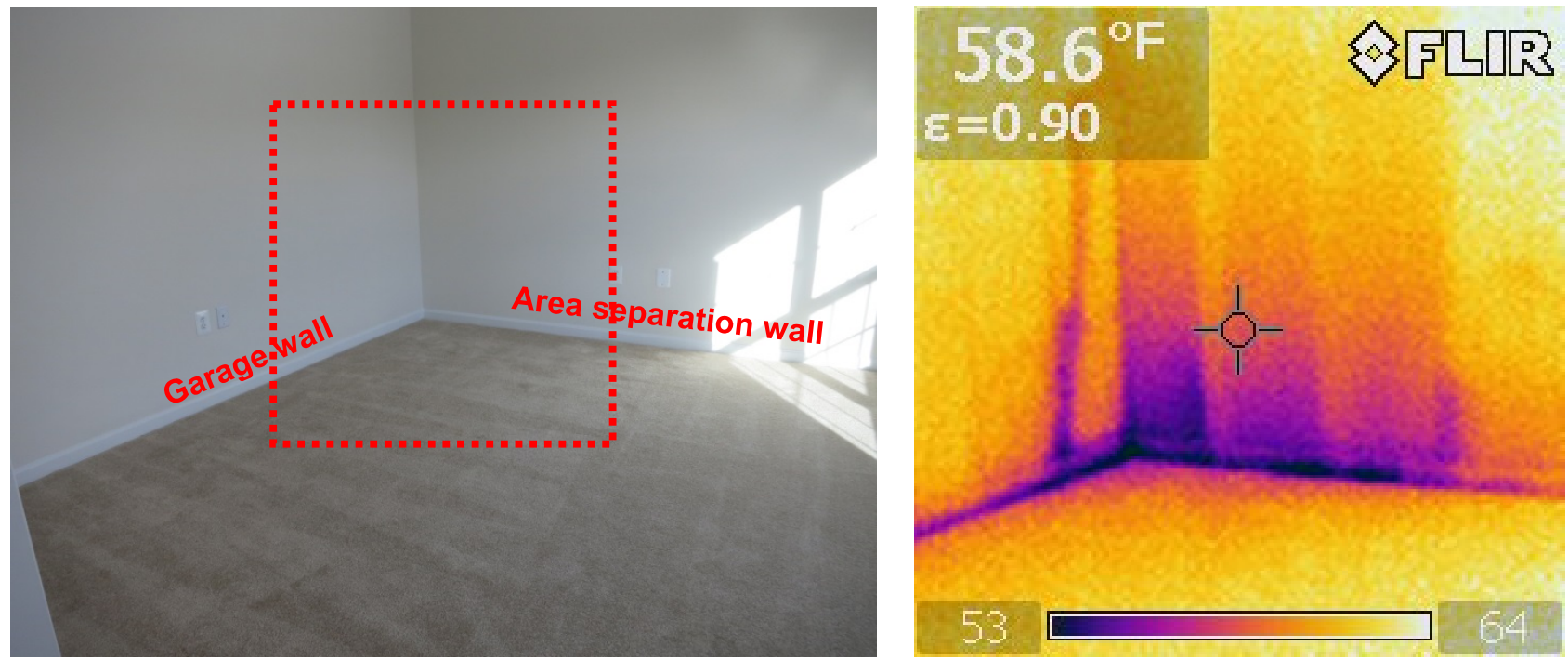

Figure 51. Garage tee wall intersection, Unit 6700, location B

This intersection is framed with ladder blocking to support the garage wall end (Figure 52); there is no simple way to seal the garage wall at this tee intersection with this framing geometry. 

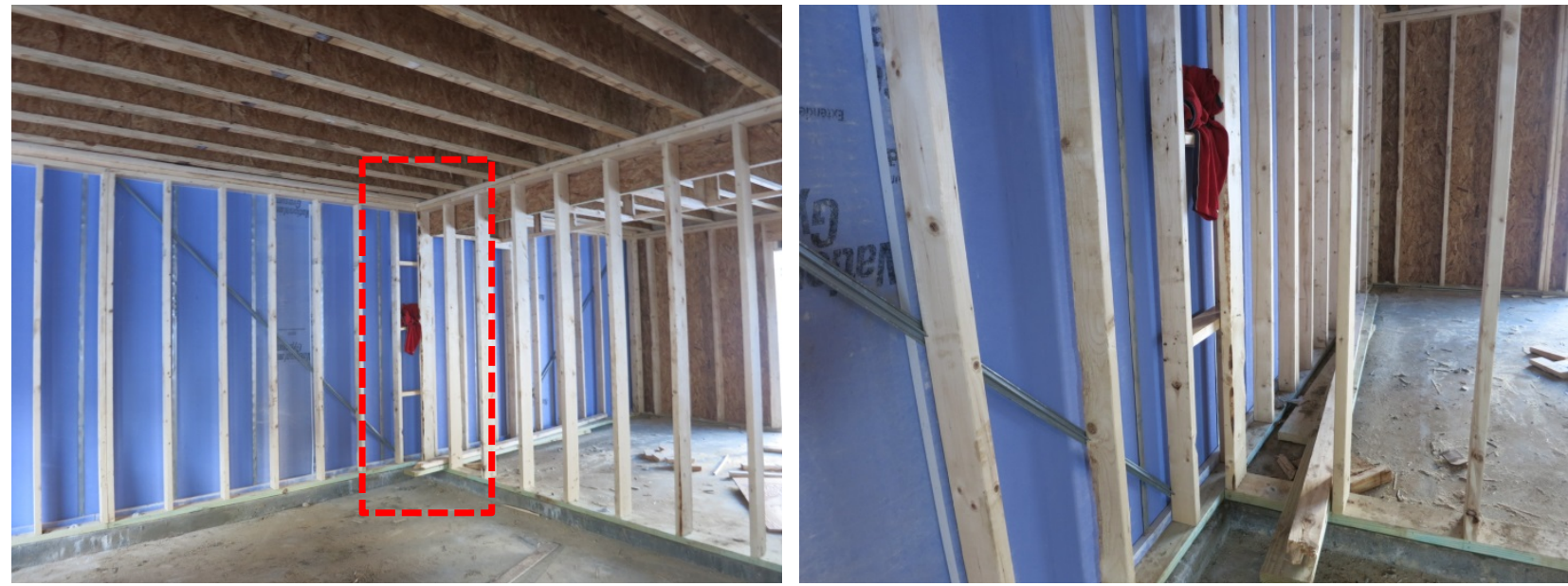

Figure 52. Garage tee wall intersection, showing ladder blocking

Where the area separation wall extends to the exterior between units, there is typically a "jog" between the exterior walls (location C). This detail apparently had leakage issues (between 6702 and 6704), as shown in Figure 53. This area should have received the tape air seal "capping" the joints and at the slab-to-wall interface.
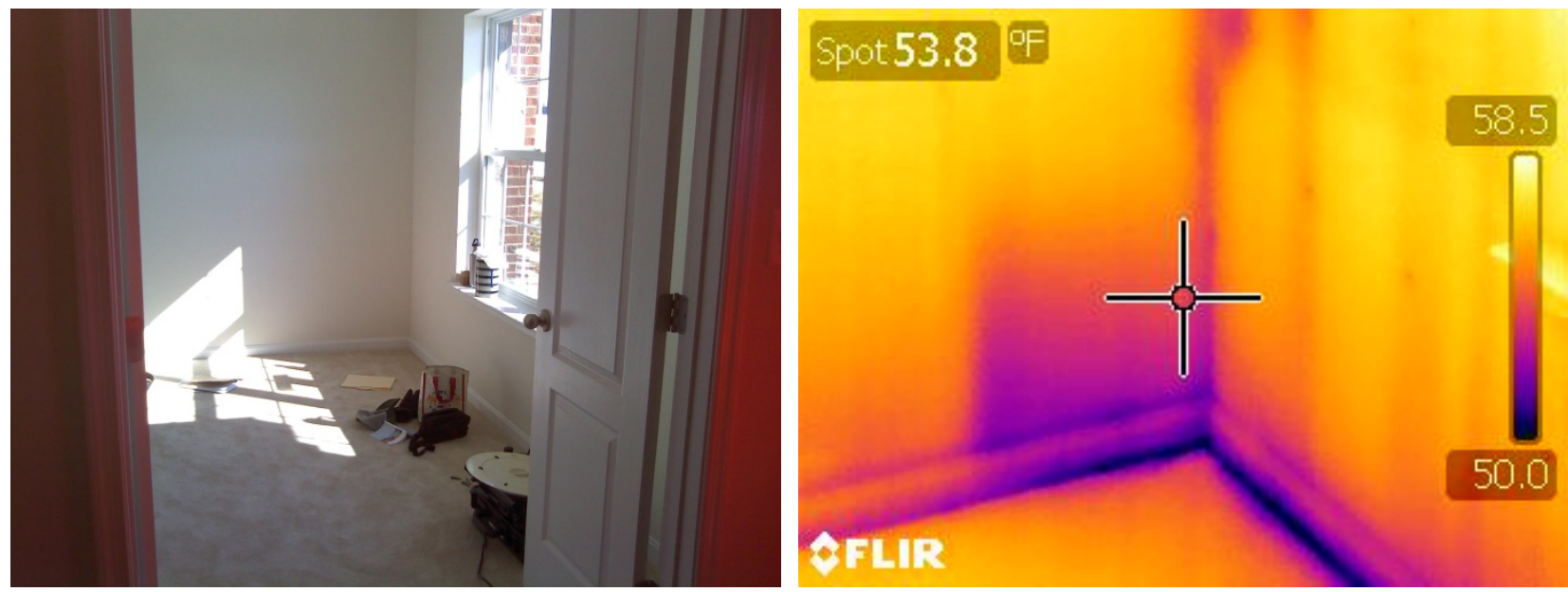

Figure 53. Area separation wall "jog" at exterior, location C

At location D in Figure 47, the rear portion of the second floor is over the unconditioned garage. During depressurization, there was substantial outside air leakage inside the area separation wall (Figure 54). This was seen in Unit 6706, and Unit 6702 had the same pattern.

The 1 -in. cavity between the interior wall $2 \times 4$ framing and the double 1 -in. shaft liner board should have been sealed with expanding foam (Figure 12); however, this detail was apparently omitted or improperly done. A similar situation was seen at the building in frame: this location should be filled with 1-in. gypsum fireblocking, but it was missing at one unit (Figure 55). 


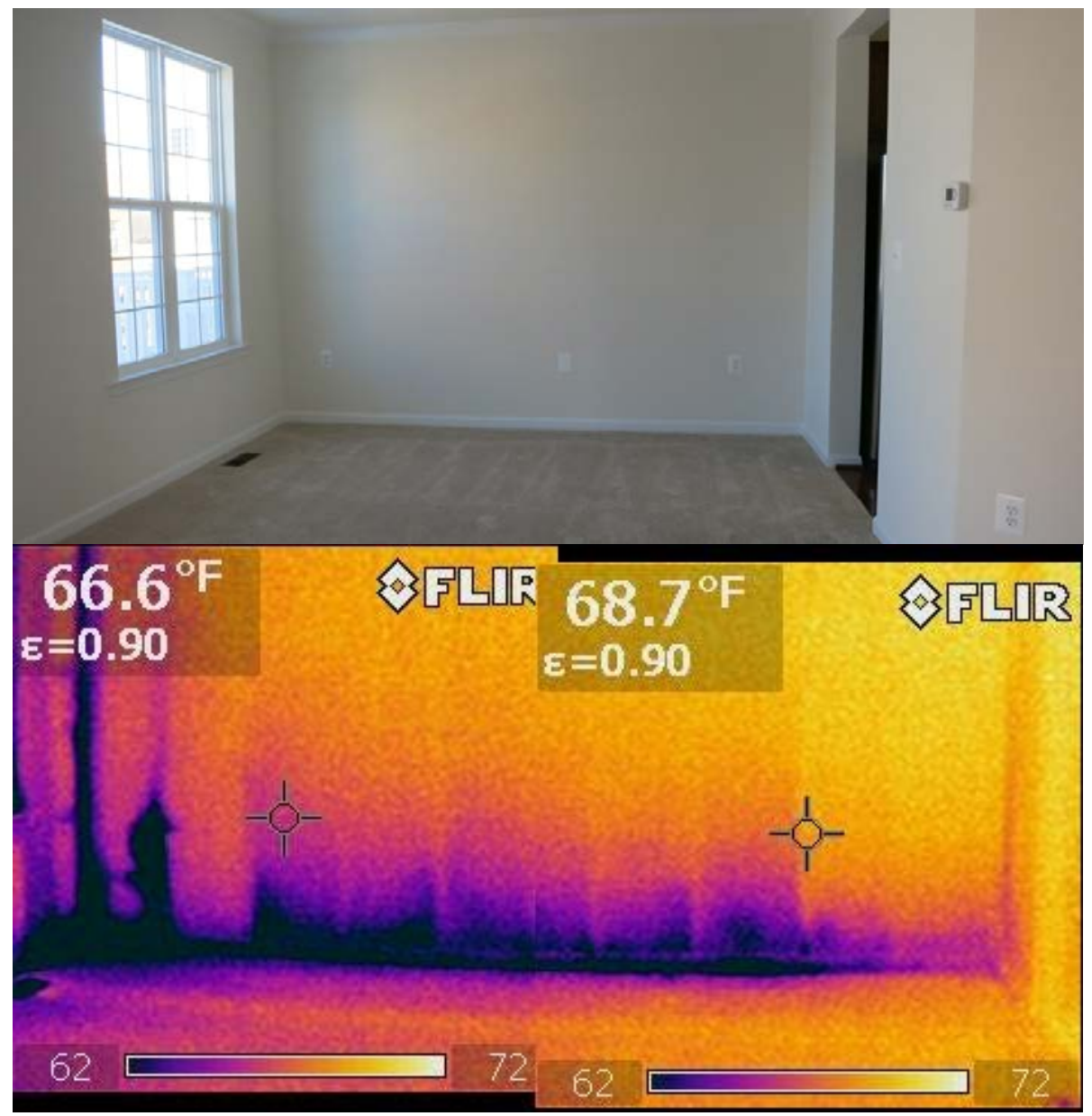

Figure 54. Second-floor living room leakage pattern over garage, Unit 6706, location D
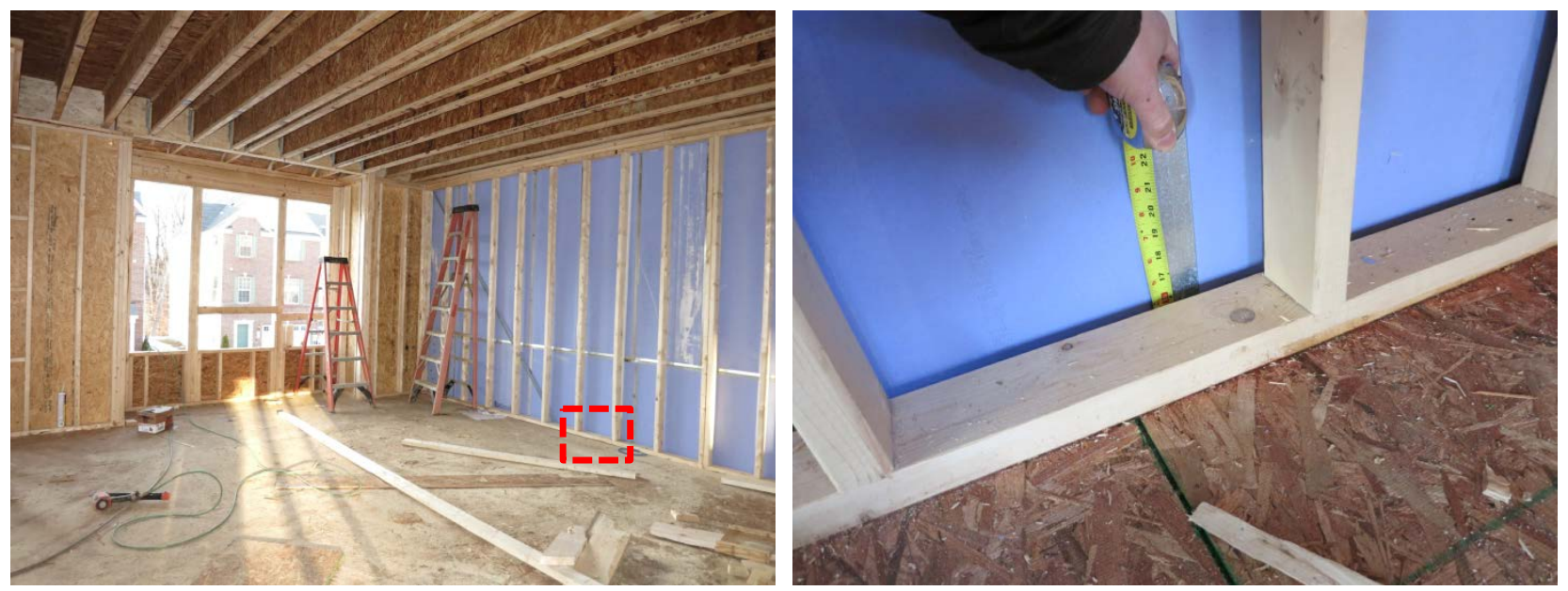

Figure 55. Missing gypsum fireblocking at garage ceiling rim joist area

The vaulted ceiling at the third-floor bedroom is adjacent to the area separation wall, and some leakage was noted at the vault line joint (Figure 56). 


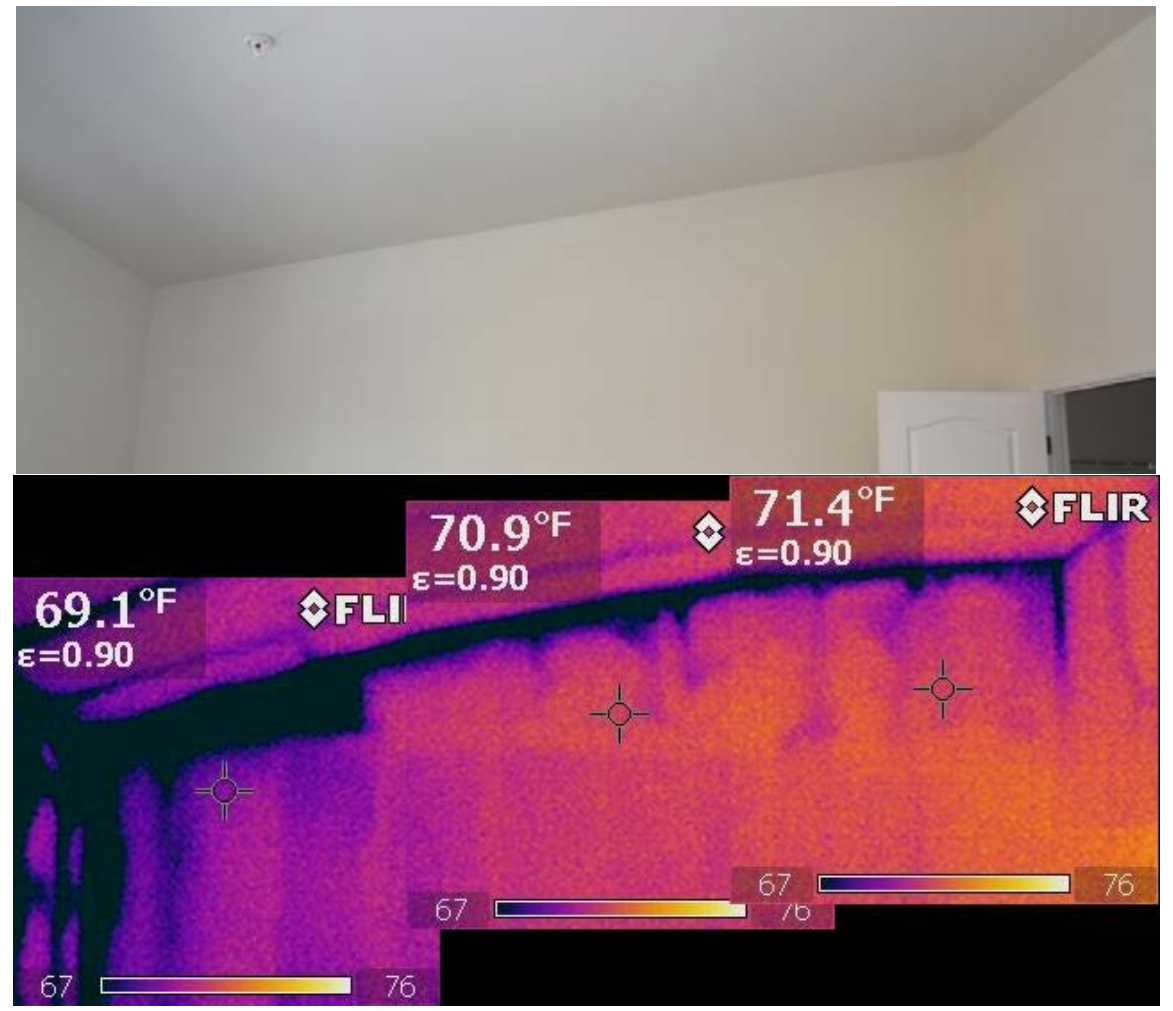

Figure 56. Leakage at vaulted ceiling connection to separation wall, Unit 6706

This area was inspected in another unit's attic (Unit 6704; Figure 57). The joints appeared to be sealed with expanding foam where they were inspected; however, access is difficult, so quality control issues are unsurprising.
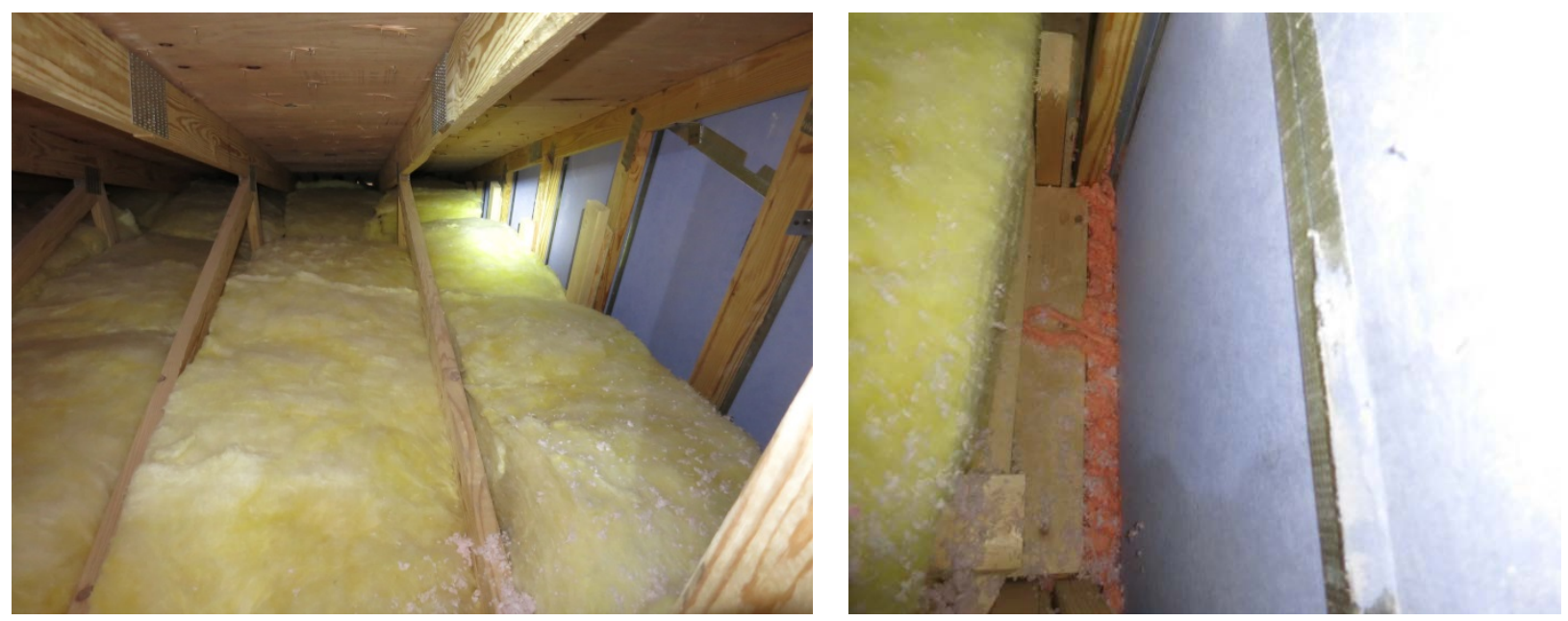

Figure 57. Vaulted attic and separation wall conditions, Unit 6704

The exterior was examined in the morning with an infrared camera (Figure 58); there was no sign of gross air leakage in the attic at the area separation wall. This would have been manifested as a warm thermal "plume" at the party wall, or significant snow melt/ice damming at the area 
separation wall. However, heat loss from the house would be diluted by outdoor air from attic ventilation.

Heat loss and snow melt caused by area separation wall leakage are worse if the stud bay cavity is extended into the attic (unlike these units), creating a "chimney" to direct interior heat to the roof sheathing.
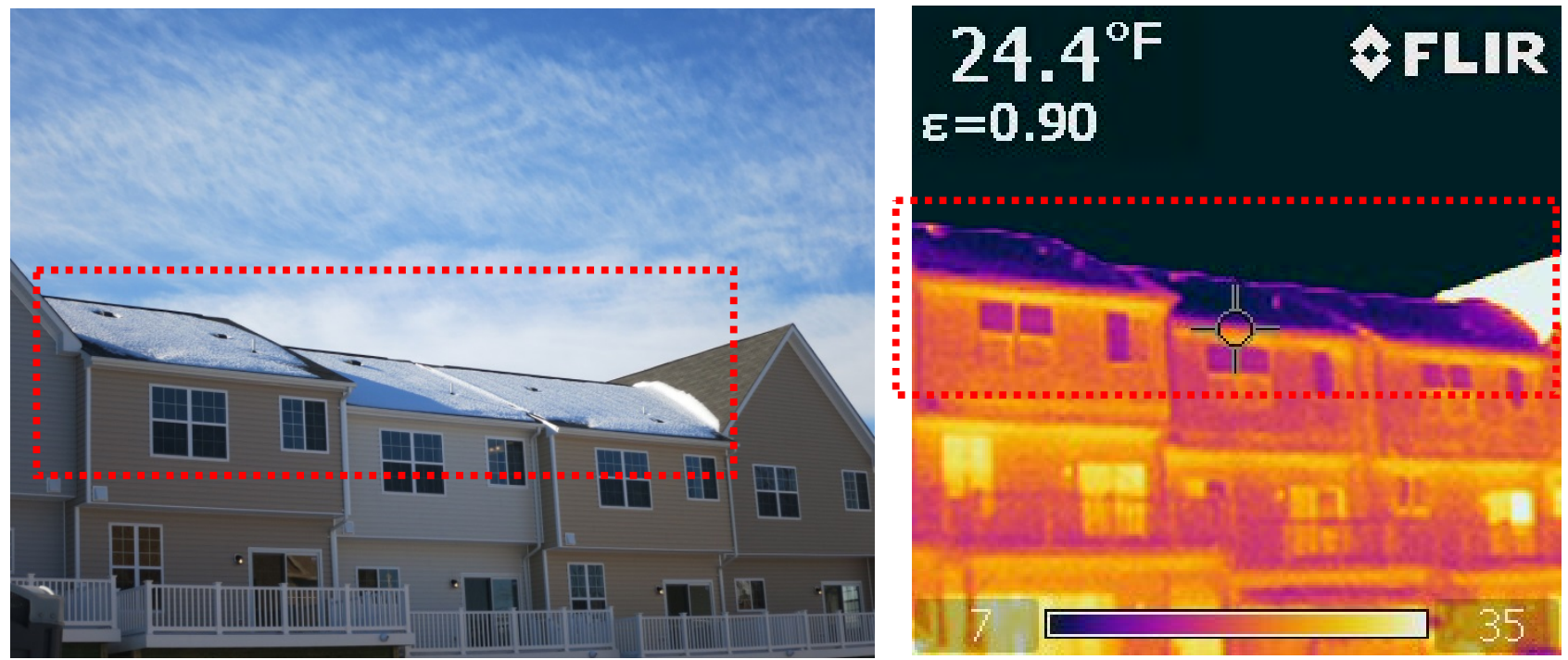

Figure 58. Exterior infrared of three middle unit attic demising walls

Mechanical penetrations through the area separation wall were often associated with air leakage from the outside. For instance, this was seen at an electrical receptacle in Unit 6706; there is a "stub" of interior-exterior wall here at the jog, as shown in Figure 60. The area separation wall stub was called out for having taped connection details, per Figure 13.
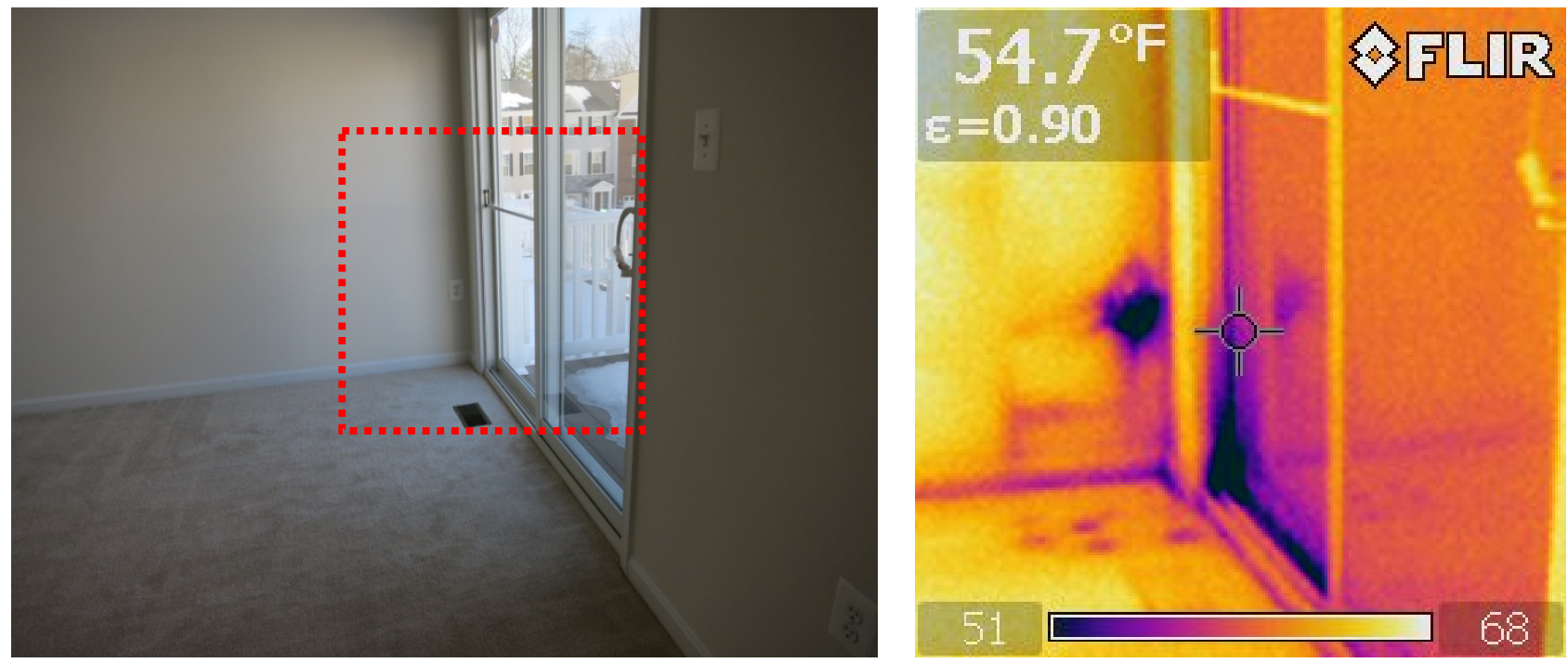

Figure 59. Area separation wall leakage at exterior "jog," Unit 6706 


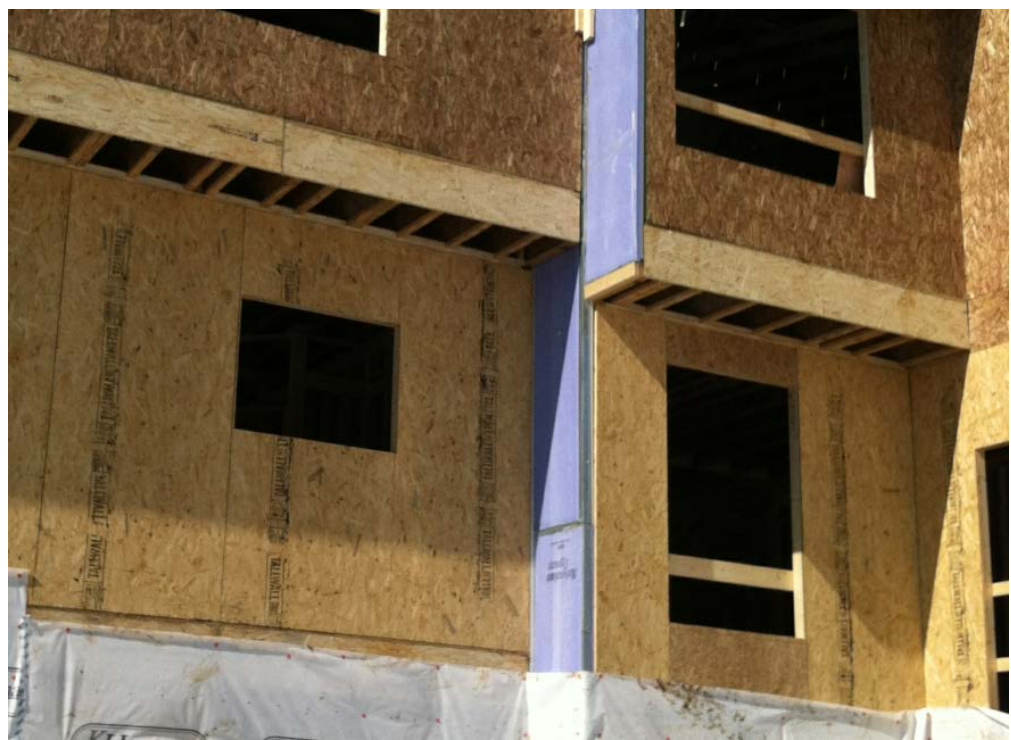

Figure 60. Separation wall "jog" at second and third floors, frame building

Another example of exterior air leakage at the area separation wall is shown in Figure 61 (light fixture) demonstrating that the wall cavity is connected to the exterior, either at the attic connection, or the exterior "jog."
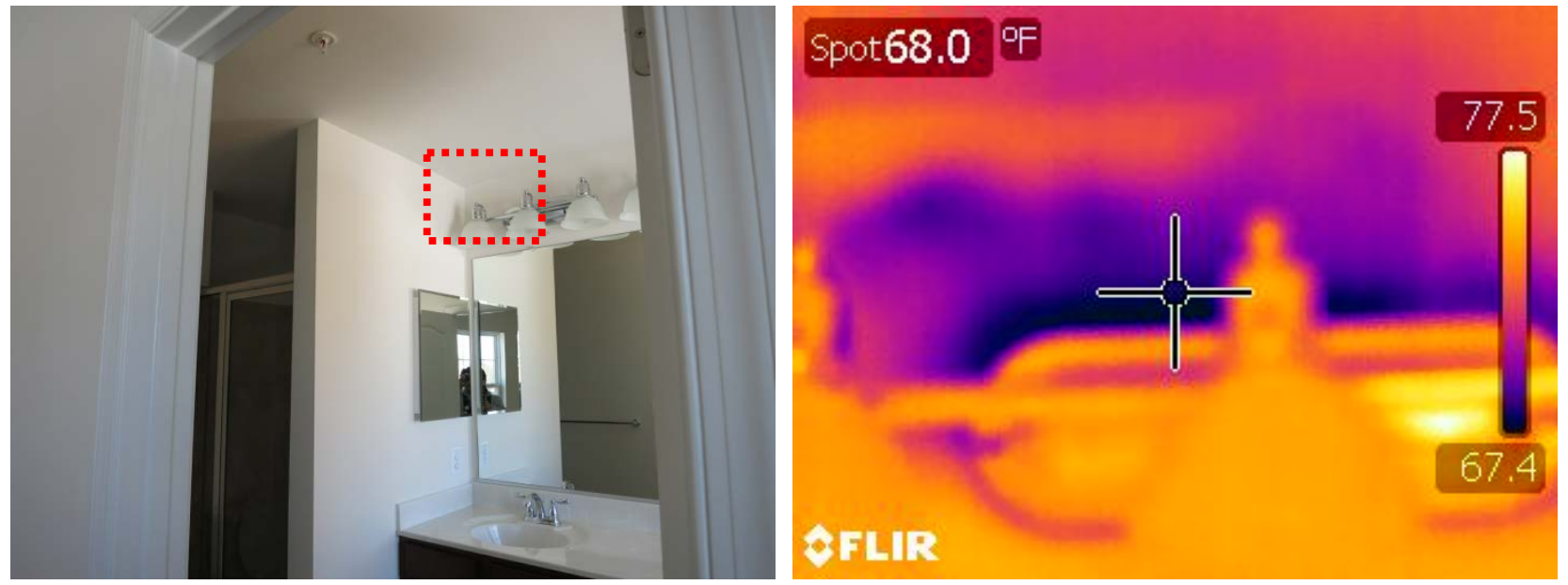

Figure 61. Air leakage at light mounted on area separation wall

Inter-unit leakage at the $\mathrm{H}$-stud and C-channel joints of the double 1-in. gypsum board wall was not examined in this testing, because the area separation wall would have had to be disassembled.

\subsection{Interstitial Pressure Measurements}

Interstitial pressure measurements were used to demonstrate wall cavities' connection to interior versus exterior, per Lstiburek (1998). The pressure within the cavity provides some indication of the relative leakage to the interior of the unit versus the exterior (or adjacent units), when the pressure difference $(\Delta \mathrm{P})$ is compared to the total unit depressurization/pressurization. 
Two adjacent middle units (6702 and 6704) were depressurized in parallel to $-50 \mathrm{~Pa}$; this operation should nominally null or neutralize the pressure difference in the area separation wall between the two units. This wall was taped at the exterior gypsum or OSB sheathing (see Figure 7 and Figure 17). Pressures were measured at the openings around electrical receptacles (Figure 62). The resulting pressure measurements are shown in Figure 63 through Figure 65.
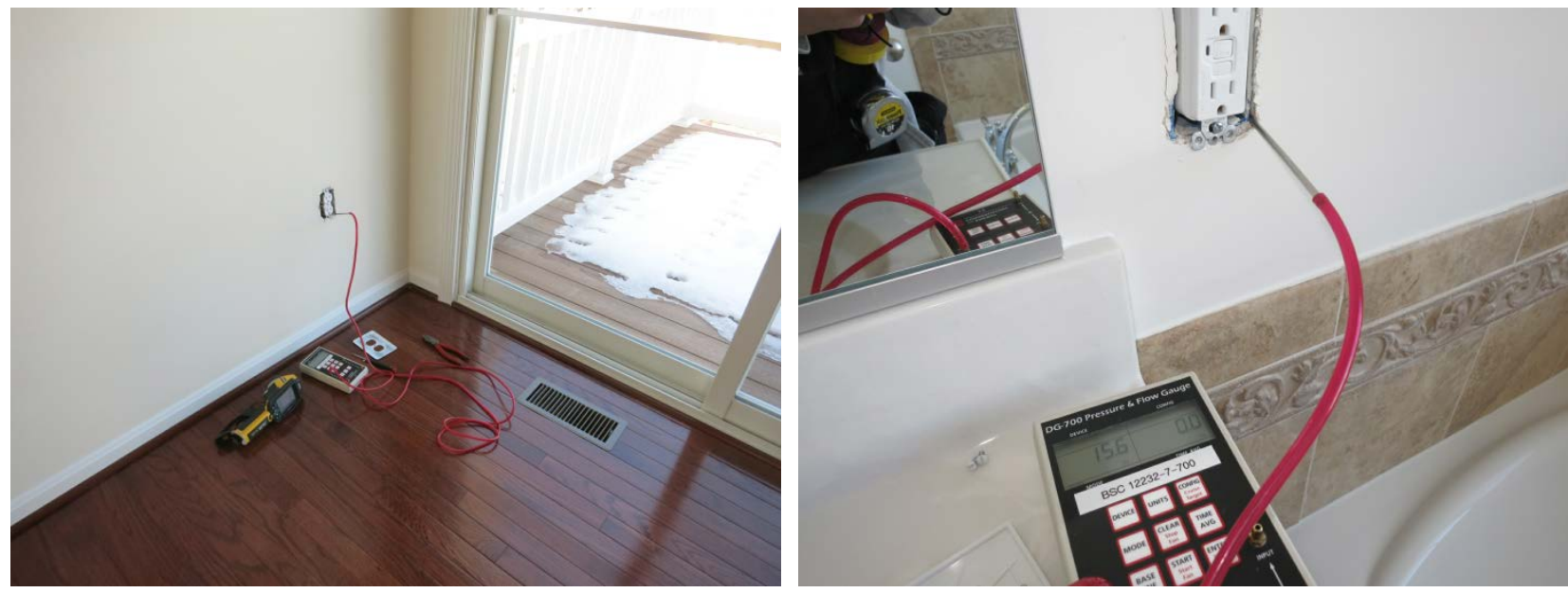

Figure 62. Pressure difference measurements at electrical box penetrations

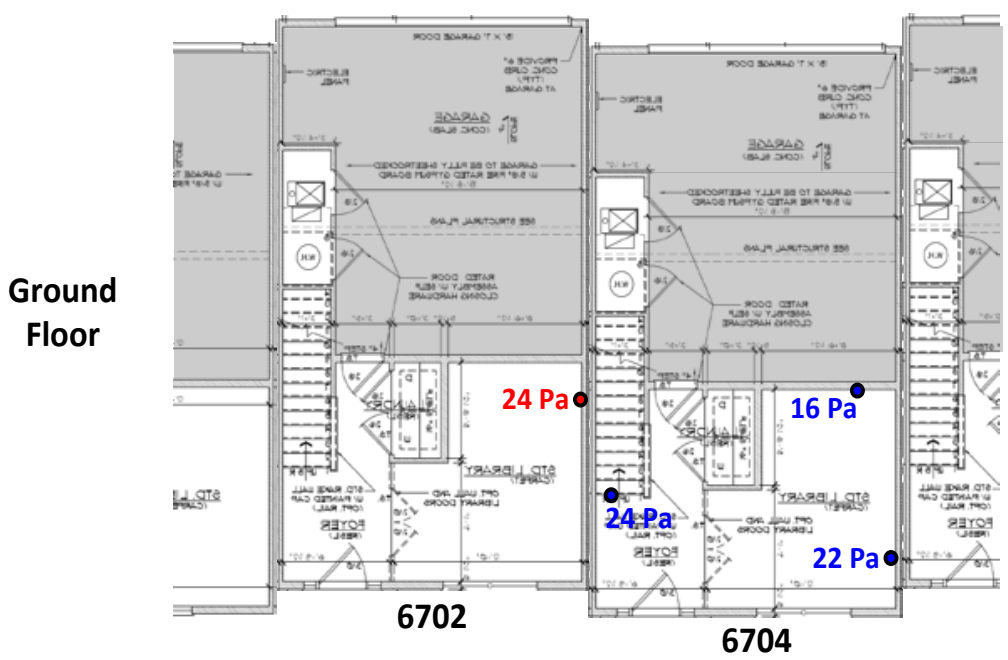

Figure 63. Pressure difference measurements, first floor (6702-6704) 


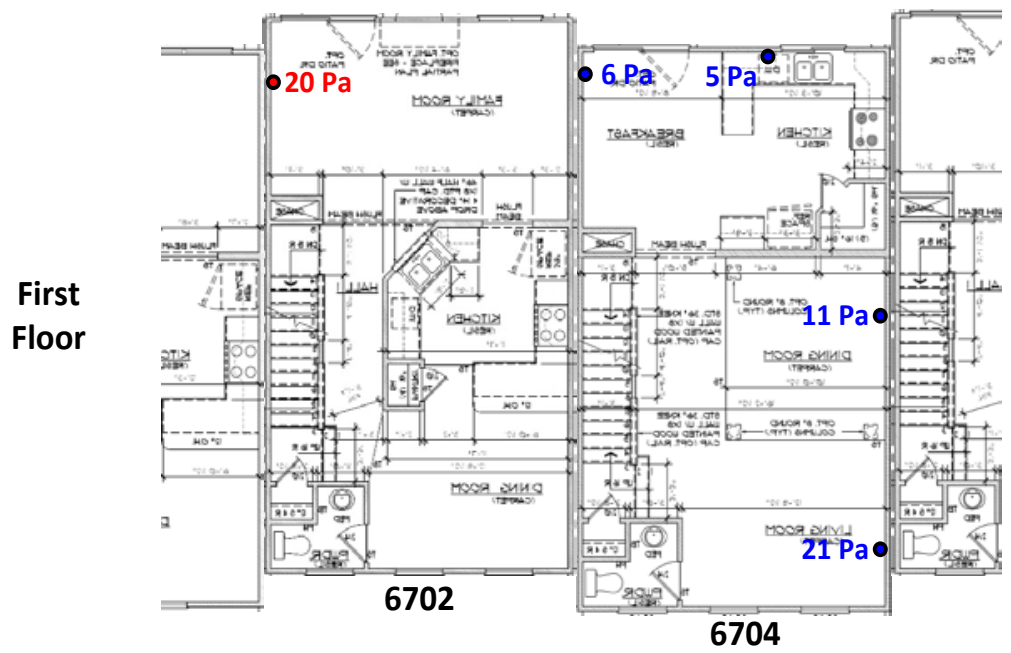

Figure 64. Pressure difference measurements, second floor (6702-6704)

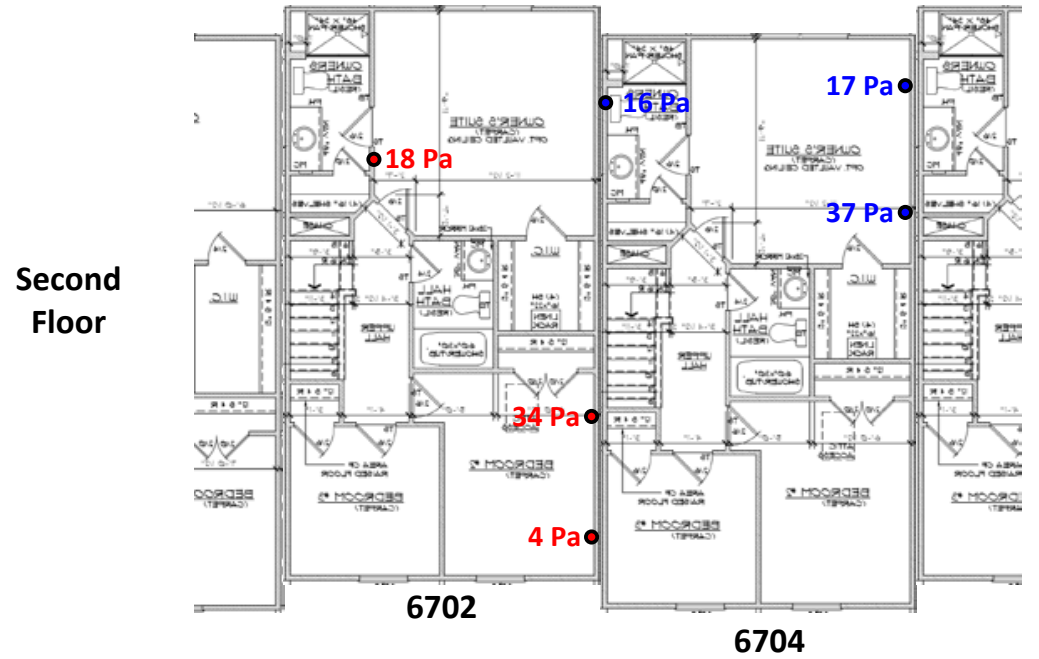

Figure 65. Pressure difference measurements, third floor (6702-6704)

Observations from these measurements included:

- The area under the stairs in Unit 6704 is still roughly half inside/half outside (24 Pa), despite the nulled test. This suggests that the leakage at the stairs is due to a connection to the mechanical room in the garage (rather than at the area separation wall alone).

- The area separation wall cavity near the garage in Unit 6702 has a large pressure drop (24 $\mathrm{Pa}$ ), despite the wall being "nulled" by the two fans. This suggests substantial leakage to the garage from this cavity (per Figure 51).

- Pressure differences to the nulled area separation wall were as low as 4-6 $\mathrm{Pa}$ in some cases, suggesting that the depressurization field has reached those cavities. However, this is not a "perfect" result (i.e., $0 \mathrm{~Pa}$ difference), which shows that the nulling test is not a complete elimination of air leakage between units. Interstitial cavities between the two nulled units result in a gradient of pressures through the various air spaces. 
- Other pressure differences into the nulled area separation wall were higher: the third floor bedroom was $34 \mathrm{~Pa}$, suggesting substantial leakage to the attic from the area separation wall cavity.

- Pressure differences to the nonnulled area separation walls ranged from 10-37 Pa, with $20 \mathrm{~Pa}$ measurements typical. This suggests that - as discussed elsewhere-there is substantial leakage from the area separation wall cavity to exterior or other units.

\subsection{Garage Connection Testing}

Previous measurements and observations suggest substantial air leakage to the garage. Multipoint blower door tests were run with the garage door open and closed in Unit 6706 (middle, "improved" details, no sheathing tape), as shown in Figure 66. The difference between the garage door open/door closed tests was $8 \%$ of the result (1336 versus 1232 CFM50).

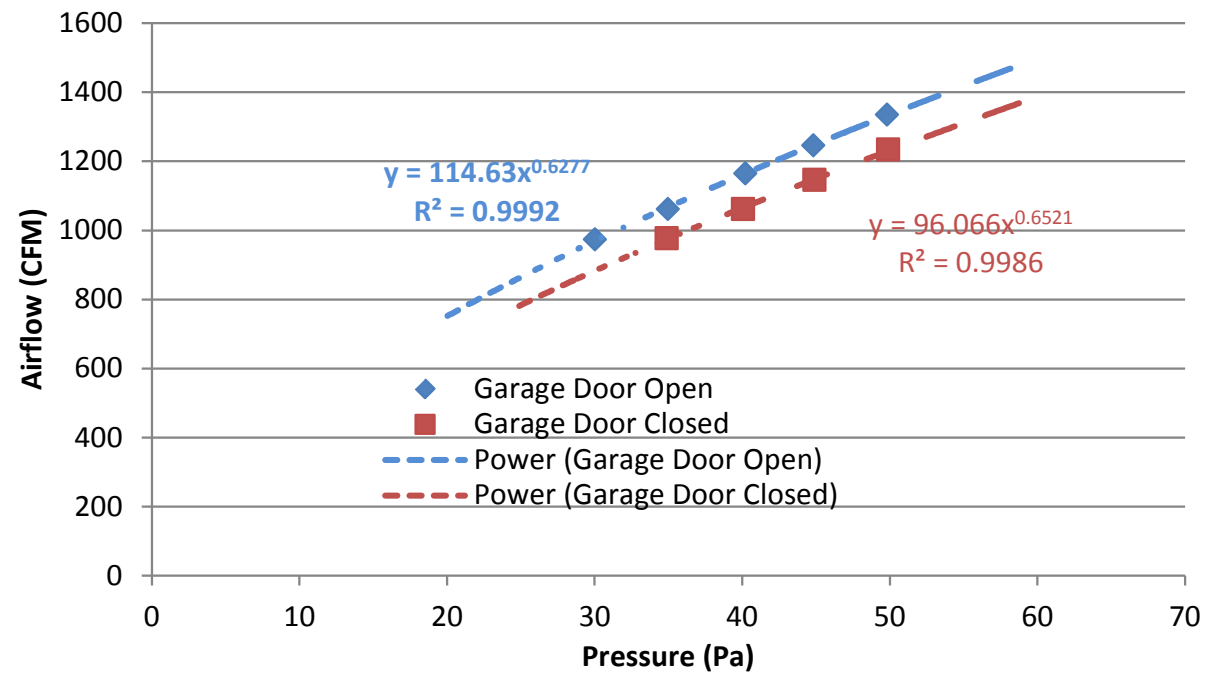

Figure 66. Air leakage results with garage door open and closed, Unit 6706

During the "door closed" test, the pressure difference from the unit to the garage was measured: the garage was consistently connected $50 \%$ to the unit. This implies that leakage from the garage to the exterior (i.e., around a leaky garage rollup door) is equal to the leakage from the unit to the garage. This has negative consequences for energy and indoor air quality (contamination from garage pollutants).

Hult and Sherman (2014) show that single-fan tests generally have higher uncertainty (when calculating relative leakage areas) than two fans in parallel tests (e.g., a guarded/nulled test). However, this test could not be performed because these plans did not include a swinging door from the exterior to the garage. Zone pressure diagnostics would have required a known sized opening from the garage to the exterior; this was not a simple matter with the roll-up garage door. 

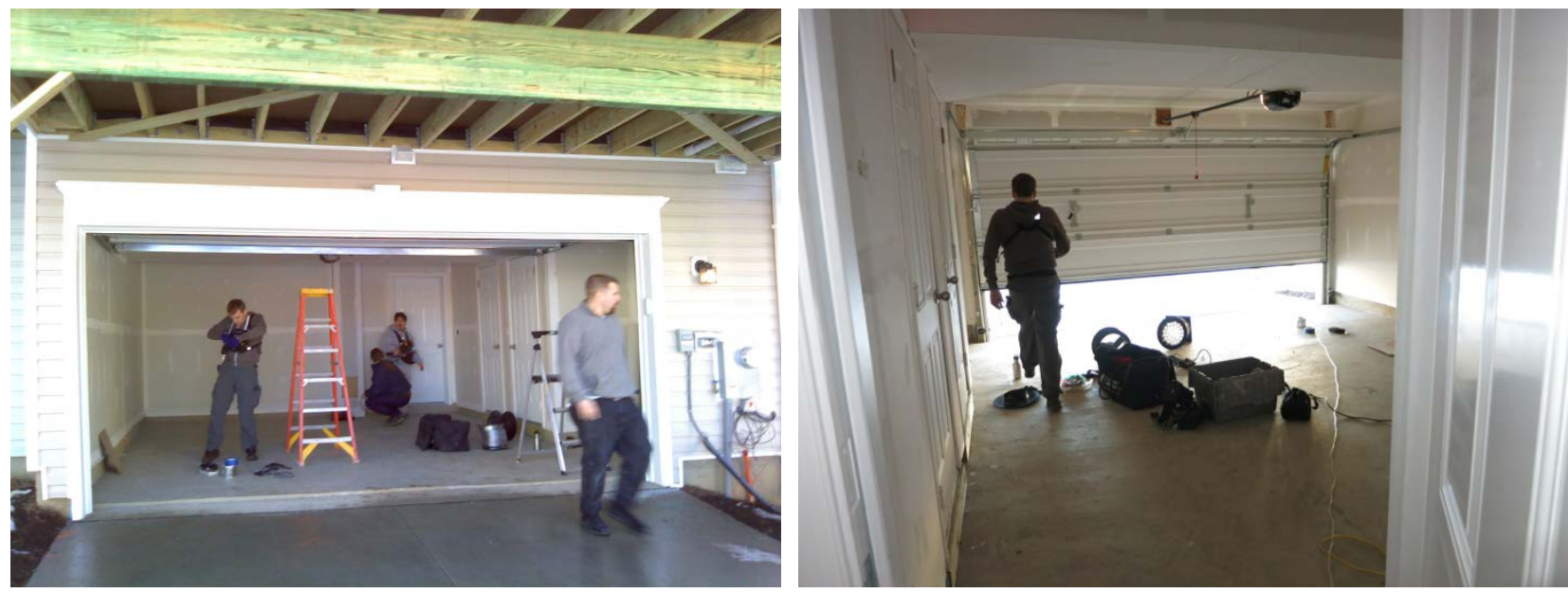

Figure 67. Unit 6706 garage overview

\subsection{Mechanical Room Connection Testing}

Previous testing indicated that the mechanical room is another source of leakage. Leakage locations likely include the swinging doors (despite weather stripping), and connections from garage gypsum board imperfections (e.g., gypsum board-to-foundation stem wall connection) into the framing cavities.

For instance, the overhead bulkheads required for ductwork running across floor framing (Figure 67) connect floor framing cavities across the width of the garage that are well-connected in turn to the interior. If draftstopping is omitted at the end of the bulkheads, they will be well connected to the area separation wall cavities (Figure 12).

Testing similar to the garage work was done in Unit 6707, measuring the pressure difference from the house to the mechanical room during a blower door test (with the garage door open). The mechanical room was consistently $42 \%$ exterior $/ 58 \%$ interior.

A nulled test was performed using a TEC Minneapolis Duct Blaster installed in the mechanical room door (Figure 68), with the unit and mechanical room simultaneously depressurized. Hult and Sherman (2014) note that a two-fan "pressure balancing" test has lower uncertainty than most single-fan methods. However, the authors also noted that the two-fan Herrlin and Modera method has even lower uncertainty than pressure balancing; this method will be considered in future work. 

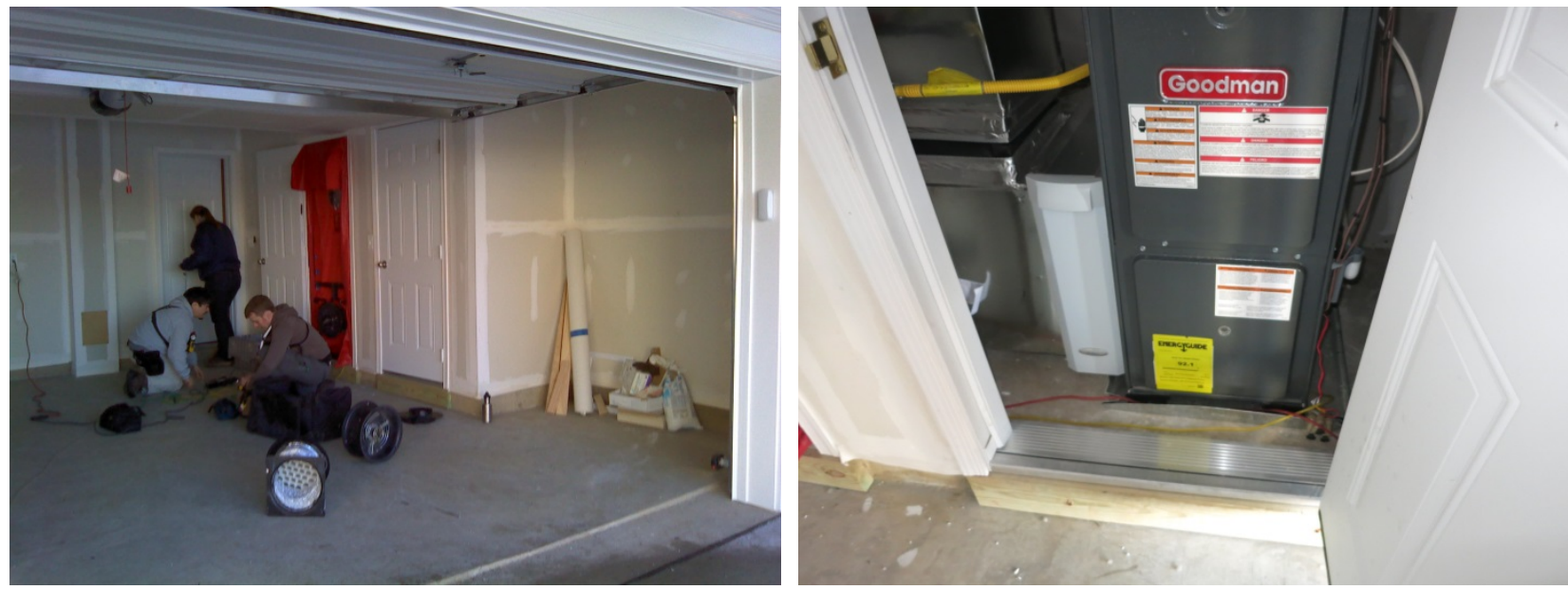

Figure 68. Mechanical room located in rear garage (Unit 6706)

TECLOG3 output and calculated results are shown in Figure 69 and Figure 70 for the nulled and nonnulled tests.

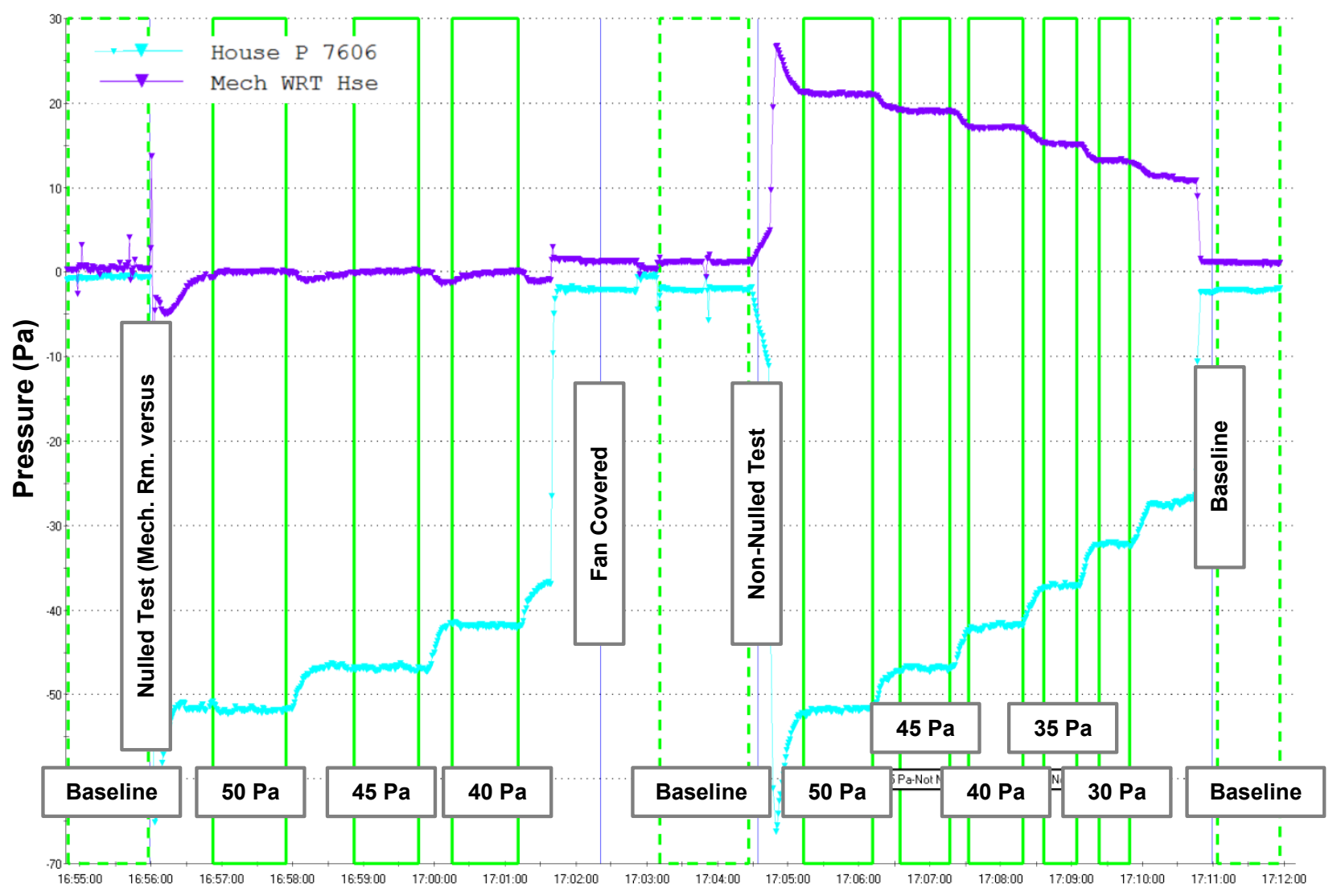

Figure 69. Nulled and nonnulled testing of the garage mechanical room TECLOG3 output 


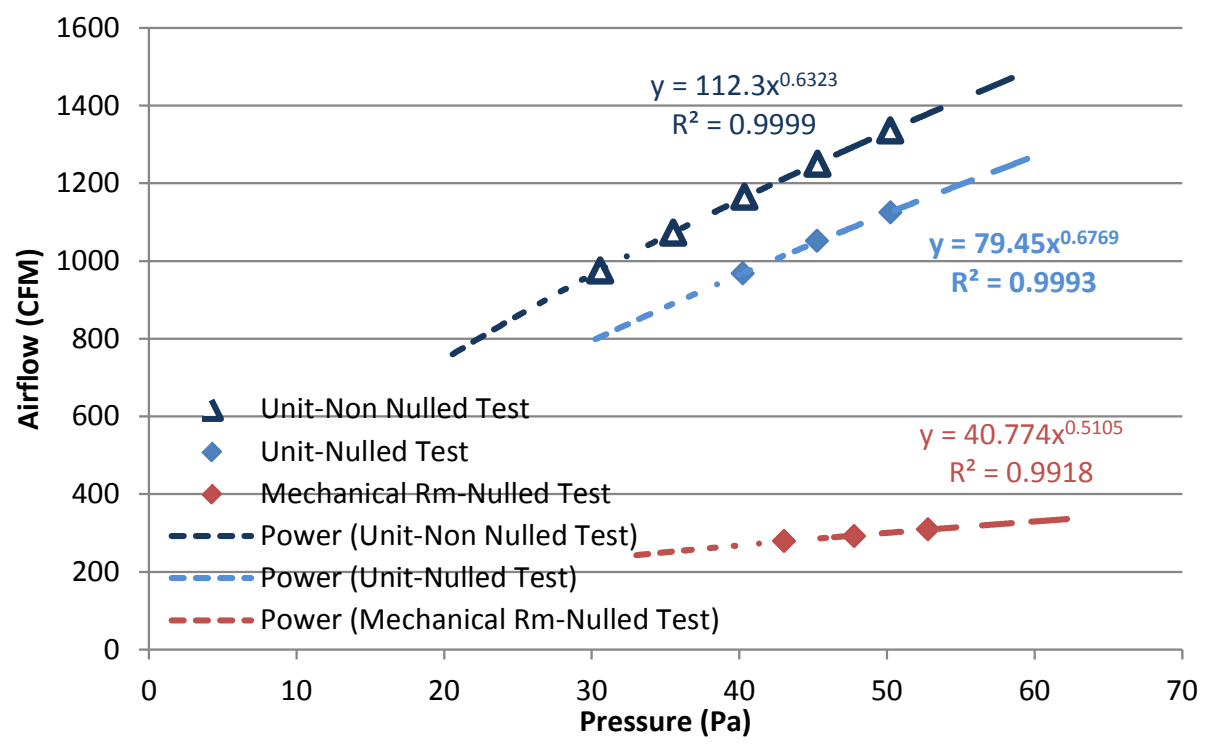

Figure 70. Garage mechanical room nulled and nonnulled tests, Unit 6706

Results are summarized in Table 6, with the CFM50 (from the multipoint test), and calculated EqLA (in square inches). The sum of the two nulled tests $(1122+300=1423$ CFM50) is not equal to the nonnulled test (1332 CFM50), even though both tests nominally measure leakage of unit and mechanical room to the exterior. The explanation is that during the nonnulled test, the pressure field does not extend completely to the mechanical room (21 $\mathrm{Pa}$ in the mechanical room, when the unit was at $50 \mathrm{~Pa}$ test pressure), resulting in a lower measured flow. But the results indicate that roughly $20 \%$ of the unit's total leakage originates at the mechanical room. These results also allow calculation of the connection of the mechanical room to the unit's interior space (210 CFM50/22 in. ${ }^{2}$ EqLA). EqLA is considered a reasonable representation of actual changes in air leakage open areas (TEC 2014).

Table 6. Results of Mechanical Room Air Leakage Connection Testing

\begin{tabular}{c|c|c}
\hline Description & CFM50 & EqLA (in. ${ }^{2}$ ) \\
\hline Unit to Exterior (Nonnulled) & 1332 & 137 \\
Unit to Exterior (Nulled) & 1122 & 116 \\
Mechanical Room to Exterior (Nulled) & 300 & 31 \\
Sum of Nulled Tests (Calculated) & 1423 & 147 \\
Mechanical Room to Unit (Calculated) & 210 & 22 \\
\hline
\end{tabular}

The mechanical room is well connected to the interior, as it is intentionally heated (see supply register in Figure 71 right). There are also many connections from the mechanical room to interstitial spaces (wall stud and floor joist cavities) from the variety of mechanical penetrations, including furnace supply/exhaust pipes (Figure 71, right), air conditioner refrigerant lines (Figure 72), supply and return duct penetrations, pipe penetrations (Figure 72), and other substantial openings (Figure 73 is a clear opening into the floor joist cavity). If the floor joist cavity is connected to the exterior or the garage, it is in turn connected to the interior. These penetrations are difficult to access and seal, given the congestion in the small mechanical room. 

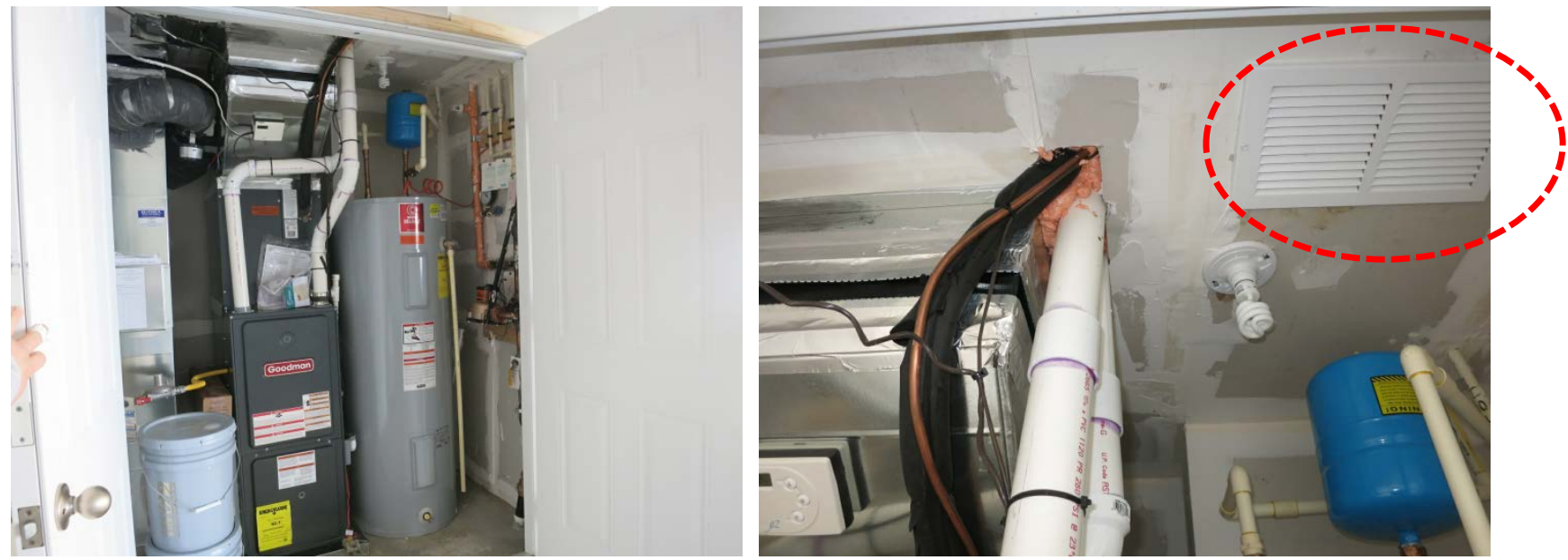

Figure 71. Furnace and water heater at mechanical room (Unit 6700); supply register
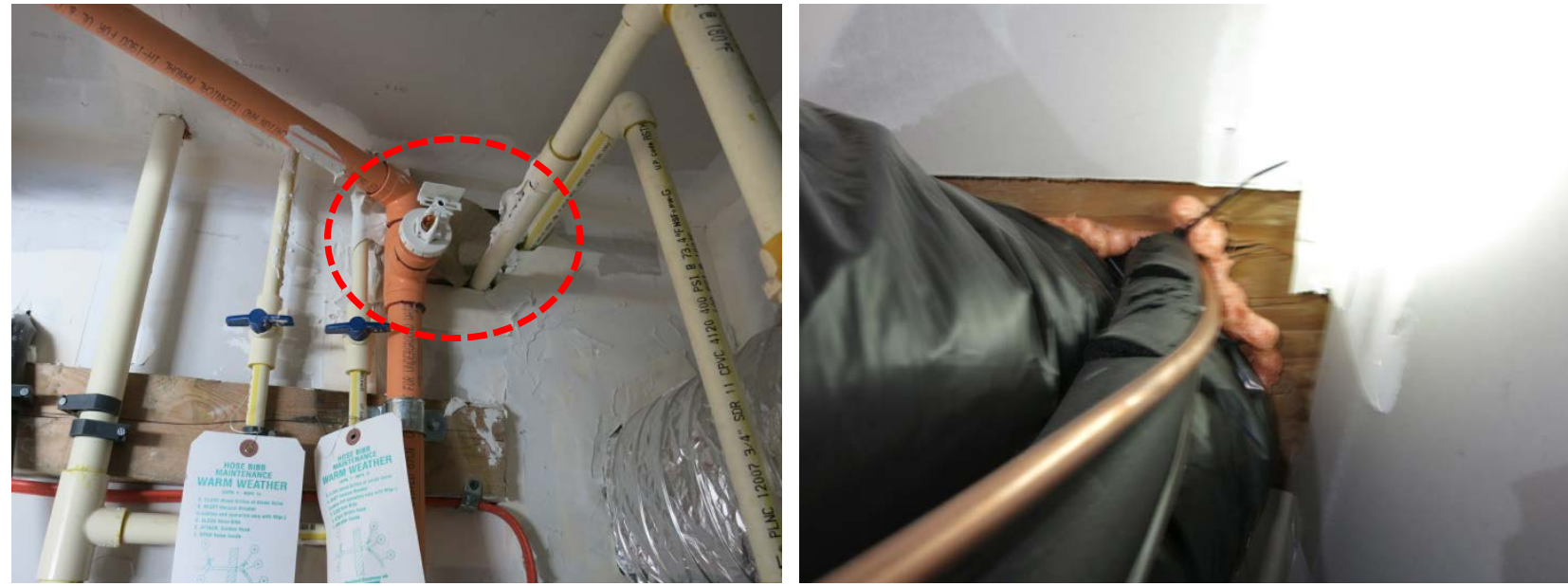

Figure 72. Ceiling and wall penetrations at mechanical room (Unit 6702)
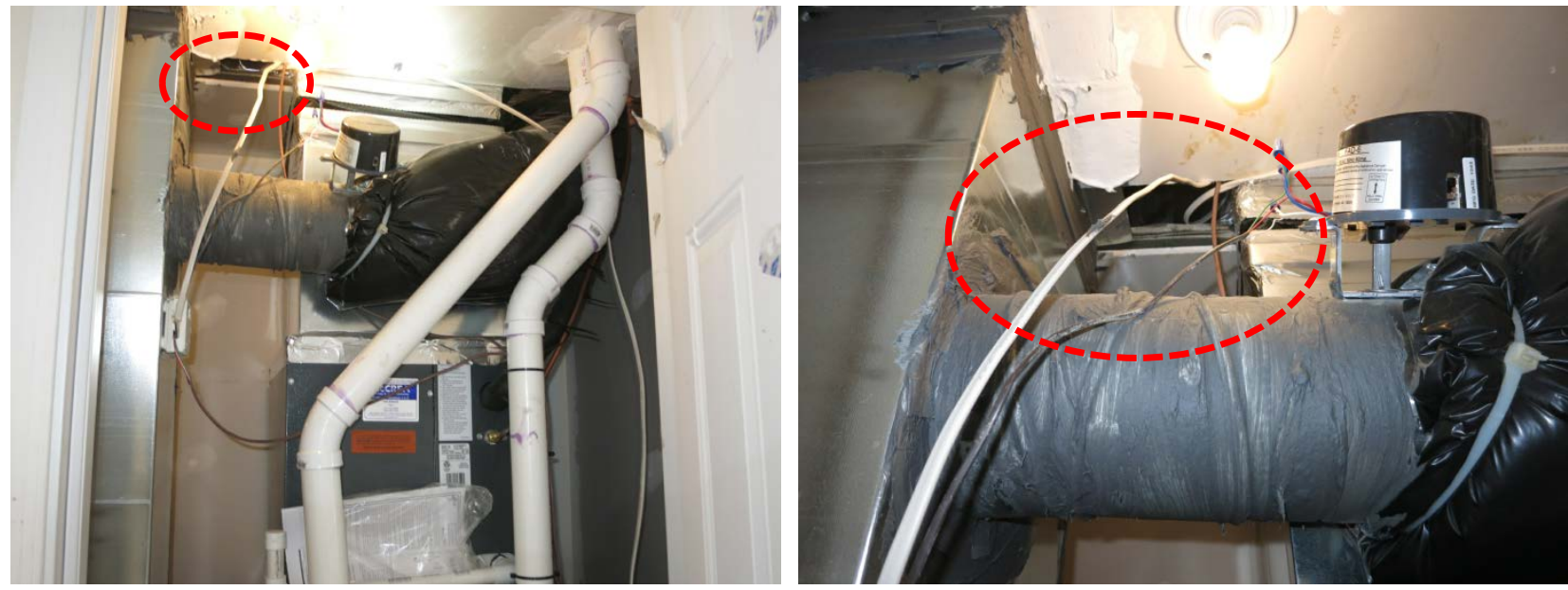

Figure 73. Ceiling penetrations at mechanical room (Unit 6702) 


\subsection{Tape Testing}

At the conclusion of Day 1 testing, samples of sheathing tape were adhered to seams at the building in frame. Geometries included flat OSB seams (Figure 74) and an OSB-to-gypsum outside corner (Figure 75). One tape was 3M All Weather Flashing Tape 8067 (high tack acrylic adhesive tape with a 10 mil proprietary backing), which Holladay (2013a, 2013b) found to be a good performer on OSB. The other was Protecto Wrap "Super Stick Building Tape" (polyester metalized foil acrylic adhesive tape), which is intended for sealing of exterior sheathing (among other uses). Both tapes had excellent initial adhesion, even at the cold temperature during application $\left(30^{\circ} \mathrm{F}\right)$. The wall-to-foundation joint was not taped in this work.

The intent was to leave the tapes in place and have the builder document the performance over time, after temperature cycling and exposure. However, house wrap was applied to the entire building the next day, so no results were obtained. This experiment could be repeated at other jobsites or at a controlled exposure site.
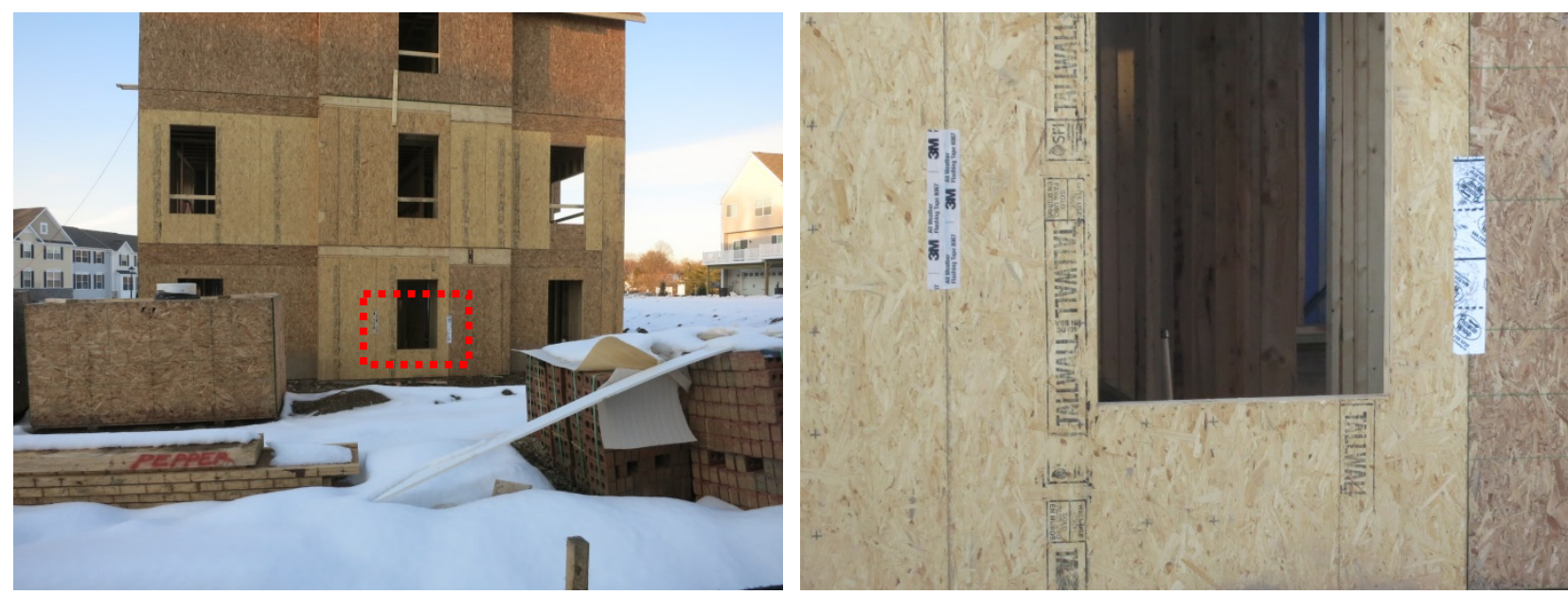

Figure 74. Test application of two types of adhesive sheathing tape
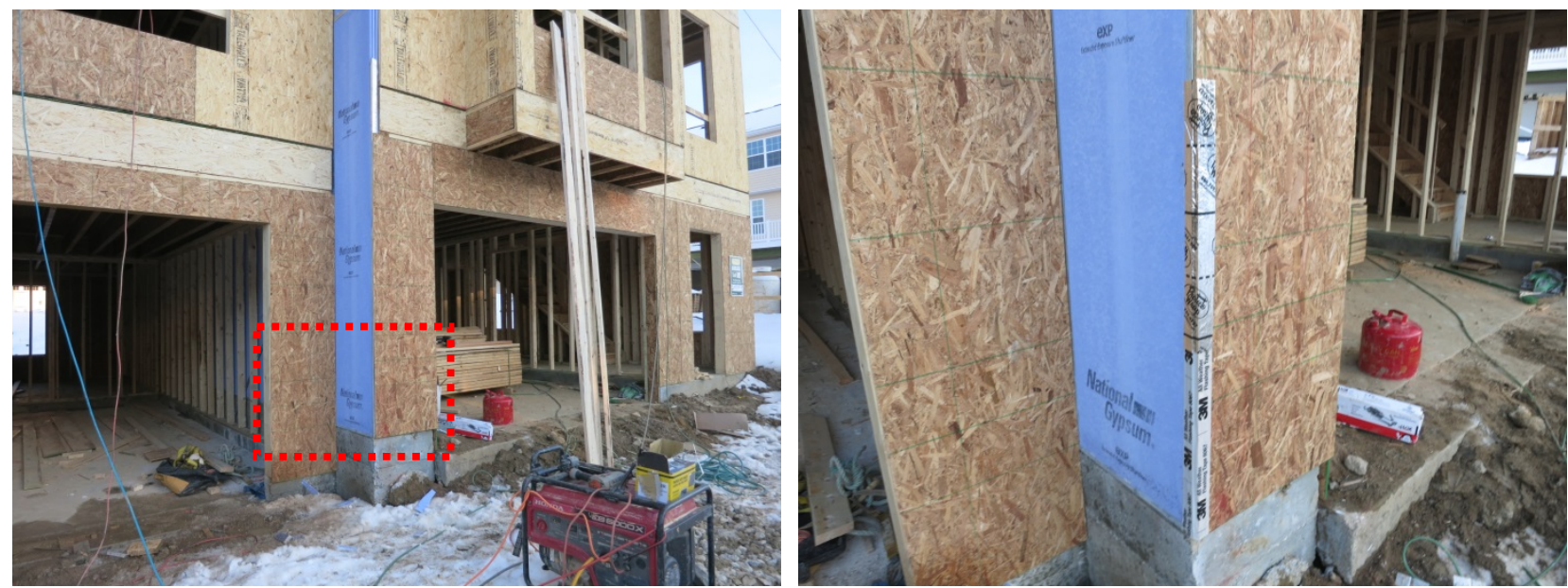

Figure 75. Test application of two types of adhesive sheathing tape 


\section{Analysis and Recommendations}

\subsection{Summary of Air Leakage Results}

A summary of the unguarded/nonnulled and guarded/nulled testing is shown in Table 7 (with results in terms of $\mathrm{ACH} 50$ ), and Table 8 (with CFM50/ $\mathrm{ft}^{2}$ enclosure).

Table 7. Unguarded and Guarded Air Leakage Test Results, With ACH50

\begin{tabular}{c|c|c|c|c|c}
\hline \multirow{2}{*}{ Unit } & \multirow{2}{*}{ Notes } & \multicolumn{2}{|c|}{ Unguarded } & \multicolumn{2}{c}{ Guarded } \\
\cline { 3 - 6 } & & CFM50 & ACH50 & CFM50 & ACH50 \\
\hline $\mathbf{6 7 0 0}$ & End-improved + taped & 1085 & 3.8 & 953 & 3.4 \\
$\mathbf{6 7 0 2}$ & Mid-improved + taped & 1329 & 5.5 & 1057 & 4.4 \\
$\mathbf{6 7 0 4}$ & Mid-conventional & 1255 & 5.2 & 1004 & 4.2 \\
$\mathbf{6 7 0 6}$ & Mid-improved & 1330 & 5.6 & 1085 & 4.5 \\
$\mathbf{6 7 0 8}$ & End-improved & 1113 & 3.9 & 989 & 3.5 \\
\hline
\end{tabular}

Table 8. Unguarded and Guarded Air Leakage Test Results, With CFM50/ft ${ }^{2}$ Enclosure

\begin{tabular}{c|c|c|c|c|c}
\hline \multirow{2}{*}{ Unit } & Notes & \multicolumn{2}{|c|}{ Unguarded } & \multicolumn{2}{|c}{ Guarded $^{\mathbf{2}}$} \\
\cline { 3 - 6 } & CFM50 & $\begin{array}{c}\text { CFM50/ft } \\
\text { Enclosure* }\end{array}$ & CFM50 & $\begin{array}{c}\text { CFM50/ft } \\
\text { Enclosure* }^{*}\end{array}$ \\
\hline $\mathbf{6 7 0 0}$ & End-improved + taped & 1085 & 0.22 & 953 & 0.20 \\
$\mathbf{6 7 0 2}$ & Mid-improved + taped & 1329 & 0.31 & 1057 & 0.24 \\
$\mathbf{6 7 0 4}$ & Mid-conventional & 1255 & 0.29 & 1004 & 0.23 \\
$\mathbf{6 7 0 6}$ & Mid-improved & 1330 & 0.31 & 1085 & 0.25 \\
$\mathbf{6 7 0 8}$ & End-improved & 1113 & 0.23 & 989 & 0.20 \\
\hline
\end{tabular}

* This conversion assumes all enclosure surface area, including adiabatic walls.

In both the unguarded and guarded testing, no units met the 3 ACH50 target of the 2012 IECC. As discussed earlier, when this target is calculated in terms of surface area-normalized leakage, it is stringent for these small three-story townhome units $\left(0.16-0.17 \mathrm{CFM} 50 / \mathrm{ft}^{2}\right)$. But the fact that the units do not meet the requirements in the nulled test suggests that the issues are not isolated to area separation wall problems alone (although it might also be due to area separation wall cavity leakage to the exterior).

The results show no improvement associated with taping the exterior sheathing; in fact, some cases were slightly worse. The "conventional" construction middle unit performed better than the "improved" detail middle units.

Unfortunately, the experiment was hampered by the addition of other variables, such as the builder's additional attic air sealing at Unit 6704 ("conventional"). Another uncontrolled variable was a front protruding bay in a single middle unit (Unit 6702, taped/improved; see Figure 29 and Figure 30). Infrared observations revealed that some details that were in the experimental plan (e.g., air sealing at interior wall top plates) were not consistently executed. A similar example was the lack of sheathing taping at the overhanging floor detail (per Figure 27). Overall, better 
results would require tighter control of experimental variables, or a larger sample size. On the other hand, close supervision of air sealing details would have only demonstrated that good airtightness can be achieved if energy specialists supervise the work closely.

The literature indicates that taped sheathing is useful for achieving very stringent airtightness targets (e.g., 1 ACH50 and lower). However, if there are more substantial leaks - as was the case here-the difference will likely be difficult to discern.

The units either achieved or were close to the normalized 0.30 CFM50/ $\mathrm{ft}^{2}$ enclosure standard recommended by Lstiburek (2005b) for multifamily units, the target proposed by Maxwell (2014), and the revised target for ASHRAE 62.2 (Brennan 2014). The units would likely consistently achieve the $0.30 \mathrm{CFM} 50 / \mathrm{ft}^{2}$ standard with some additional air sealing details and/or technologies (e.g., interior spray-applied latex sealant).

Table 9. Unguarded and Guarded Air Leakage Test Results, With $\Delta$ CFM50

\begin{tabular}{c|c|c|c|c|c}
\hline \multirow{2}{*}{ Unit } & \multicolumn{2}{c}{ Notes } & $\begin{array}{c}\text { Unguarded } \\
\text { CFM50 }\end{array}$ & $\begin{array}{c}\text { Guarded } \\
\text { CFM50 }\end{array}$ & \multicolumn{2}{c}{$\Delta$ CFM50 } & \multicolumn{1}{c}{$\begin{array}{c}\Delta \text { CFM50 } \\
\text { CF }\end{array}$} \\
\hline $\mathbf{6 7 0 0}$ & End-improved + taped & 1085 & 953 & -132 & $-12 \%$ \\
$\mathbf{6 7 0 2}$ & Mid-improved + taped & 1329 & 1057 & -271 & $-20 \%$ \\
$\mathbf{6 7 0 4}$ & Mid-conventional & 1255 & 1004 & -250 & $-20 \%$ \\
$\mathbf{6 7 0 6}$ & Mid-improved & 1330 & 1085 & -245 & $-18 \%$ \\
$\mathbf{6 7 0 8}$ & End-improved & 1113 & 989 & -125 & $-11 \%$ \\
\hline
\end{tabular}

The shifts from unguarded to guarded testing were $11 \%-12 \%$ for the end units and $18 \%-20 \%$ for the middle units. This is consistent with leakage caused by connections at the area separation walls, and a reduction proportional to the one versus two area separation walls. However, testing indicated that this nulling was not perfect and that outside air was drawn into the area separation wall framing cavity from the exterior.

\subsection{Recommendations: Conventional Leakage Locations}

The conventional leakage locations that were identified in this report are all details with known solutions. Solving them is primarily a matter of identifying these shortcomings and executing the correct detail consistently. This is largely a matter of educating site personnel, air sealing subcontractors, and construction tradespeople to make them aware of these shortcomings and solutions. In fairness to the builder, the results from this work are worse than previous similar townhomes and other developments; it is entirely possible that these units - and some of the problems seen-were simply outliers.

\subsection{Recommendations: Area Separation Walls}

Details at the area separation walls were found to be sources of air leakage rom adjacent units and the exterior. Problems were seen at the space under the stairwell, the junction over the garage, the tee wall at the garage, the "jog" at the exterior wall, and at the vaulted ceiling wall at the vented attic. Many air leakage issues appeared to be linked to the air barrier failures at the 1in. cavity between the $2 \times 4$ frame wall, and the double 1-in. gypsum panel layer: this cavity results in a network path for air leakage that can be connected across multiple floors. Leakage 
through the double 1-in. gypsum board (at the H-stud and C-channel joints) was not eliminated as a component of the total leakage, however.

One question that must be resolved is the acceptability of various air sealing materials in the 1in. cavity, per Rudd and Prahl (2014a). Although the local code official accepted singlecomponent expanding urethane foam, there is insufficient clarity in the code to guarantee that this material will be universally accepted.

In some cases an air sealing detail was called out, but was not executed in practice. One example was the junction over garage (Figure 54); the specified detail is shown in Figure 12. This might be a sequencing and inspection issue, where it is not easily inspected from a distance.

One innovative method used by practitioners for the horizontal joint is to replace the 1-in. gypsum fire stop with $\sim 1$-in. mineral fiber insulation, topped with flowable/high-slump concrete or gypcrete. The mineral fiber insulation is noncombustible and provides a stop/form for the concrete. The concrete or gypcrete will flow laterally in the joint; thus, it might be clearer if part of the joint is missed (i.e., the detail will not be "full"). One negative, though, is that these materials are not flexible, so as the wood frame shrinks and moves, gaps may develop. Alternate details are also being developed by BSC for compartmentalizing and sealing the 1-in. cavity of these area separation walls.

Vertical joints such as the tee wall were another source of leakage (Figure 51); this was ascribed to the ladder blocking used at the tee intersection (Figure 76, left). A proposed alternate detail places a stud directly behind the tee wall, and seals the gap to the 1-in. gypsum board with expanding foam. The joints at the wood framing are sealed with caulk.

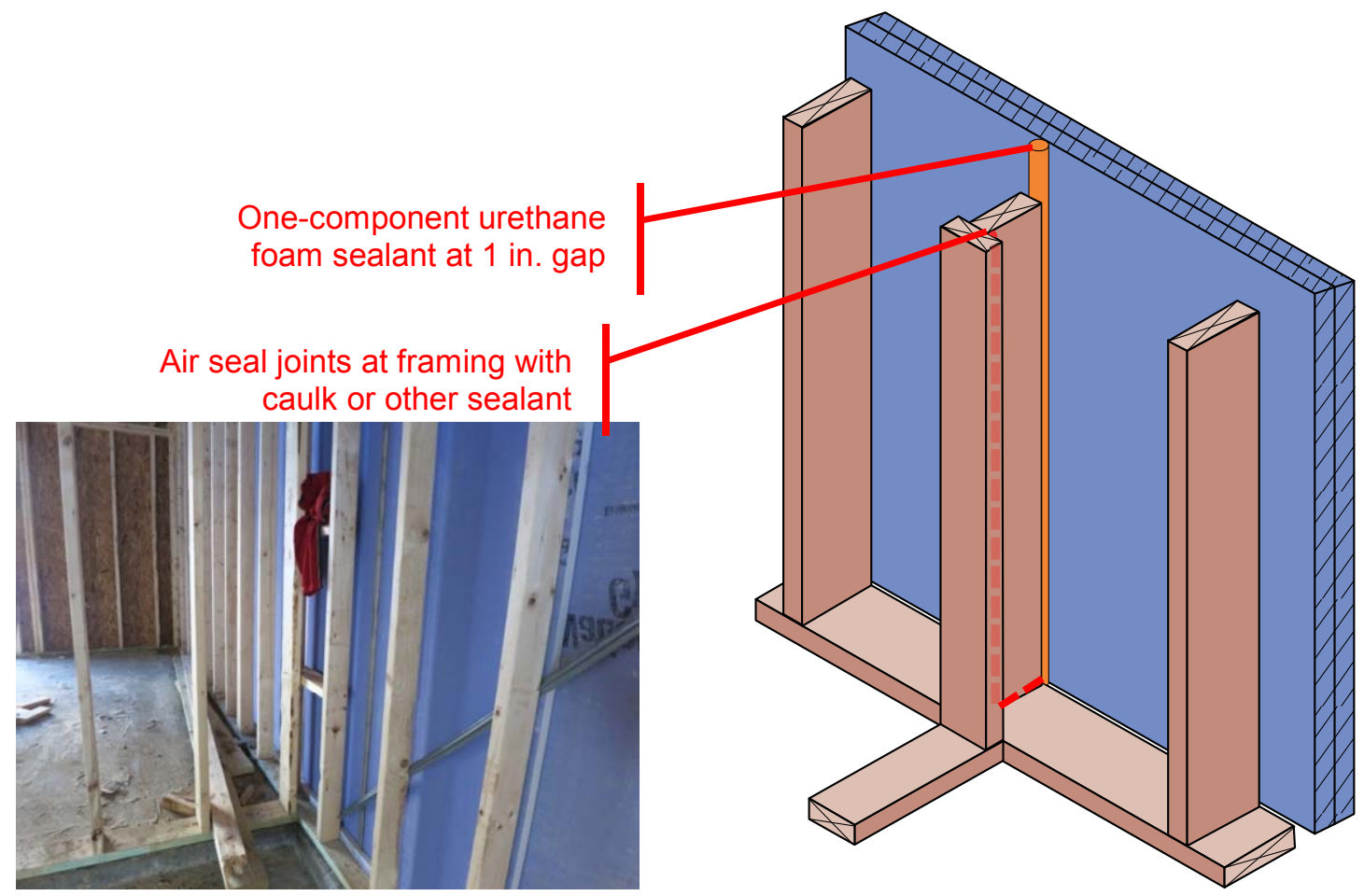

Figure 76. Garage tee wall intersection, current (L) and proposed air sealing details (R) 
The interior staircase effectively functions as a component of the air barrier, based on the air leakage patterns and interstitial pressure measurements (Figure 48 through Figure 50). Ideally, the triangular volume under the stairs would be contained entirely within conditioned space, and a vertical air seal detail per Figure 76 would be installed at the end wall of this space. The rough frame condition of a stairwell (albeit on an exterior wall) is shown in Figure 77.
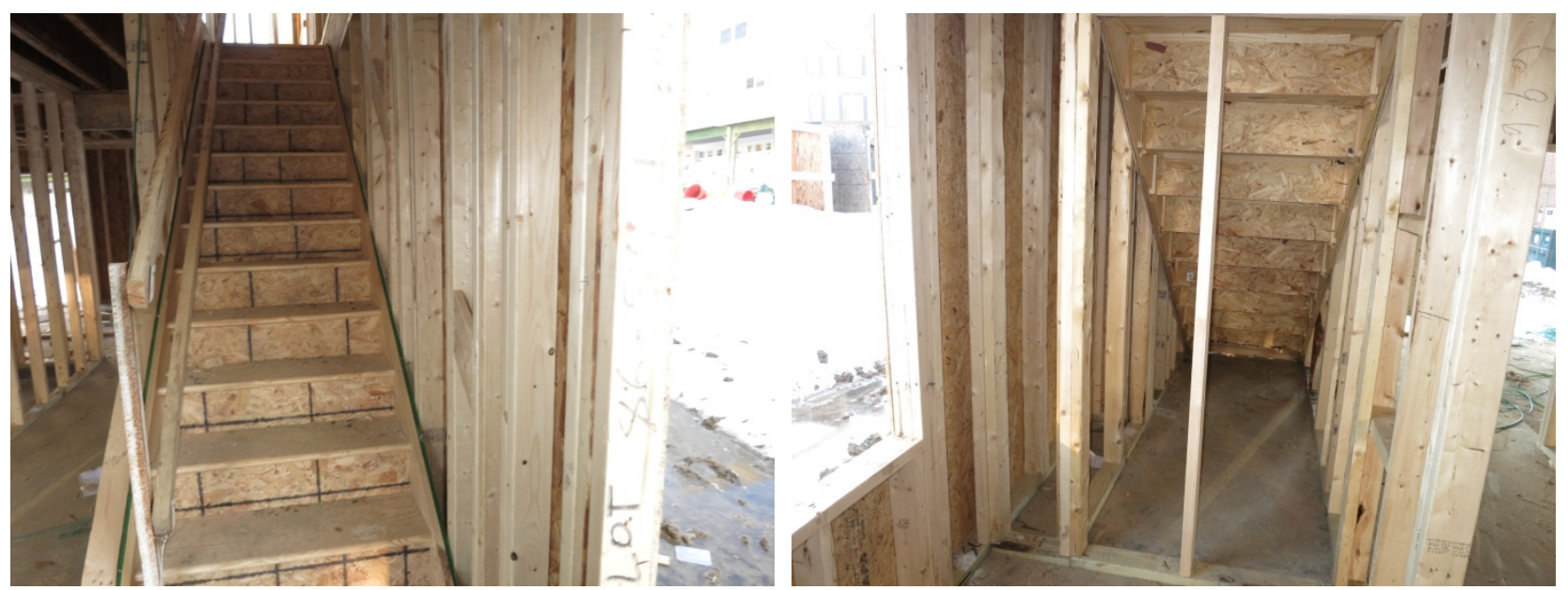

Figure 77. Stairwell on exterior wall

\subsection{Recommendations: Mechanical Systems}

The field testing revealed that mechanical rooms located in the garage can be significant sources of air leakage, despite gasketed exterior-grade doors and attempts at air sealing. Many penetrations, including ductwork penetrations, are difficult to access and seal. Achieving "perfection" at these mechanical penetrations requires substantial time, effort, and quality control. HVAC chases also provide network pathways, connecting imperfections as interior-to-exterior pathways. The builder reports that rear-load garage buildings (with mechanical rooms in garages) have worse air leakage numbers than front-load garage buildings (with mechanical rooms in conditioned space). If interior mechanical rooms could be designed into all floor plans (including rear-load garages), this might improve airtightness.

One possible solution to the mechanical rooms and ductwork issues is to eliminate them by switching from a conventional furnace/split system to a multiheaded mini-split heat pump (MSHP) system. A single outdoor heat pump condenser (Figure 78, left) can be connected to multiple indoor heads, including wall-mounted exposed units and recessed ceiling air handlers (Figure 78, right) that can be connected to a limited amount of ductwork.

As shown in a conceptual layout (Figure 79), the second and third floors could be conditioned by the small recessed air handlers in a central location per floor. Given the limited square footage of the first-floor room, it could be conditioned by a less expensive wall-mounted unit. 

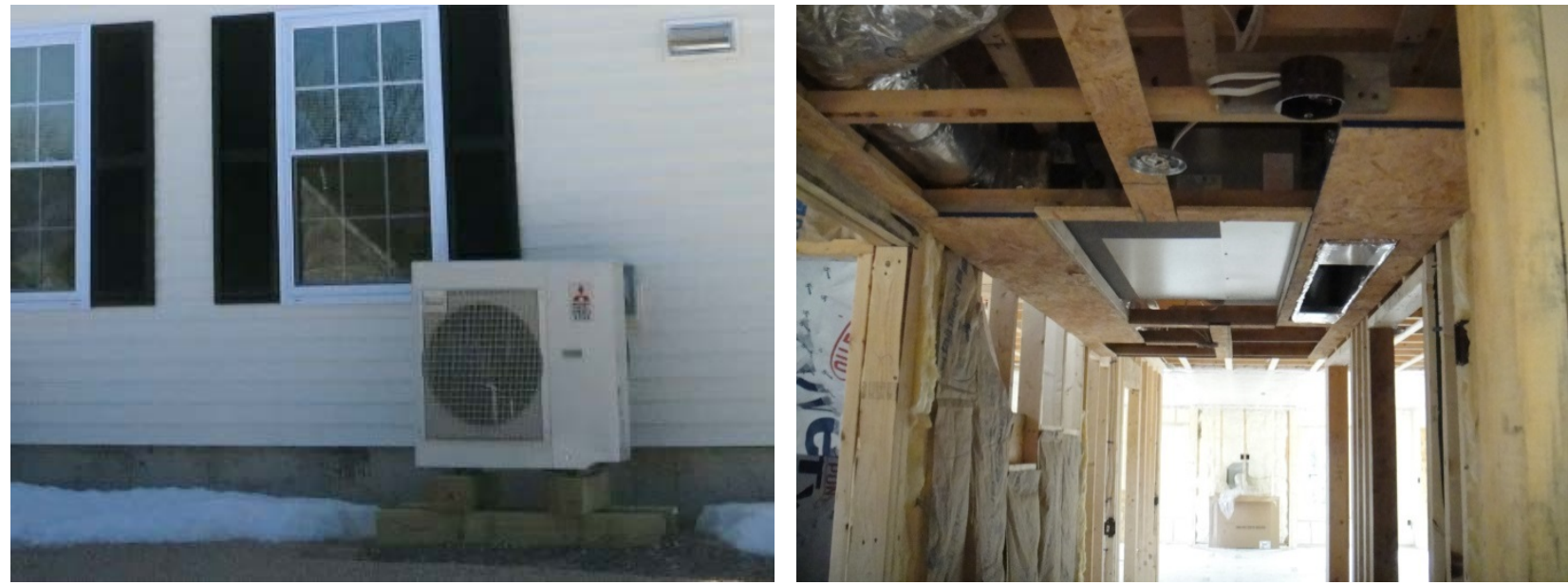

Figure 78. MSHP 3:1 outdoor unit (L) and indoor ceiling recessed air handler (R)
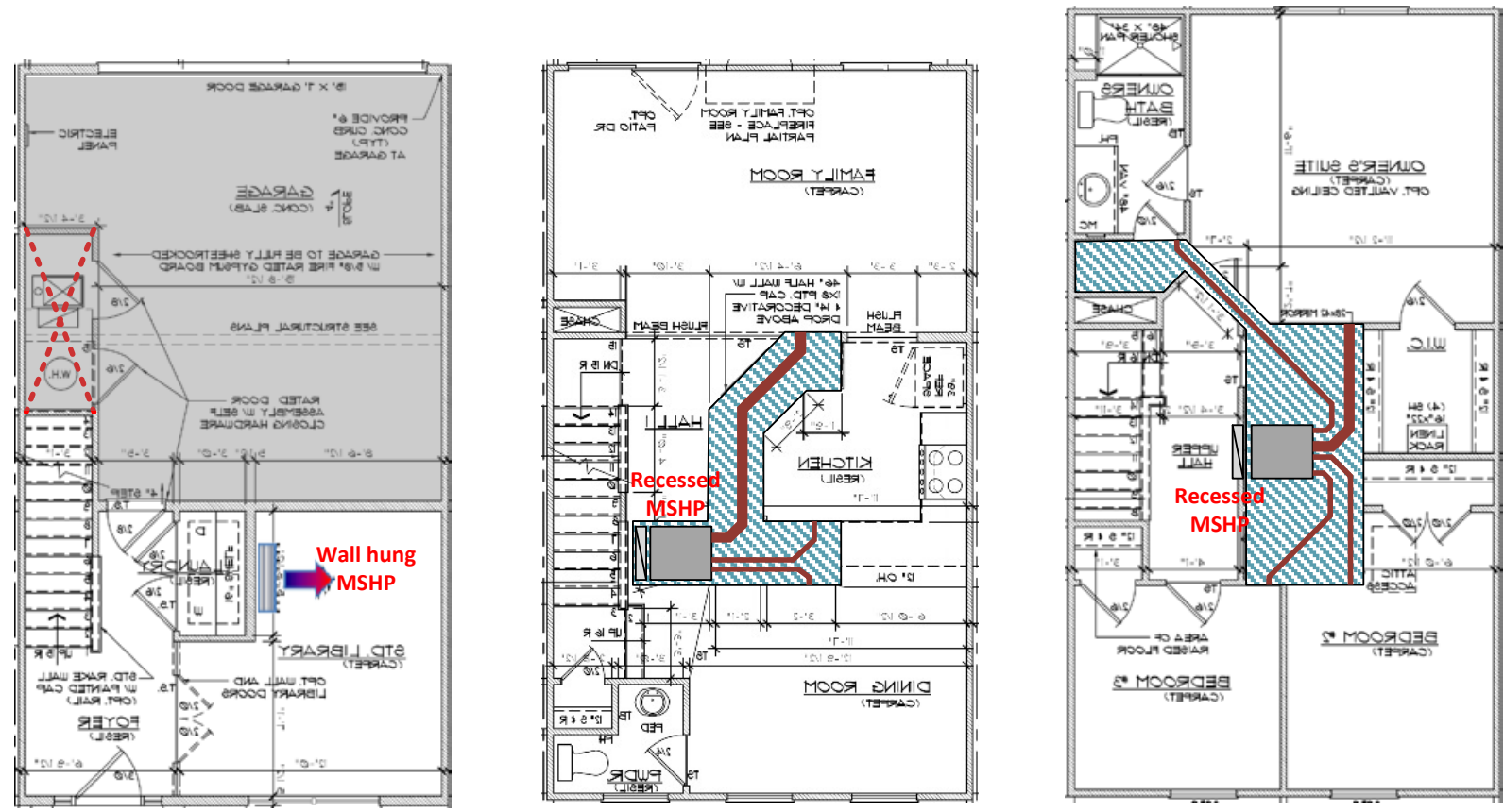

Figure 79. Conceptual example of multihead MSHP layout in three-story unit

Performance advantages to this option include:

- Elimination of the mechanical room and ductwork running floor to floor, and thus the associated air leakage issues.

- Floor-by-floor zoned temperature control: stratification and uneven temperatures are common complaints in these three-story small-footprint townhomes.

- Higher efficiency levels (15-17.5 seasonal energy efficiency ratio for a recessed air handler; comparable source energy efficiencies to $90 \%+$ gas furnaces). This is only an 
advantage for the builder, though, if the cost of this performance improvement can be recouped through some program (e.g., an incentive program or a rebate).

However, the equipment cost increase is substantial: retail equipment costs of the MSHP option (from online sources) are more than double the conventional split system (Table 10 and Table 11).

Table 10. Mini-Split System Rough Equipment Costs (30,000 Btu/h Heat Pump)

\begin{tabular}{c|c}
\hline Unit & Cost \\
\hline $\mathbf{3 0 , 0 0 0 ~ B t u ~ - ~ D u a l / T r i ~ Z o n e ~ - ~ M S H P ~ O u t d o o r ~ C o n d e n s e r ~ - ~ H e a t ~ P u m p ~}$ & $\$ 2399$ \\
$\mathbf{9 , 0 0 0 ~ B t u ~ - ~ M S H P ~ I n d o o r ~ U n i t ~ - ~ W a l l ~ M o u n t e d ~ - ~ H e a t ~ P u m p ~}$ & $\$ 470$ \\
$\mathbf{9 , 0 0 0 ~ B t u ~ - ~ M S H P ~ I n d o o r ~ U n i t ~ - ~ C o n c e a l e d ~ D u c t ~ - ~ H e a t ~ P u m p ~}$ & $\$ 841$ \\
$\mathbf{1 2 , 0 0 0 ~ B t u ~ - ~ M S H P ~ I n d o o r ~ U n i t ~ - ~ C o n c e a l e d ~ D u c t ~ - ~ H e a t ~ P u m p ~}$ & $\$ 895$ \\
Total & $\mathbf{\$ 4 6 0 5}$ \\
\hline
\end{tabular}

Table 11. Conventional Split System Rough Equipment Costs (30,000 Btu/h Air Conditioner and Furnace)

\begin{tabular}{c|c}
\hline Unit & Cost \\
\hline 70,000 Btu - Gas-Fired Furnace - NG - 92.1\% AFUE - Single-Stage & $\$ 749$ \\
2.5 Ton - Upflow/Downflow Coil - Cased & $\$ 283$ \\
3 Ton - Air Conditioning Condenser - 13 Seasonal Energy Efficiency Ratio - & $\$ 879$ \\
Single-Stage - R-410A Refrigerant & $\$ 1911$ \\
\hline
\end{tabular}

Cost savings would be associated with this switch to an MSHP system, though:

- Ductwork costs could be substantially reduced: the smaller diameter ductwork runs are limited in length and run in a ceiling soffit only; no floor-to-floor runs or large returns are needed.

- The elimination of the mechanical room (if the water heater can be relocated) would result in construction savings, and/or possible square footage for other purposes.

- Build-outs for soffits, chases, and bulkheads would be reduced (with a matching recovery of interior square footage).

- Gas service to developments might be eliminated (assuming electric water heating, per the existing buildings). These MSHP units are capable of low ambient temperature heating without a loss in capacity, especially in a less challenging location such as climate zone 4A. 


\section{Conclusions and Further Work}

\subsection{Conclusions}

In both the unguarded and guarded (pressure-neutralized) testing, no units met the 3 ACH50 target of the 2012 IECC. When this target is calculated in terms of surface area-normalized leakage, it is stringent for these small three-story townhome units $\left(0.16-0.17 \mathrm{CFM} 50 / \mathrm{ft}^{2}\right)$. For reference, typical results for this builder were $4.8 \mathrm{ACH} 50$ at this development, and 3.2 ACH50 at a development that had used a spray latex sealant (both unguarded tests).

Middle units had worse air leakage than end units; guarded testing showed greater reductions for middle units than end units, which is consistent with one versus two area separation walls. But the fact that the units do not meet the requirements in the nulled test indicates that the issues may not be confined to area separation wall problems.

The guarded or nulled test results should be interpreted with caution, though: interstitial pressure measurements showed that the area separation wall cavity was sometimes well connected to the exterior or other units. As a result, the leakage between units was not completely eliminated in these guarded tests. These inadvertent connections occurred at details such as garage ceilings, wall jogs, and attics. Substantial air leakage issues were found at the garage (50\% interior/50\% exterior) and mechanical room.

The results show no improvement associated with taping the exterior sheathing; in fact, some cases are slightly worse. No noticeable change was seen in the "improved" units compared to the conventional control. Unfortunately, the experiment was hampered by the addition of other variables, such as unplanned additional air sealing in some units, and missing or incompletely executed air barrier details in other units. Testing identified several air leaks not specific to multifamily construction; variation in this leakage made it difficult to consistently differentiate experimental options.

The literature indicates that taped sheathing is useful for achieving very stringent airtightness targets (e.g., 1 ACH50 and below). However, if there are more substantial air leaks - as was the case here - the difference will likely be difficult to discern.

The units either achieved or were close to the normalized $0.30 \mathrm{CFM} 50 / \mathrm{ft}^{2}$ enclosure standard, based on all enclosure area (to exterior and to adjacent units). This target is consistent with recommendations from Lstiburek (2005b) for multifamily units, standards proposed by Maxwell (2014), and the revised target for ASHRAE 62.2 (Brennan 2014).

\subsection{Further Work}

As demonstrated by the inability to reach airtightness targets, further work needs to be conducted on developing airtightness details for area separation walls (or similar demising or party walls). These details would ideally be executed more consistently than current detailing, and be more readily inspectable. They should also integrate with the current construction practices and sequencing. 
Additional air leakage testing could be conducted to quantify the air leakage typically occurring at the $\mathrm{C}$-channel and $\mathrm{H}$-stud connections at the double 1 in. gypsum board layer. Leakage at these joints would result in unit-to-unit connections.

Per Rudd and Prahl (2014a), clear guidance to code officials on accepted air sealing materials in area separation walls (e.g., UL U347, U373, and U336 assemblies) would simplify the practice of providing airtightness at these troublesome details.

A possible future test could examine the effect of taping the structural sheathing on airtightness, if the major air leakage sites (seen in this work) can be eliminated.

Although these units failed to meet $3 \mathrm{ACH} 50$, all were close to meeting the standard of 0.30 CFM $50 / \mathrm{ft}^{2}$ enclosure. Area-based metrics address the penalty seen here for smaller units, and have been espoused by BSC, ASHRAE, Passive House Institute US, and Steven Winter Associates. Maxwell (2014) suggested that $0.30 \mathrm{CFM} 50 / \mathrm{ft}^{2}$ enclosure may be a useful target for multifamily construction, and Brennan (2014) has stated that ASHRAE 62.2 is shifting to this standard. Overall, much of the industry appears to be converging toward this airtightness target. Of course, if and when the relevant standards change, the direction of research should be adapted accordingly. 


\section{References}

ASHRAE (2009). ANSI/ASHRAE/USGBC/IES Standard 189.1-2009 Standard for the Design of High-Performance Green Buildings Except Low-Rise Residential Buildings. Atlanta, GA: American Society of Heating, Refrigerating, and Air-Conditioning Engineers, Inc.

ASHRAE (2013). ANSI/ASHRAE Standard 62.2-2013, Ventilation and Acceptable Indoor Air Quality in Low-Rise Residential Buildings. Atlanta, GA: American Society of Heating, Refrigerating, and Air-Conditioning Engineers, Inc.

ASHRAE (2014). "ASHRAE Proposes to Move All Residential IAQ Requirements to Standard 62.2." (Press Release, Apr 4, 2014). https://www.ashrae.org/news/2014/ashrae-proposes-tomove-all-residential-iaq-requirements-to-standard-62-2 Atlanta, GA: American Society of Heating, Refrigerating, and Air-Conditioning Engineers, Inc.

ASTM (2003). ASTM Standard E 779-03 Standard Test Method for Determining Air Leakage Rate by Fan Pressurization Method, West Conshohocken, PA: American Society for Testing and Materials.

ASTM (2004). ASTM Standard E 2178 - 03 Standard Test Method for Air Permeance of Building Materials, West Conshohocken, PA: American Society for Testing and Materials.

Bailes, A. (2013). "Does Your Air Barrier Work in Both Directions?” Energy Vanguard Blog, May 13, 2013. Accessed January 2014: www.energyvanguard.com/blog-building-scienceHERS-BPI/bid/59648/Does-Your-Air-Barrier-Work-in-Both-Directions.

Brennan, T. (2014). Camroden Associates, Personal communication.

CEE (2004). "Reduction of Environmental Tobacco Smoke Transfer in Minnesota Multifamily Buildings Using Air Sealing and Ventilation Treatments." CEE/TR04-1-MF. Minneapolis, MN: Center for Energy and Environment.

EPA (2013). "ENERGY STAR Multifamily High Rise National Performance Path Requirements, Version 1." "ENERGY STAR Multifamily High Rise National Prescriptive Path Requirements, Version.” Revision 02 - September 2013. Washington, D.C.: U.S. Environmental Protection Agency.

Finch, G.; Straube, J.F.; Genge, C. (2009) "Air Leakage within Multi-Unit Residential Buildings: Testing and Implications for Building Performance." 12th Canadian Conference on Building Science and Technology - Montreal, Quebec, 2009.

Genge, C. (2007). "Measuring Leakage in High-Rise Buildings.” Home Energy Magazine, September-October 2007. Berkeley, CA: Home Energy Magazine.

Griffiths, D. (2012). "Expert Meeting Report: Determining Air Change Rates and Envelope Leakage in Attached Dwellings." Norwalk, CT: Steven Winter Associates, Inc./Consortium for Advanced Residential Buildings.

Klocke, S.; Faakye, O.; Puttagunta, S. (2014). "Challenges of Achieving 2012 IECC Air Sealing Requirements in Multifamily Dwellings.” Norwalk, CT: Steven Winter Associates, Inc./Consortium for Advanced Residential Buildings. 
Gadgil, A.; Price, P.N.; Shehabi, A.; Chan, R, (2006). Indoor-Outdoor Air Leakage of Apartments and Commercial Buildings.

Handegord, G.O. (2001). "A New Approach to Ventilation of High Rise Apartments." Proceedings of the Eighth Conference on Building Science and Technology, Ontario Building Envelope Council, Toronto, Ontario, February 2001.

Hill, D. (2005). "Assessment of Suite Compartmentalization and Depressurization in New HighRise Residential Buildings." Canada Mortgage and Housing Corporation, Technical Series 05112, October 2005.

Hill, D. (2006). "Evaluation of Air Leakage Control Measures to Compartmentalize Newly Constructed Suites in a New High-Rise Residential Building", Canada Mortgage and Housing Corporation, Technical Series 06-102, January 2006.

Holladay, M. (2010). "Musings of an Energy Nerd: Airtight Wall and Roof Sheathing: Arguments in Favor of Exterior Air Barriers." Accessed January 2014:

www.greenbuildingadvisor.com/blogs/ dept/musings/airtight-wall-and-roof-sheathing.

Holladay, M. (2013a). “Backyard Tape Test.” Fine Homebuilding Magazine, April-May 2013, pp. 46-51. Newtown, CT: Taunton Press.

Holladay, M. (2013b). "Musings of an Energy Nerd: Return to the Backyard Tape Test." Accessed January 2014: www.greenbuildingadvisor.com/blogs/dept/musings/return-backyardtape-test.

Holton, J.; Prahl, D. (2005) "Research Report on Party Walls in Multifamily Buildings." Pittsburgh, PA: IBACOS, Inc. (Integrated Building and Construction Solutions).

Hult, E.L.; Sherman M.H. (2014) "Estimates of Uncertainty in Multi-Zone Air Leakage Measurements." International Journal of Ventilation, 12(4): 359-368.

ICC (2012a). 2012 International Energy Conservation Code. Country Club Hills, IL: International Code Council, Inc.

ICC (2012b). 2012 International Residential Code ${ }^{\circledR}$ for One- and Two-Story Dwellings. Country Club Hills, IL: International Code Council, Inc.

ICC (2013). 2013 ICC Public Comment Agenda. RB96-13, §R302.13 (New) and Table N1102.4.1.1. (pp. 1720-1725). Country Club Hills, IL: International Code Council, Inc.

Lstiburek, J.W. (1998). “The Pressure Response of Buildings.” DOE, ASHRAE, ORNL Conference - Thermal Envelopes VII, Clearwater, FL, December 1998.

Lstiburek, J. (2005a). "Understanding Air Barriers," ASHRAE Journal, July 2005, Vol. 47, No. 7, pp. 24-30. Atlanta, GA: American Society of Heating, Refrigeration, and Air-Conditioning Engineers, Inc.

Lstiburek, J. (2005b). "Multifamily Buildings: Controlling Stack Effect-Driven Airflows" ASHRAE Journal, December 2005, Vol. 47, No. 12, pp. 30-38. Atlanta, GA: American Society of Heating, Refrigeration, and Air-Conditioning Engineers, Inc. 
Lstiburek, J. (2006). Builder's Guide to Cold Climates. Westford, MA: Building Science Press.

Lstiburek, J. (2013a). "Building Sciences: Stuck on You,” ASHRAE Journal, February 2013, Vol. 55, No. 2, pp. 56-62. Atlanta, GA: American Society of Heating, Refrigeration, and AirConditioning Engineers, Inc.

Lstiburek, J. (2013b). "Building Sciences: Deal with Manure \& Then Don't Suck," ASHRAE Journal, July 2013, Vol. 55, No. 7, pp. 56-56. Atlanta, GA: American Society of Heating, Refrigeration, and Air-Conditioning Engineers, Inc.

Maxwell, S. (2014), Steven Winter Associates, Inc., Personal communication.

NRCERT (2012). Building America Expert Meeting Presentation: Air Change Rate \& Envelope Leakage in Attached Dwellings. "Multifamily Low-Rise Auditing: Feasibility and Future of Infiltration Testing." Christiansburg, VA: New River Center for Energy Research and Training.

NREL (2013). Building America Technical Innovations Leading to 50\% Savings - A Critical Path. Golden, CO: National Renewable Energy Laboratory.

Otis, C.; Maxwell, S. (2012). Measure Guideline: Air Sealing Attics in Multifamily Buildings. Norwalk, CT: Steven Winter Associates, Inc./Consortium for Advanced Residential Buildings.

Rosenbaum, M. (2010). "Exterior Air Barriers - Getting Below 1 ACH50.” Better Buildings by Design 2010 Conference, Burlington, VT.

Rudd, A.; Prahl, D. (2014a). "Duct System Flammability and Air Sealing Fire Separation Assemblies in the International Residential Code." Pittsburgh, PA: IBACOS, Inc. (Integrated Building and Construction Solutions).

Rudd, A.; Prahl, D. (2014b). "Building America Focus Meeting: Code Challenges with MultiFamily Area Separation Walls.” (Sept. 29, 2014) Pittsburgh, PA: IBACOS, Inc. (Integrated Building and Construction Solutions).

TEC (2014). "User Tips.” Minneapolis, MN: The Energy Conservatory. Accessed January 2014: www.energyconservatory.com/ support/user-tips.

Uhler, T. (2011). "On Site with Zip System Sheathing." Journal of Light Construction, February 2011, pp. 2-8. Washington, DC: Hanley-Wood LLC.

USGBC (2010a). “LEED® for Homes Rating System Multifamily Mid-Rise” (October 2010). Washington, DC: U.S. Green Building Council.

USGBC (2010b). "LEED for Homes Multifamily Mid-Rise 2010 Summary of Changes (from 2008 Pilot).” Washington, DC: U.S. Green Building Council. 


\section{Appendix A: Equipment Summary}

A summary of the equipment used in field testing and the relevant ranges and accuracy is shown in Table 12.

Table 12. Equipment Summary, With Range and Accuracy

\begin{tabular}{|c|c|c|}
\hline Measurement & Equipment & Range/Accuracy \\
\hline $\begin{array}{c}\text { Air Leakage } \\
\text { (higher flow fans) }\end{array}$ & $\begin{array}{c}\text { TEC Minneapolis Blower Door } \\
\text { Model } 3 \text { Fan }\end{array}$ & $\begin{array}{c}300 \text { to } 6,300 \text { CFM (Ring B/Open) } \\
\text { Flow Accuracy: } \\
\pm 3 \% \text { with DG-700 }\end{array}$ \\
\hline $\begin{array}{c}\text { Air leakage } \\
\text { (lower flow fans) }\end{array}$ & $\begin{array}{l}\text { TEC Minneapolis Duct } \\
\text { Blaster }{ }^{\circledR} \text { Series B Fan }\end{array}$ & $\begin{array}{c}10 \text { to } 1500 \text { CFM (Ring 3/Open) } \\
\text { Flow Accuracy: } \\
\pm 3 \% \text { of reading or } \pm 1 \text { CFM, } \\
\text { whichever is greater, with DG-700 }\end{array}$ \\
\hline $\begin{array}{l}\text { Differential Pressure } \\
\text { Measurement }\end{array}$ & $\begin{array}{c}\text { TEC DG-700 Pressure and Flow } \\
\text { Gauge }\end{array}$ & $\begin{array}{c}-1,250 \text { to }+1,250 \mathrm{~Pa} \text {. Accuracy: } 1 \% \\
\text { of pressure reading or } 0.15 \mathrm{~Pa}, \\
\text { whichever is greater }\end{array}$ \\
\hline $\begin{array}{l}\text { Telecommunications } \\
\text { Software }\end{array}$ & $\begin{array}{l}\text { TEC TECLOG3 software with } \\
\text { wired remote connections }\end{array}$ & ( \\
\hline $\begin{array}{l}\text { Telecommunications } \\
\text { Hardware }\end{array}$ & $\begin{array}{c}\text { StarTech ICUSB2324 } 4 \text { Port } \\
\text { USB to RS232 Serial DB9 } \\
\text { Adapter Hub }\end{array}$ & $\mathrm{n} / \mathrm{a}$ \\
\hline Infrared Observation & FLIR b40 Infrared Camera & $\begin{array}{c}\text { Thermal sensitivity }<0.2^{\circ} \mathrm{F} @ 77^{\circ} \mathrm{F} \\
\left(0.1^{\circ} \mathrm{C} @ 25^{\circ} \mathrm{C}\right)\end{array}$ \\
\hline
\end{tabular}




\section{Appendix B: Air Leakage Test Results—Unguarded Tests Day 1}

The following figures show detailed air leakage test results from the unguarded single fan testing on Day 1, using a TEC Minneapolis Duct Blaster Series B Fan and TECTITE 4.0 software.

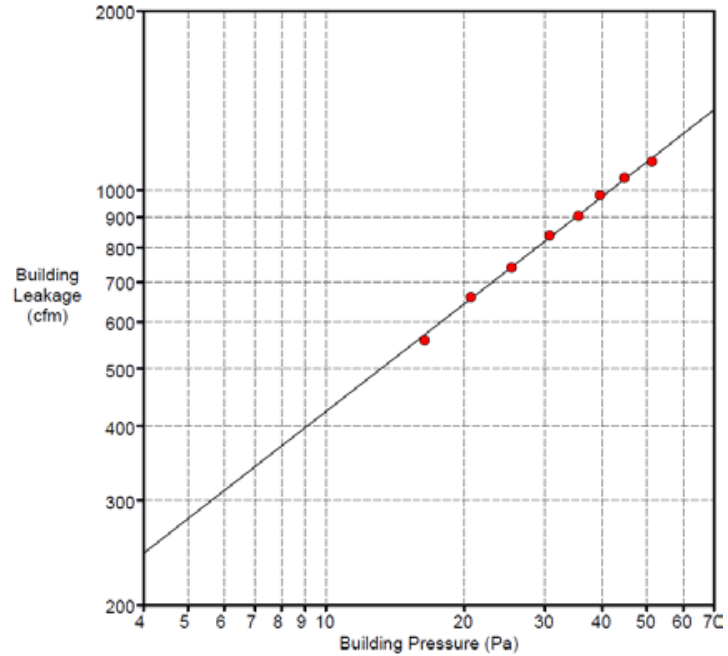

Figure 80. Detailed test results for Unit 6700 (end, improved and taped)

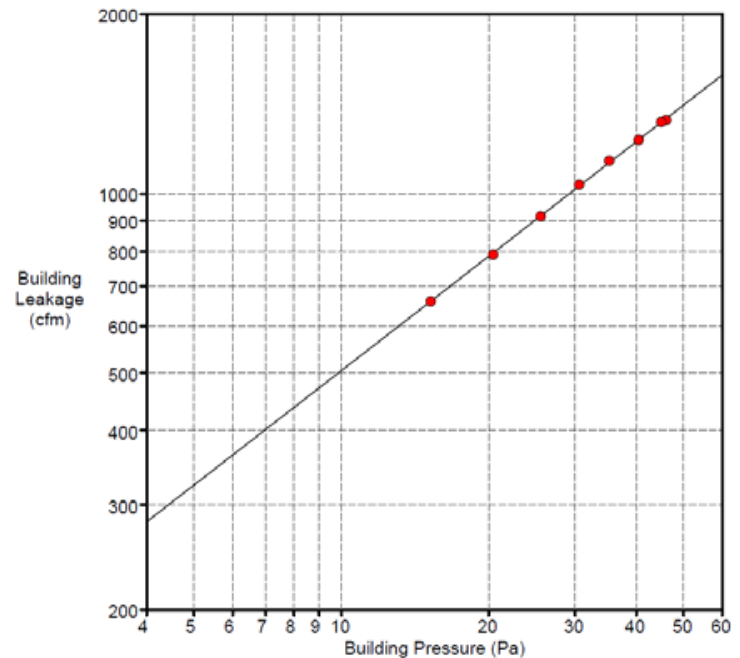

Airflow at $50 \mathrm{~Pa}$ :

1408 CFM50 $( \pm 0.3 \%)$

$5.88 \mathrm{ACH} 50$

0.8285 CFM50/ft ${ }^{2}$ floor area

0.3238 CFM50/ft ${ }^{2}$ surface area

Leakage Areas:

148.2 in. $^{2}$ ( $\left.\pm 0.8 \%\right)$ Canadian EqLA @ $10 \mathrm{~Pa}$

79.8 in. $^{2}( \pm 1.3 \%)$ LBL ELA @ 4 Pa

Building Leakage Curve:

Flow Coefficient $(C)=116.1( \pm 2.2 \%)$

Exponent $(n)=0.638( \pm 0.006)$

Correlation Coefficient $=0.99973$

Test Settings:

Test Standard: CGSB

Test Mode: Depressurization

Figure 81. Detailed test results for Unit 6702 (middle, improved and taped) 


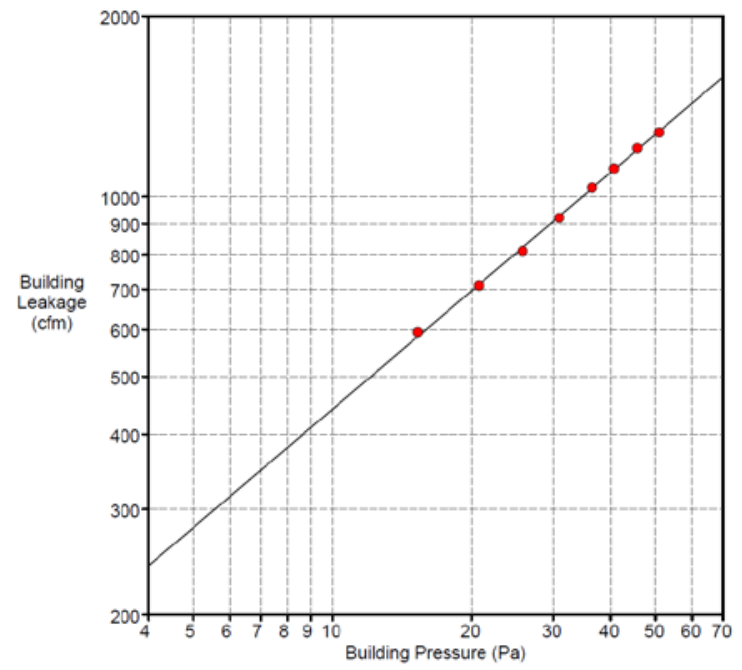

Airflow at $50 \mathrm{~Pa}$ :

1271 CFM50 $( \pm 0.4 \%)$

$5.30 \mathrm{ACH} 50$

0.7474 CFM50/ft ${ }^{2}$ floor area

0.2921 CFM50/ft ${ }^{2}$ surface area

Leakage Areas:

129.5 in. $^{2}( \pm 1.2 \%)$ Canadian EqLA @ $10 \mathrm{~Pa}$

68.5 in. $^{2}( \pm 1.9 \%)$ LBL ELA @ 4 Pa

Building Leakage Curve:

Flow Coefficient $(C)=96.9( \pm 3.1 \%)$

Exponent $(n)=0.658( \pm 0.009)$

Correlation Coefficient $=0.99948$

Test Settings:

Test Standard: CGSB

Test Mode: Depressurization

Figure 82. Detailed test results for Unit 6704 (middle, conventional construction)

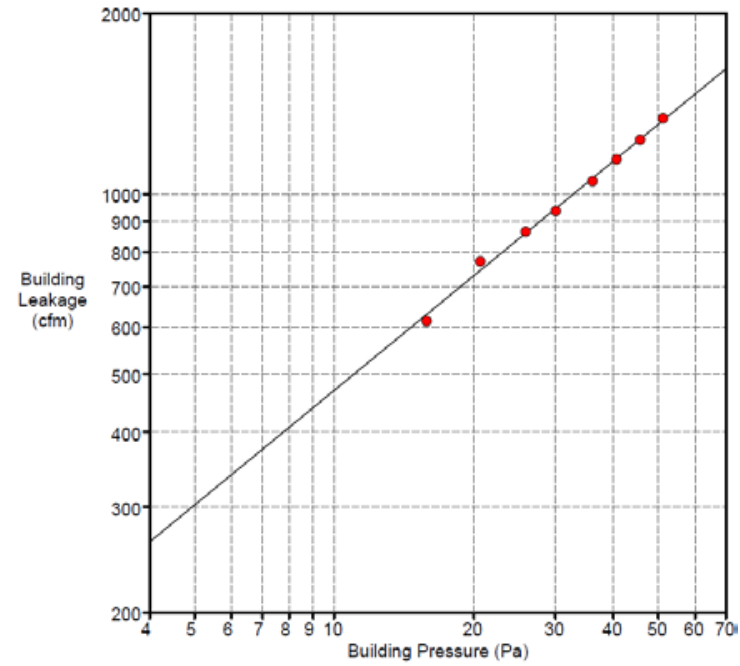

Airflow at $50 \mathrm{~Pa}$ :

1307 CFM50 $( \pm 0.7 \%)$

$5.46 \mathrm{ACH} 50$

0.7688 CFM50/ft ${ }^{2}$ floor area

0.3005 CFM50/ft ${ }^{2}$ surface area

Leakage Areas:

138.0 in. $^{2}( \pm 2.1 \%)$ Canadian EqLA @ $10 \mathrm{~Pa}$

74.5 in. $^{2}( \pm 3.6 \%)$ LBL ELA @ 4 Pa

Building Leakage Curve:

Flow Coefficient $(C)=108.7( \pm 5.8 \%)$

Exponent $(n)=0.636( \pm 0.016)$

Correlation Coefficient $=0.99810$

Test Settings:

Test Standard: CGSB

Test Mode: Depressurization

Figure 83. Detailed test results for Unit 6706 (middle, improved, no sheathing tape)

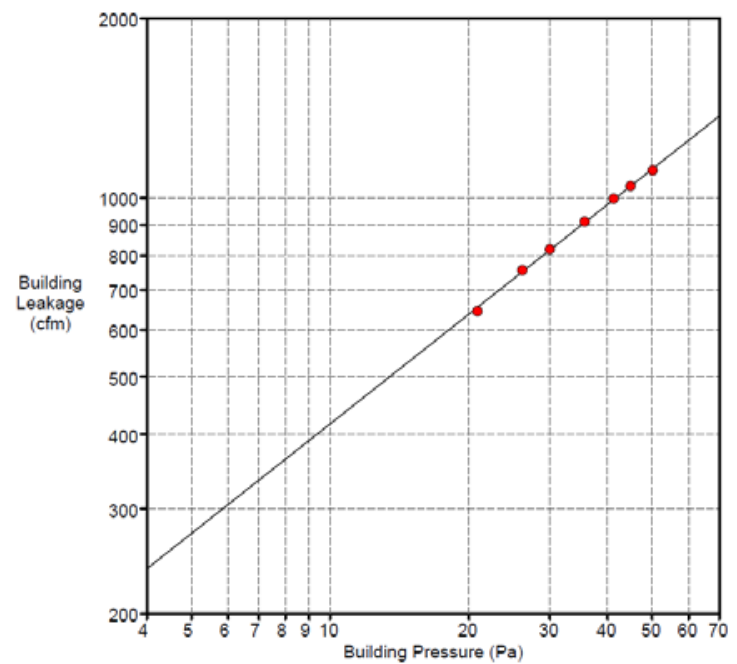

Airflow at $50 \mathrm{~Pa}$

1117 CFM50 $( \pm 0.4 \%)$

$3.93 \mathrm{ACH} 50$

0.5572 CFM50/ft ${ }^{2}$ floor area

0.2295 CFM50/ft ${ }^{2}$ surface area

Leakage Areas:

122.5 in. $^{2}$ ( $\left.\pm 1.3 \%\right)$ Canadian EqLA @ $10 \mathrm{~Pa}$

67.5 in. $^{2}( \pm 2.3 \%)$ LBL ELA @ 4 Pa

Building Leakage Curve:

Flow Coefficient $(C)=101.8( \pm 3.6 \%)$

Exponent $(n)=0.612( \pm 0.010)$

Correlation Coefficient $=0.99933$

Test Settings:

Test Standard: CGSB

Test Mode: Depressurization

Figure 84. Detailed test results for Unit 6708 (end, improved, no sheathing tape) 


\section{Appendix C: Air Leakage Test Results-Unguarded and Guarded Tests Day 2}

The following figures show detailed air leakage test results (multipoint air leakage tests) from the unguarded and guarded multi fan testing on Day 2, using TEC Minneapolis Duct Blaster® Series B and Minneapolis Blower Door fans, with results collected by TECLOG3 software. Unguarded results are shown in red (two-point test); guarded results are shown in blue (multipoint test). Only depressurization was used in this testing; all building pressures are negative with respect to outdoors.

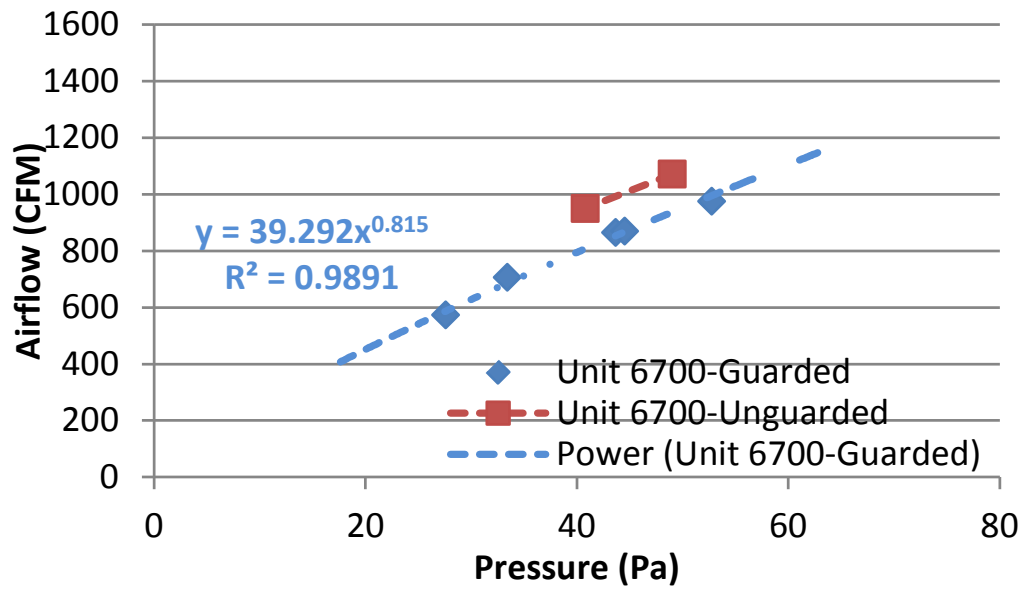

Figure 85. Detailed test results for Unit 6700 (end, improved, and taped)

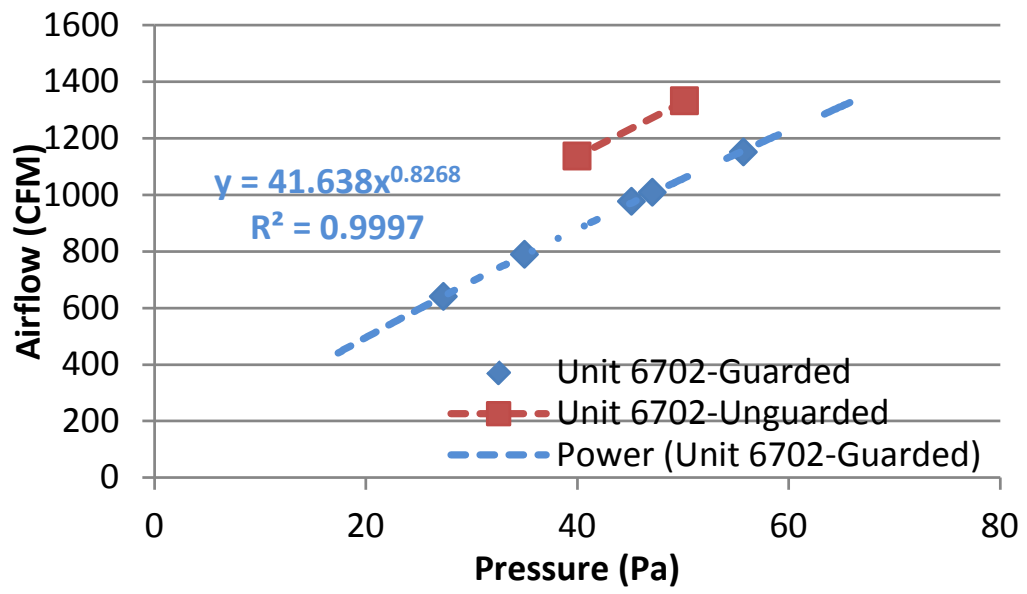

Figure 86. Detailed test results for Unit 6702 (middle, improved, and taped) 


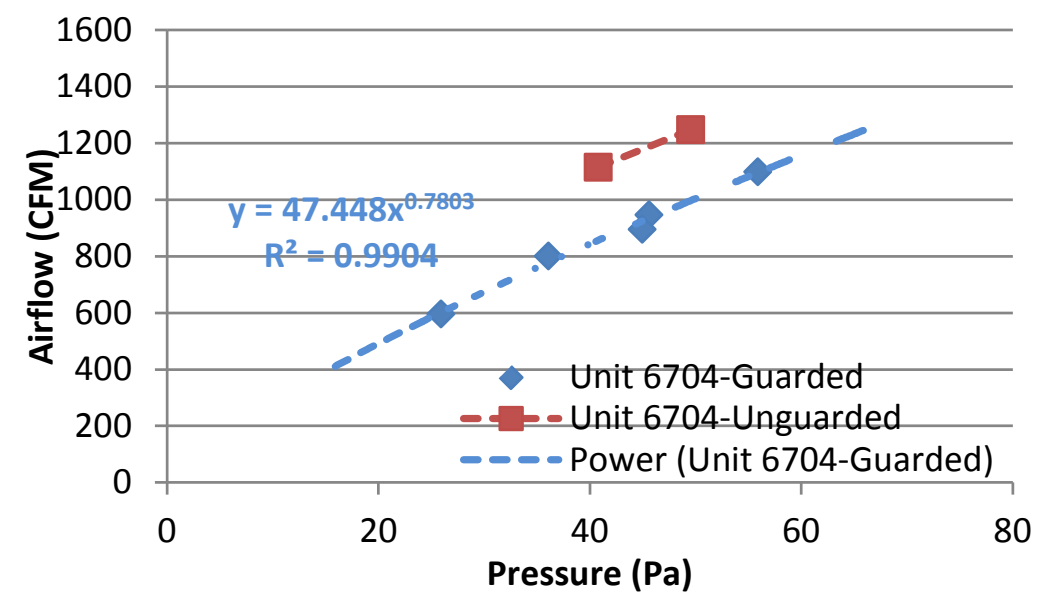

Figure 87. Detailed test results for Unit 6704 (middle, conventional construction)

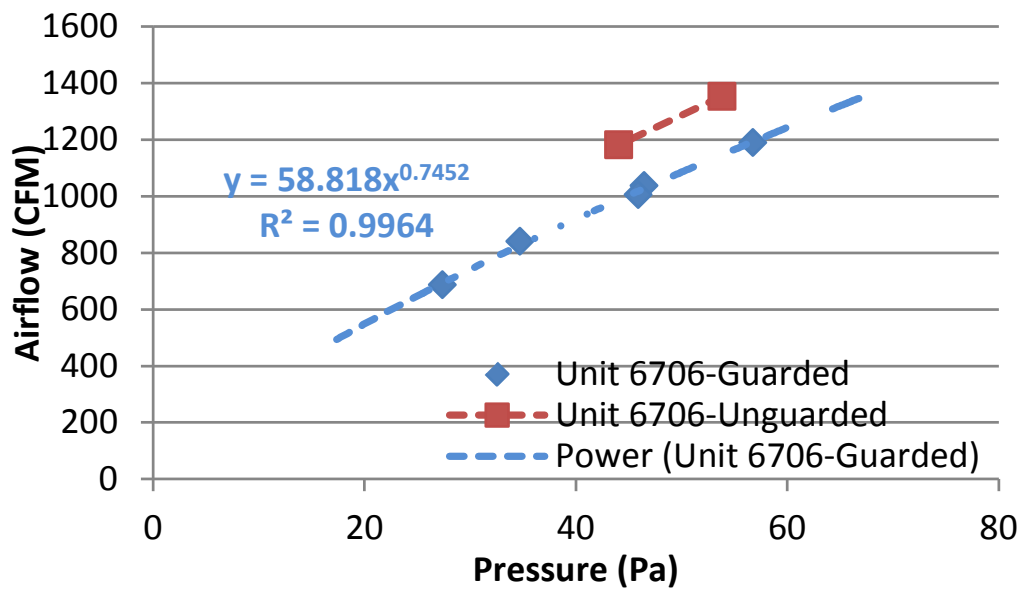

Figure 88. Detailed test results for Unit 6706 (middle, improved, no sheathing tape)

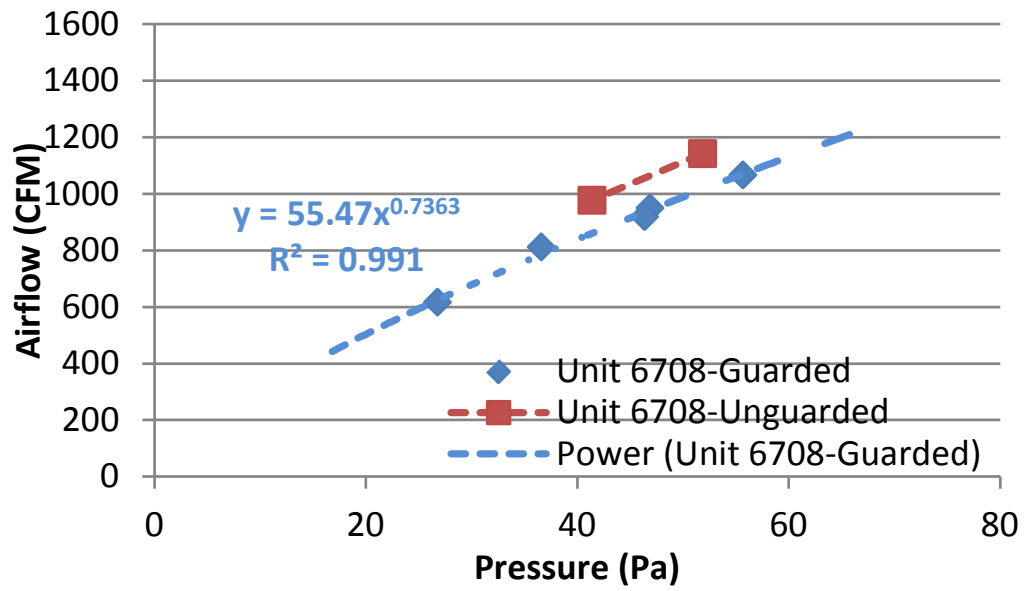

Figure 89. Detailed test results for Unit 6708 (end, improved, no sheathing tape) 
buildingamerica.gov

\section{us. oferarnuent of \\ Energy Efficiency \& Renewable Energy}

